\title{
Molecular investigation of mitochondrial inner membrane morphology
}

\author{
Dissertation \\ for the award of the degree \\ "Doctor rerum naturalium" (Dr. rer. nat.) \\ Division of Mathematics and Natural Sciences \\ of the Georg-August-Universität Göttingen
}

submitted by

Daryna Tarasenko

born in Slavutych, Ukraine

Göttingen, 2018 



\section{Members of the Thesis Committee}

Prof. Dr Michael Meinecke (first reviewer)

Institute of Cellular Biochemistry, University Medical Center Göttingen, Germany

Prof. Dr Blanche Schwappach-Pignataro (second reviewer)

Institute of Molecular Biology, University Medical Center Göttingen, Germany

Dr Roland Dosch

Department of Developmental Biochemistry, University Medical Center Göttingen, Germany

\section{Additional reviewers}

Prof. Dr Stefan Jakobs

Department of NanoBiophotonics, Max Planck Institute for Biophysical Chemistry, Göttingen

Prof. Dr Dörthe Katschinski

Department of Cardiovascular Physiology, University Medical Center Göttingen

\section{Dr Alexander Stein}

Membrane Protein Biochemistry, Max Planck Institute for Biophysical Chemistry, Göttingen

Date of the oral examination: 14.02.2019 


\section{Affidavit}

Herewith I declare that I prepared my Doctoral Thesis "Molecular investigation of mitochondrial inner membrane morphology" on my own and with no other sources and aids than quoted.

Göttingen, December 2018

Daryna Tarasenko

The results presented in this thesis constitute parts the following article:

(C2017 TARASENKO et al. Originally published in JOURNAL OF CELL BIOLOGY. https://doi.org/10.1083/jcb.201609046 
- To my family - 


\section{ABSTRACT}

The mitochondrial inner membrane (MIM) is highly curved and displays a complex but extremely organised ultrastructure. It is subdivided into two morphologically, topologically, as well as functionally, distinct compartments. The relatively flat inner boundary membrane (IBM) runs in the proximity to the mitochondrial outer membrane (MOM). The cristae membranes (CM) protrude towards the mitochondrial matrix. IBM and $\mathrm{CM}$ are joint by so-called cristae junctions (CJ). These narrow, tubular segments of the MIM are important not only for MIM organisation but also for overall mitochondrial and cellular physiology. The evolutionary conserved multi-subunit protein complex MICOS (mitochondrial contact sites and cristae organising system) was shown to play a profound role in $\mathrm{CJ}$ formation and stabilisation. MICOS deletion leads to a significant change of the MIM ultrastructure resulting in $\mathrm{CJ}$ loss and accumulation of $\mathrm{CM}$ in the form of enclosed membranous stacks.

During this study, it was revealed that the MICOS core protein Mic60 displays membrane bending properties. Mic60 is able to remodel artificial membranes in vitro and induces the formation of cristae-like membrane invaginations when targeted to the bacterial cytoplasmic membrane in vivo. The membrane remodelling and lipid binding properties of the Mic60 protein are allocated to its intermembrane space domain. Experiments performed with the alphaproteobacterial homologues of Mic60 revealed that Mic60 membrane bending properties are evolutionary conserved. The alphaproteobacterial Mic60 proteins not only display membrane-remodelling effects on artificial and bacterial membranes but also, at least partially, are able to rescue the morphological defects of the MIM in mic60 $\Delta$ eukaryotic cells.

Thus, an unexpected role of Mic60 as a membrane-remodelling MICOS subunit was discovered. It was shown that these properties are driven by a very ancient and conserved mechanism, which, most probably, arose prior to the endosymbiotic event more than 1.5 billion years ago. 


\section{TABLE OF CONTENTS}

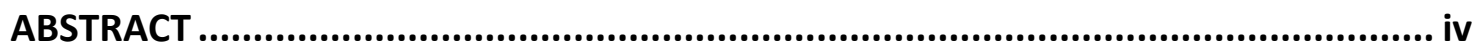

LIST OF ABBREVIATIONS ….............................................................................. ix

LIST OF FIGURES................................................................................................. xii

LIST OF TABLES............................................................................................... xiv

1 INTRODUCTION .............................................................................................. - 1 -

1. 1 MITOCHONDRIA: THEIR ORIGIN AND FUNCTIONS ......................................... 1 -

1. 2 MITOCHONDRIAL MORPHOLOGY AND ULTRASTRUCTURE ............................... 2 -

1. 3 CONTACT SITES, CRISTAE JUNCTIONS AND MICOS........................................... 6 -

1. 4 MECHANISMS OF CRISTAE JUNCTIONS MAINTENANCE .................................. 8 -

1. 5 MICOS IS EVOLUTIONARY CONSERVED....................................................... - 10 -

1. 6 ROLE OF PROKARYOTIC MIC6O HOMOLOGUES IN ALPHAPROTEOBACTERIA - 13 -

2 AIMS OF THIS WORK …………………………………................................ - 16 -

3 MATERIALS AND METHODS......................................................................... 18 -

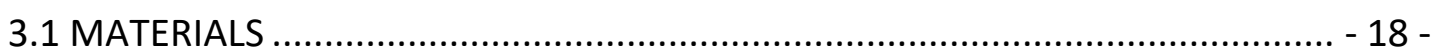

3.1.1 Chemicals and reagents......................................................................... - 18 -

3.1.2 Antibodies.................................................................................... - 20 -

3.1.3 Microorganisms ........................................................................... - 21 -

3.1.4 Plasmids ........................................................................................... - 22 -

3.1.5 Instruments and software .................................................................... - 23 -

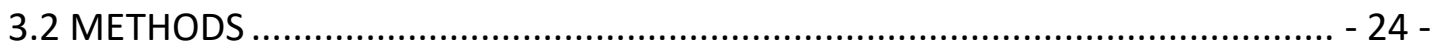

3.2.1 Microbial culture and sample preparation................................................ - 24 -

3.2.1.1 Cultivation of E.coli ......................................................................... 24 -

3.2.1.2 Transformation of chemically competent E.coli cells...................... - 25 -

3.2.1.3 Preparation of E.coli total cell lysate ............................................. - 25 -

3.2.1.4 Fractionation of E.coli cells ............................................................ - 25 - 
3.2.1.5 Cultivation of S. cerevisiae ........................................................... 26 -

3.2.1.6 Transformation of S. cerevisiae cells .............................................. - 26 -

3.2.1.7 Preparation of S. cerevisiae total cell extract .................................. - 27 -

3.2.1.8 Isolation of crude mitochondria from S. cerevisiae ......................... - 27 -

3.2.2 Molecular cloning ..................................................................... -28 -

3.2.2.1 Plasmid DNA isolation............................................................. - 28 -

3.2.2.2 Yeast genomic DNA isolation ....................................................... - 28 -

3.2.2.3 Obtaining of alphaproteobacterial Mic60 coding sequences............ - 29 -

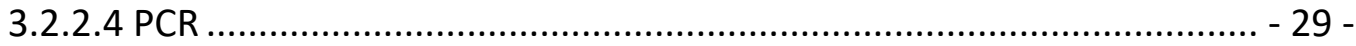

3.2.2.5 Agarose gel electrophoresis........................................................... - 29 -

3.2.2.6 Purification of PCR fragments....................................................... - 29 -

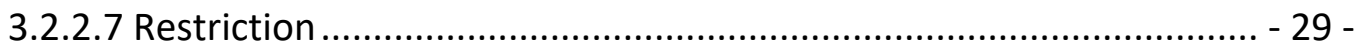

3.2.2.8 Ligation .............................................................................. - 30 -

3.2.2.9 DNA sequencing .................................................................... 30 -

3.2.3 Protein biochemistry methods ...................................................... 30 -

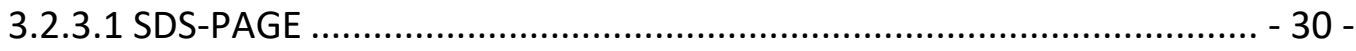

3.2.3.2 Coomassie brilliant blue staining ................................................... - 31 -

3.2.3.3 Western blot and immunodetection ............................................. - 31 -

3.2.3.4 Recombinant protein expression and purification .......................... - 31 -

3.2.3.4.1 Protein targeting to the cytoplasmic membrane of E.coli .......... - 31 -

3.2.3.4.1 Isolation of inclusion bodies................................................... - 32 -

3.2.3.4.2 Affinity His-tag chromatography.......................................... - 32 -

3.2.3.4.3 Affinity GST-tag chromatography ....................................... - 33 -

3.2.3.5 Size-exclusion chromatography ................................................ - 33 -

3.2.3.6 Protein refolding .................................................................... 33 - 
3.2.3.7 Protein labelling ......................................................................... - 34 -

3.2.3.7 TCA precipitation ...................................................................... 34 -

3.2.3.8 CD measurements.................................................................. 34 -

3.2.4 Lipid membranes .......................................................................... - 35 -

3.2.4.1 Preparation of liposomes.......................................................... - 35 -

3.2.4.2 Detergent-mediated incorporation ................................................ - 35 -

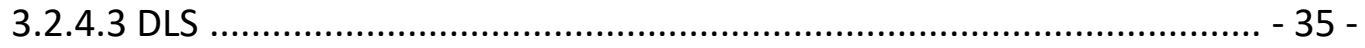

3.2.4.4 Flotation assay …...................................................................... 35 -

3.2.4.5 Sodium carbonate extraction ..................................................... - 36 -

3.2.4.6 Preparation of GUVs ........................................................................ 36 -

3.2.5 Visualization techniques.................................................................... 36 -

3.2.5.1 Electron microscopy of LUVs ...................................................... - 36 -

3.2.5.2 Light microscopy of GUVs ...................................................... - 37 -

3.2.5.3 Electron microscopy for E.coli cells ........................................... - 37 -

3.2.5.4 Electron microscopy for S. cerevisiae cells ................................... - 38 -

3.2.5.5 Light microscopy for S. cerevisiae cells........................................... - 38 -

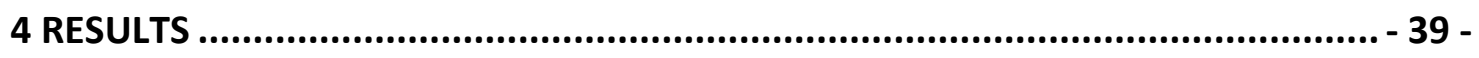

4.1 THE FULL-LENGTH MATURE FORM OF THE MIC60 PROTEIN CAN BE

SUCCESSFULLY EXPRESSED IN E. COLI ................................................................ 39 -

4.2 THE FULL-LENGTH MATURE FORM OF THE MIC60 PROTEIN CAN BE PURIFIED

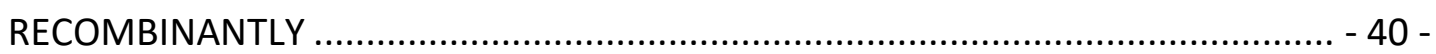

4.3 THE RECOMBINANTLY EXPRESSED MIC60 PROTEIN CAN BE INCORPORATED

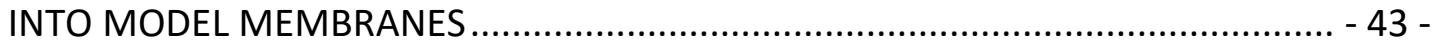

4.4 MIC60 INDUCES HIGH DEGREES OF CURVATURE WHEN INCORPORATED INTO

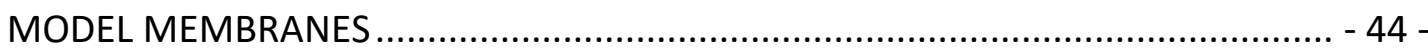


4.5 MIC60 IS ABLE TO INTRODUCE MEMBRANE CURVATURE IN REAL BIOLOGICAL MEMBRANES DE NOVO $-48-$

4.6 THE MIC60 IMS DOMAIN IS RESPONSIBLE FOR THE MEMBRANE REMODELLING FUNCTION OF THE MIC6O PROTEIN $-52-$

4.7 MEMBRANE REMODELLING ACTIVITY OF THE MIC60 PROTEIN IS EVOLUTIONARY CONSERVED $-54-$

4.8 ALPHAPROTEOBACTERIAL HOMOLOGUES OF MIC60 ARE ABLE TO COMPLEMENT ITS EUKARYOTIC FUNCTIONS $-57-$

5 DISCUSSION $60-$

5.1 PURIFICATION OF THE RECOMBINANT FULL-LENGTH MIC60 PROTEIN $-60-$

5.2 MECHANISM OF MIC60-MEDIATED MEMBRANE BENDING $-63-$

5.3 THE NECESSITY OF TWO MEMBRANE BENDING PROTEINS AT THE SITES OF CRISTAE JUNCTIONS $-66-$

5.4 ALPHAPROTEOBACTERIAL MIC60 PROTEIN CAN RECOVER CRISTAE JUNCTIONS IN MIC60D EUKARYOTIC CELLS $68-$ 


\section{LIST OF ABBREVIATIONS}

\begin{tabular}{|c|c|}
\hline${ }^{\circ} \mathbf{C}$ & Degree Celsius \\
\hline$\mu L$ & Microlitre \\
\hline 6×His-tag & Hexahistidine tag \\
\hline Approx. & Approximately \\
\hline ATP & Adenosintriphosphate \\
\hline BSA & Bovine serum albumin \\
\hline CD & Circular dichroism \\
\hline CHAPS & 3-[(3-Cholamidopropyl)dimethylammonio]-1-propanesulfonate \\
\hline CJ & Cristae junctions \\
\hline $\mathrm{CL}$ & Cardiolipin \\
\hline $\mathrm{CM}$ & Cristae membrane \\
\hline $\mathbf{c m}$ & Centimetre \\
\hline CMC & Critical micellar concentration \\
\hline DDM & N-Dodecyl $\beta$-D-maltoside \\
\hline Deg & Degree \\
\hline DLS & Dynamic light scattering \\
\hline DM & N-Decyl- $\beta$-D-maltopyranoside \\
\hline dmol & Decimolar \\
\hline DMSO & Dimethylsulfoxide \\
\hline DNA & Deoxyribonucleic acid \\
\hline DNase I & Deoxyribonuclease I \\
\hline dNTP & Deoxyribonucleoside triphosphate \\
\hline DOPE & 1,2-Dioleoyl-sn-glycero-3-phosphoethanolamine \\
\hline DTT & Dithiothreitol \\
\hline $\mathrm{ECL}$ & Enhanced chemiluminescence \\
\hline EDTA & Ethylenediaminetetraacetic acid \\
\hline ENTH & Epsin N-terminal homology \\
\hline g & Gram \\
\hline GST & Glutathione S-transferase \\
\hline GUV & Giant unilamellar vesicle \\
\hline $\mathbf{h}$ & Hour \\
\hline HEPES & 4-(2-hydroxyethyl)-1-piperazineethanesulfonic acid \\
\hline His & Histidine \\
\hline HRP & Horseradish peroxidase \\
\hline IBM & Inner boundary membrane \\
\hline ICM & Intracytoplasmic membrane \\
\hline IgG & Immunoglobulin G \\
\hline ILS & Intraluminal sheets \\
\hline ILV & Intraluminal vesicles \\
\hline IMAC & Immobilised metal ion affinity chromatography \\
\hline IMS & Intermembrane space \\
\hline
\end{tabular}


IPTG

ITO

L

LB

LUV

mA

MBP

Mega 9

MES

mg

MIA

MICOS

MIM

$\min$

MINOS

Mitos

MitOS

$\mathrm{mL}$

$\mathrm{mM}$

MOM

MOPS

$\mathrm{MPa}$

ng

$\mathrm{nm}$

OD

OG

OXA

PBS

PC

PCR

PE

PEG

PI

PK

PMSF

PS

psi

PVDF

Q

RD

Rhodamine PE rpm

SAM
Isopropyl $\beta$-D-1-thiogalactopyranoside

Indium tin oxide

Litre

Lysogeny broth

Large unilamellar vesicle

Milliampere

Maltose binding protein

Acyl-N-methylglucamine 9

2-(N-morpholino)ethanesulfonic acid

Milligram

Mitochondrial IMS import and assembly machinery

Mitochondrial contact site and cristae organizing system

Mitochondrial inner membrane

Minute

Mitochondrial inner membrane organizing system

Mitochondria

Mitochondrial organizing structure

Millilitre

Millimolar

Mitochondrial outer membrane

3-(N-morpholino)propanesulfonic acid

Megapascal

Nanogram

Nanometre

Optical density

n-Octyl $\beta$-D-glucopyranoside

Oxidase assembly translocase

Phosphate-buffered saline

Phosphatidylcholine

Polymerase chain reaction

Phosphatidylethanolamine

Polyethylene glycol

Phosphatidylinositol

Proteinase $\mathrm{K}$

Phenylmethylsulfonyl fluoride

Phosphatidylserine

Pound-force per square inch

Polyvinylidendifluoride membrane

Molar ellipticity

Relative distribution

L- $\alpha$-PE-N-(lissamine rhodamine B sulfonyl) (Ammonium Salt)

Revolutions per minute

Sorting and assembly machinery 


$\begin{array}{ll}\text { SD } & \text { Standard deviation } \\ \text { SDS-PAGE } & \text { Sodium dodecyl sulphate polyacrylamide gel electrophoresis } \\ \text { SEM } & \text { Sucrose, EDTA, MOPS } \\ \text { SG } & \text { Selective glycerol } \\ \text { TB } & \text { Terrific broth } \\ \text { TBS } & \text { Tris-buffered saline } \\ \text { TBS-T } & \text { Tris-buffered saline with Tween } \\ \text { TCA } & \text { Trichloroacetic acid } \\ \text { TEM } & \text { Transmission electron microscope or electron microscopy } \\ \text { TEMED } & \text { Tetramethylethylenediamine } \\ \text { TIM } & \text { Translocase of the inner membrane } \\ \text { TOM } & \text { Translocase of the outer membrane } \\ \text { U } & \text { Unit } \\ \text { UV } & \text { Ultraviolet light } \\ \text { V } & \text { Volt } \\ \text { VDAC } & \text { Voltage-dependent anion channel } \\ \text { w/w } & \text { Wet weight } \\ \text { WT } & \text { Wild-type } \\ \times \text { g } & \text { Times gravitation } \\ \text { YPAD } & \text { Yeast extract, peptone, adenine hemisulphate, glucose }\end{array}$




\section{LIST OF FIGURES}

Figure 1. 1: Mitochondrial ultrastructure............................................................ 2 -

Figure 1. 2: Schematic representation of mitochondrial inner

membrane architecture.

$-3-$

Figure 1. 3: Morphology of cristae membranes' and cristae junctions'

ultrastructure

$-5-$

Figure 1. 4: Schematic representation of S. cerevisiae MICOS components domain organisation and their topology in mitochondria.

Figure 1. 5: Morphological effects of MICOS subunits deletions on the ultrastructure of mitochondrial inner membrane in S. cerevisiae. $-8-$

Figure 1. 6: Distribution of MICOS subunits across the evolutionary tree. $-12-$

Figure 1. 7: Intracytoplasmic membranes of modern alphaproteobacteria. $-13-$

Figure 4. 1: Expression of full-length mature Mic60 protein in E.coli. $-42-$

Figure 4. 2: Purification of the recombinant full-length mature form of the Mic60 protein.

Figure 4. 3: The full-length, mature form of the recombinant Mic60 protein can be successfully and efficiently reconstituted into model membranes $-45-$

Figure 4. 4: The Mic60 protein is able to induce curvature in the model LUV membranes $-47-$

Figure 4. 5: The Mic60 protein is able to induce curvature of the model GUV membranes $-49-$

Figure 4. 6: Mic60 is able to bend biological membranes in vivo and to induce membrane curvature in a living cell de novo $-50-$

Figure 4. 7: Immunogold labelling of $E$. coli cells expressing the MBP-Mic60 fusion protein. $-51-$

Figure 4. 8: The IMS domain of Mic60 possesses an affinity to lipids and bends model membranes in vitro as well as real biological membranes in vivo $-53-$

Figure 4. 9: Immunogold labelling of $E$. coli cells expressing the MBP-Mic60 IMs fusion protein. - 54 - 
Figure 4. 10: Alphaproteobacterial Mic60 homologues possess an inherent membrane remodelling activity $-56-$

Figure 4. 11: Mic60's membrane remodelling function evolved in an alphaproteobacterial progenitor of mitochondria before the endosymbiotic event and is essential for cristae junction formation -58 - 


\section{LIST OF TABLES}

Table 3. 1: Chemicals and reagents used in this study...................................... - 18 -

Table 3. 2: Commercial kits used in this study .................................................. - 19 -

Table 3. 3: List of lipids used in this study .......................................................... 19 -

Table 3. 4: List of primary antibodies used for immunodetection .......................... - 20 -

Table 3. 5: List of secondary antibodies ........................................................... - 20 -

Table 3. 6: List of E.coli strains used in this study ............................................... 21 -

Table 3. 7: List of S. cerevisiae strains used in this study ................................... - 21 -

Table 3. 8: List of bacterial plasmids used in this study .......................................... 22 -

Table 3. 9: List of yeast plasmids used in this study ........................................... 22 -

Table 3. 10: List of the specific devices and equipment used in this study ............. - 23 -

Table 3. 11: List of software used in this study ................................................ 24 - 


\section{INTRODUCTION}

\section{1 MITOCHONDRIA: THEIR ORIGIN AND FUNCTIONS}

Mitochondria got their name from the combination of Greek words "mitos" and "khondrion" for "thread" and "granule", respectively. This name reflects the overall morphology which scientists could observe when they first examined these organelles under a microscope. From the very beginning, they noted that these organelles, by appearance and behaviour, resembled small bacteria. Accumulation of such observations resulted in an early version of the endosymbiotic theory of the origin of mitochondria and eukaryotic cells $s^{1,2}$. The elaborated version of this theory remains the only theory for the evolutionary origin of mitochondria that is widely accepted nowadays. According to it, mitochondria are ancestors of an ancient, free-living bacterium of the alphaproteobacterial lineage ${ }^{3}$. Such an aerobic bacterium, capable of oxidative phosphorylation, was engulfed by an anaerobic heterotrophic archaeon capable of glycolysis or substrate phosphorylation ${ }^{4}$. Instead of being digested, this alphaproteobacterium developed mutualistic relationships with its predator. Although the described scenario is very much generalised and simplified, and several alternative views on the endosymbiotic event do exist ${ }^{5-8}$, it still represents the main idea of an adopted symbiont providing new evolutionary benefits to the host cell. In this case, the provided benefit was the process of oxidative phosphorylation, a more efficient than glycolysis ATP production pathway, which allowed for the development of high-energy demanding evolutionary novel cellular traits.

Although keeping distinguishable prokaryotic features as own genomic DNA, replication and translation machineries ${ }^{9}$, as well as the protein transport mechanisms homologous to such in bacteria ${ }^{10,11}$, mitochondria became tightly integrated into the metabolic network of the cell. This integration happened as a result of the parallel process of co-evolution and development when an early endosymbiont was gradually delegating the control over some of its biochemical pathways to the host while adopting new eukaryote-specific functions. Thus, modern mitochondria provide a suitable environment for reactions of the Krebs cycle, urea cycle, biosynthesis of heme 


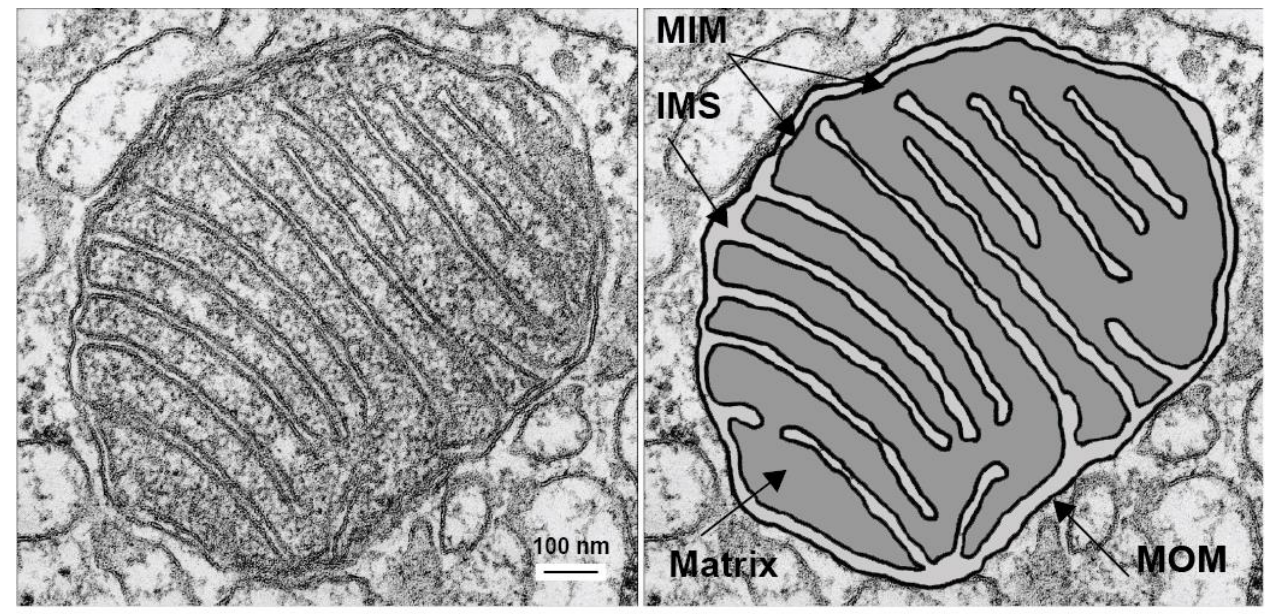

Figure 1. 1: Mitochondrial ultrastructure.

Transmission electron microphotograph of the cross section of a mitochondrion (left) and schematic representation of its ultrastructure (right). A mitochondrion is surrounded by two functionally and morphologically distinct membranes: mitochondrial outer and mitochondrial inner membrane. These membranes define such mitochondrial compartments as intermembrane space and mitochondrial matrix (designated on the left picture). MOM stands for mitochondrial outer membrane, MIM stands for mitochondrial inner membrane, and IMS stands for intermembrane space. Transmission electron photograph was modified from [12]

and iron-sulphur clusters. They are also tightly involved in the lipid metabolism, including synthesis of cardiolipin, and regulation of apoptosis. Nevertheless, similar as 1.5 billion years ago, the main function of these organelles still is oxidative phosphorylation and ATP production.

Successful and efficient conductance of such range of simultaneously occurring processes and functions, especially the bioenergetical function of ATP synthesis, strongly rely on the mitochondrial compartmentalisation, hence on their morphology and ultrastructure.

\section{2 MITOCHONDRIAL MORPHOLOGY AND ULTRASTRUCTURE}

Within the cell, mitochondria can adopt a variety of different shapes arraying from small rod-shaped bacteria-like to extensive and highly branched interconnected tubular networks. Their morphology is very dynamic since it changes accordingly to the energetic demands of the cell ${ }^{13-17}$. This process is managed by the interplay between mitochondrial fusion and fission, two constantly undergoing, antagonistic processes. Moreover, the fission processes play an important role in the elimination of 
morphologically and physiologically impaired mitochondria, contributing to the mechanisms of mitochondrial quality control ${ }^{18,19}$. Besides the overall morphology, proper ultrastructural organisation, or mitochondrial inner "anatomy", is equally important for their function. Owing to their prokaryotic ancestry mitochondria exhibit rather distinctive ultrastructural features. They are enclosed by two membranes, which divide the organelles into four different subcompartments (Figure 1. 1). The Mitochondrial outer membrane (MOM) together with mitochondrial inner membrane (MIM) encompasses the intermembrane space (IMS). The inner mitochondrial membrane also borders a comparably large aqueous compartment, known as the mitochondrial matrix.

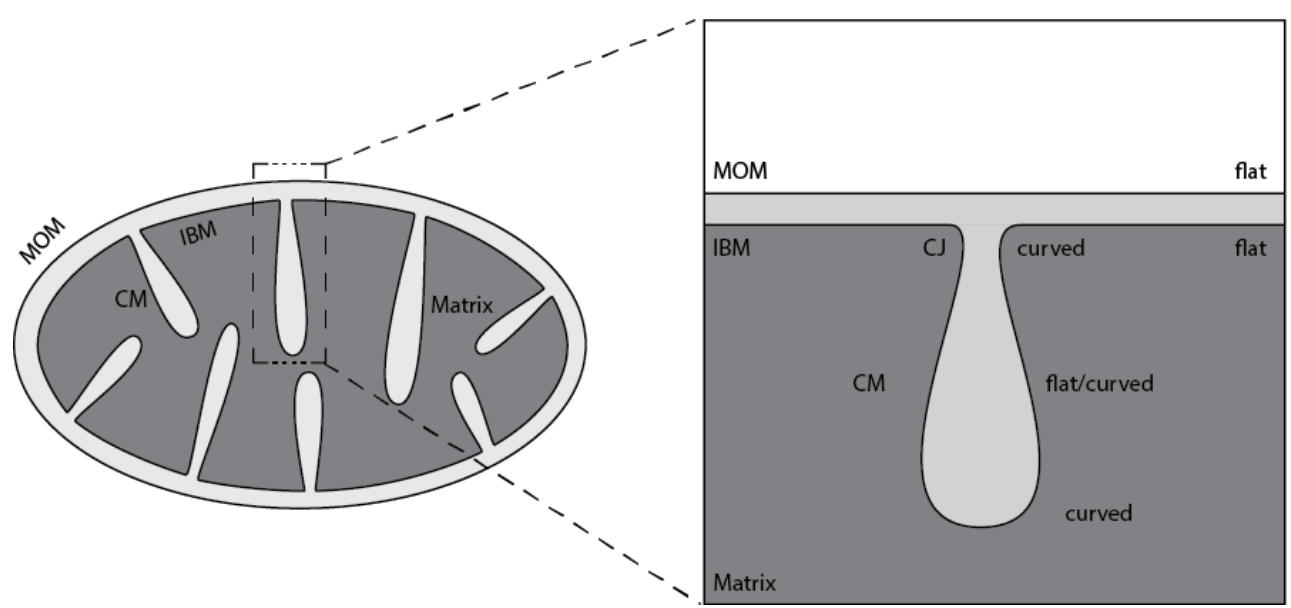

Figure 1. 2: Schematic representation of mitochondrial inner membrane architecture.

Mitochondrial inner membrane (MIM) exhibits complex ultrastructure. In comparison to the mitochondrial outer membrane (MOM), it possesses a much larger surface and is highly folded. MIM can be subdivided into two topologically, structurally and functionally distinct subdomains. Relatively flat inner boundary membrane (IBM) opposes mitochondrial outer membrane and cristae membranes (CM), which protrude towards mitochondrial matrix. IBM and CM are interconnected by narrow, slot-like structures known as cristae junctions (CJs).

MOM separates mitochondria from the cytosol. Hence its protein machineries are mainly devoted to provide means for efficient exchange of ions, metabolites and other biomolecules between mitochondria and the rest of the cell. On the one hand, the MOM serves as a molecular sieve: It allows for facilitated diffusion of ions, small molecules and metabolites into as well as from mitochondria. These processes are carried out by multiple transport proteins, one of which is the highly abundant voltage- 
dependent anion channel (VDAC) - a $\beta$-barrel protein, which resembles channels of the outer membrane of Gram-negative bacteria called porins ${ }^{20}$. On the other hand is the MOM an entry gate for mitochondrial proteins, which were synthesised on the cytoplasmic ribosomes. Such proteins are transported into mitochondria through the translocase of the outer membrane $(\mathrm{TOM})^{21,22}$. Transport of the proteins destined to reside in the MOM, such as $\beta$-barrel proteins as well as $\alpha$-helical proteins containing one or more transmembrane domains, are handled by the outer membrane sorting and assembly complex (SAM) and outer membrane protein Mim1 and Mdm1023.

Functions of the mitochondrial inner membrane are more diverse. In order to fulfil them, the MIM is extensively studded with various protein machineries and therefore exhibits a high protein to lipid ratio in comparison to such of the MOM. To efficiently accommodate these amounts of protein complexes, plane surface of mitochondrial inner membrane became comparably large. Therefore, to be able to fit within MOMconstrained volume mitochondrial inner membrane is arranged in multiple folds. On this ground, MIM can be divided into two morphologically, topologically, as well as functionally, distinct subdomains known as inner boundary membrane (IBM) and cristae membranes (CM) which are connected by so-called cristae junctions (CJs) ${ }^{24-26}$ (Figure 1. 2). The inner boundary membrane is relatively flat and is situated near the mitochondrial outer membrane. The IBM's main function is transport ${ }^{24}$. It is highly enriched with complexes of the presequence translocase of the inner membrane (TIM23), which take over the vast majority of proteins being transported by TOM and mediate their further insertion into the MIM or the mitochondrial matrix. Alternatively (depending on their structural nature and sub-mitochondrial destination) translocated proteins can be handed over to other complexes such as $\operatorname{TIM}_{22} 2^{27}, \mathrm{MIA}^{28,29}$ or OXA ${ }^{30}$. Cristae membranes invaginate from IBM into the mitochondrial matrix. Their number, size and shape can greatly differ depending on the energetic status of the cell, tissue type or organism ranging from lamellar and tubular to even triangular structures (Figure 1. 3). Functionally, cristae membranes are 

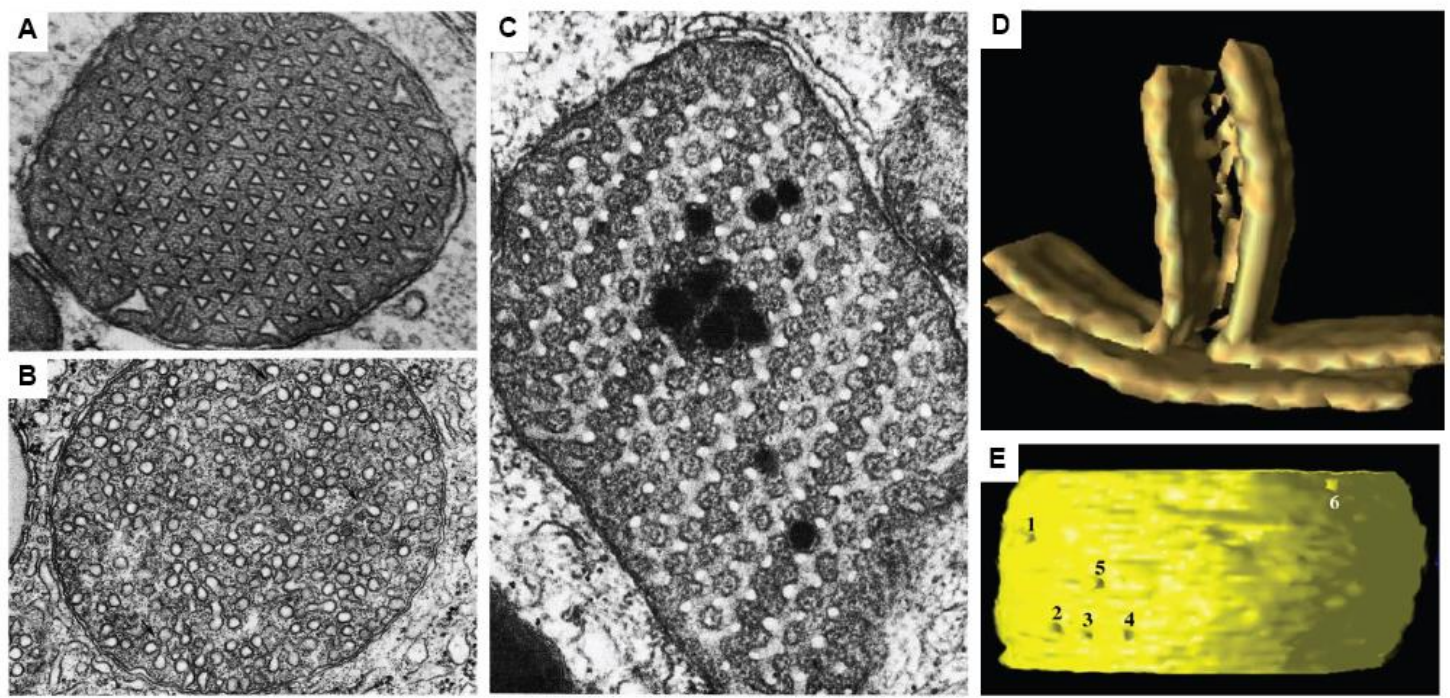

Figure 1. 3: Morphology of cristae membranes' and cristae junctions' ultrastructure.

Cristae membranes ultrastructural morphology can vary to a great extent. A-C represent transmission electron microphotographs of mitochondria from different tissues of various organisms. A - a crosssection of a mitochondrion of astrocyte from hamster brain. B - a cross-section of a mitochondrion from rat adrenal cortex. $\mathrm{C}$ - a cross-section of a mitochondrion from mature Sertoli cells of frog testes. Cristae junctions, in contrast, exhibit remarkably stable ultrastructural morphology. D represents an EM tomogram of a cristae junction, and E represents EM tomogram of the side view of mitochondrial inner membrane with tubular cristae junctions' openings (numbered 1-6) of uniform diameter. A-C is taken from [31], D is taken from [32], and $E$ is taken from [33].

sites of the crucial step of aerobic cellular respiration namely oxidative phosphorylation and are densely packed with electron transport chain complexes, $\mathrm{F}_{1} \mathrm{~F}_{\mathrm{O}}$-ATP synthase and ADP/ATP carriers ${ }^{26,34-36}$. Cristae junctions, in comparison to the cristae membranes, are morphologically extremely homogeneous. They adopt a defined shape of prolonged tubular membrane segments of narrow diameter $(20-30 \mathrm{~nm})$ and are characterised by a high degree of membrane curvature (Figure 1. 3). CJs are suggested to impose a diffusion barrier between the intra-cristae lumen and IMS for solutes 37,38 and signalling molecules (such as cytochrome c) ${ }^{39-42}$. They are further believed to be involved in forming the functional specialisation of the MIM by maintaining the uneven distribution of integral membrane proteins between IBM and cristae membranes ${ }^{43}$. Besides, CJs were shown to partake to morphologically stable contact sites between the outer and inner mitochondrial membranes ${ }^{44}$. Despite accumulating knowledge regarding the range of functions exerted by $\mathrm{CJ}$, the nature of their formation, as well as mechanisms 
behind the stabilisation of their characteristic morphology inflicted by an energetically unfavourable high degree of membrane curvature for a long time, remained unknown.

\section{3 CONTACT SITES, CRISTAE JUNCTIONS AND MICOS}

Intra-mitochondrial contact sites are patches of extremely close (3-8 nm) apposition of MOM and $\mathrm{MIM}^{45-48}$. Formation of such patches improves the efficiency of multiple mitochondrial processes. For instance, drawing the protein translocases of outer and inner membranes TOM and TIM23 into the proximity increases spatial and temporal fidelity of protein translocation across two mitochondrial membranes ${ }^{49,50}$. Likewise, summoning the proteins of mitochondrial fusion machinery, located in both MOM and MIM, into physical proximity promotes coordination and accurate merging of corresponding membranes with each other ${ }^{19,51,52}$. Normally such membrane contacts are very dynamic and tend to exist only temporary. However, there is another type of contact sites, which is characterised by a remarkably permanent morphology. These contacts are so stable that they remain uninterrupted even under harsh conditions such as high osmolarity when the rest of the MIM separates and retracts from the MOM due to dehydration and shrinkage of the mitochondrial matrix ${ }^{44,53}$. Such outstanding cohesion and stability imply the existence of some sort of steady support or scaffold. Presumably, such support could be provided by a protein molecule which is strongly bound to both outer and inner mitochondrial membranes. Despite long-lived debates on this matter, the task of identification of the actual protein appeared to be very challenging.

The prime advance which helped to shed some light onto this issue was the identification of protein called mitofilin as a constituent of such contact sites ${ }^{54-56}$. Initial characterisation studies of this protein performed in cell culture and backer's yeast revealed its preferential localisation to cristae junctions ${ }^{57,58}$, multiple interactions with various MOM proteins ${ }^{58,59}$ and importance for the maintenance of normal MIM morphology 57,58 . Later, several parallel studies discovered that mitofilin is a constituent of a larger protein complex which was independently termed mitofilin complex ${ }^{60}$, mitochondrial inner membrane organising system (MINOS) ${ }^{61}$, mitochondrial organising 


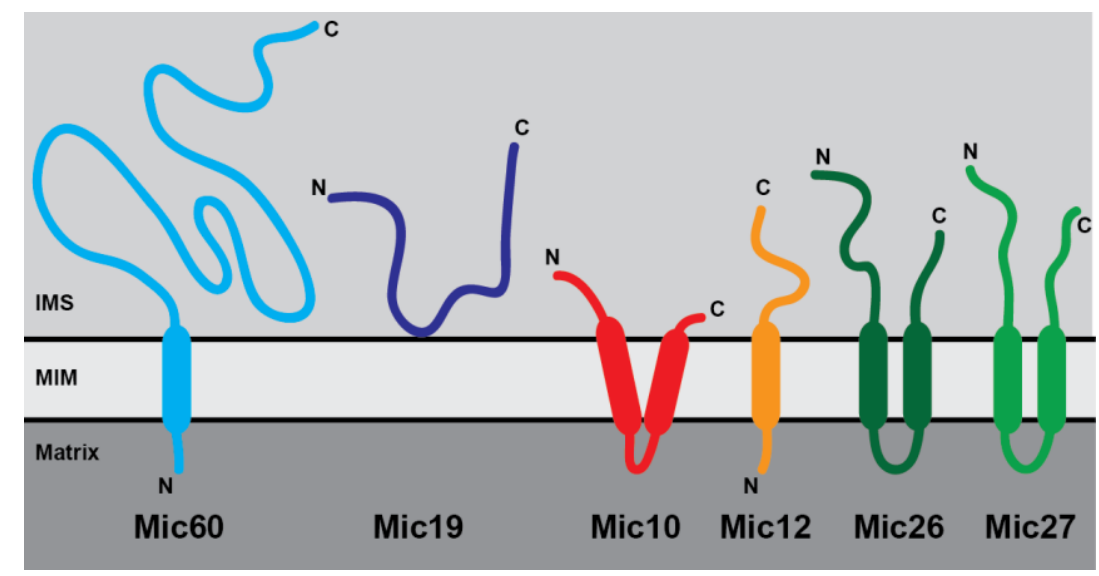

Figure 1. 4: Schematic representation of S. cerevisiae MICOS components domain organisation and their topology in mitochondria.

structure $(\mathrm{MitOS})^{62}$, as well as mitochondrial contact sites and cristae organising system $(\mathrm{MICOS})^{58}$. According to proposed universal terminology ${ }^{63}$, this protein complex was named MICOS and its subunits were named as "Mic" with the addition of numerical sign corresponding to the approximate molecular weight of the subunit. In baker's yeast MICOS consists of 6 subunits: Mic10, Mic12, Mic19, Mic26, Mic27 and formerly known as mitofilin protein Mic60. MICOS subunits are membrane proteins containing at least one transmembrane domain with the exception of Mic19, which is a peripheral membrane protein ${ }^{58,60-62,64}$ (Figure 1. 4). Deletion of MICOS components impairs normal growth of yeast on non-fermentable carbon sources, which indicates compromised mitochondrial function. MICOS-deficient cells exhibit a strikingly abnormal ultrastructure: Their mitochondria lose virtually all cristae junctions because cristae membranes detach from the inner boundary membrane and accumulate as stacks of enclosed membranous sacks or onion-like concentric rings (Figure 1. 5) ${ }^{58,60-}$ 62,65 .

Based on these observations, it was presumed that the MICOS complex could play a dual role in the organisation of mitochondrial membrane morphology. On the one hand, defining the contact sites formation by stapling mitochondrial outer and inner membranes together and on the other hand contributing to the maintenance of normal MIM architecture by stabilisation of high membrane curvature at the sites of CJs. 


\section{4 MECHANISMS OF CRISTAE JUNCTIONS MAINTENANCE}

The mechanism of biogenesis and regulation of cristae junction formation was one of the biggest unanswered questions of mitochondrial biology. Although the discovery of MICOS boosted this research area very much, investigation of discrete MICOS subunits, as well as their individual contribution to the function of the complex as a whole, was not easy to conduct.
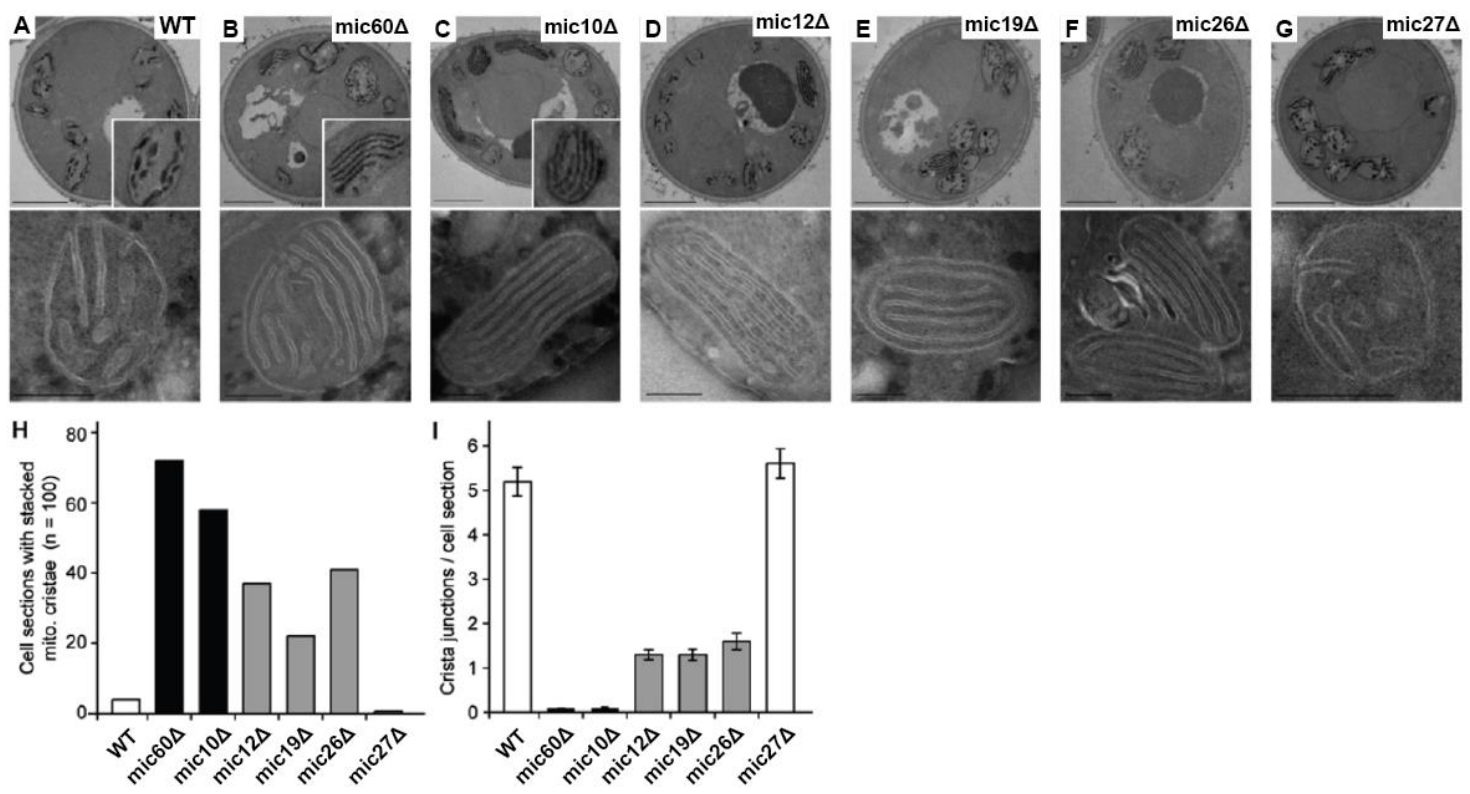

Figure 1. 5: Morphological effects of MICOS subunits deletions on the ultrastructure of mitochondrial inner membrane in S. cerevisiae.

Upper panel $(A-G)$ represents TEM microphotographs of whole $S$. cerevisiae cells: wild-type $(A)$ and various $\triangle \mathrm{MICOS}$ strains $(B-G)$. The lower panel represents details of mitochondrial ultrastructure of such strains. (H) and (I) represent quantification of cross sections with stacked mitochondrial cristae membranes and number of cristae junctions respectively. Microphotographs and quantification histograms were taken from [61] and modified according to uniform MICOS nomenclature proposed in [63].

The main drawback was imposed by the fact that the phenotypic manifestations of the single-subunit deletions are represented by the same set of morphological effects. All individual deletions of MICOS subunit result in CJs loss and alteration of normal cristae membrane morphology depicted by the accumulation of membrane stacks ${ }^{58,60-62,66}$. Moreover, deletion of each MICOS subunit is accompanied by partial dissociation of remaining subunits from the complex. These factors made it very challenging to 
differentiate between the primary effects of an individual subunit deletion and the effects induced by overall MICOS disturbance. However, the degree to which these effects are pronounced varies for different subunits ${ }^{61}$ (Figure 1. 5). Mic60 and Mic10 were considered to be the core subunits of MICOS since their deletions lead to the most drastic effects on the MIM morphology. The rest of the subunits (Mic12, Mic26, Mic27 and Mic19) due to the milder effects of their deletion on the IMM morphology were considered to be minor or auxiliary subunits of the MICOS complex. Despite being core components of MICOS and causing extremely similar effects on the MIM morphology upon their deletion, the Mic60 and Mic10 proteins are very different from each other. Mic60 is the biggest subunit of the whole complex. It is an integral membrane protein of approximately $60 \mathrm{kDa}$ in size, which is imported into mitochondria following the recognition of a classical $\mathrm{N}$-terminal mitochondrial targeting cleavable peptide and integrated into the MIM via a single transmembrane domain (Figure 1. 4). This way, Nterminus of mature Mic60 protein faces the mitochondrial matrix, and the rest of the protein sequence including C-terminus is exposed into the IMS. This intermembrane space domain is constituted by extensive central coiled-coil domain and small Cterminal mitofilin signature domain ${ }^{67}$. The coiled-coil domain of Mic60 as typical for such types of protein domains was shown to be involved in multiple protein-protein interactions. It was shown that by its means Mic60 interacts with other MICOS subunits as well as with protein of the outer mitochondrial membrane such as TOM, SAM, TIM23, VDAC and Ugo1 ${ }^{58-62,65,68-70}$. C-terminal domain of Mic60 was shown to be involved in the maintenance of MIM architecture.

In contrast to Mic60, Mic10 is the smallest MICOS subunit. It is a protein of $10 \mathrm{kDa}$ the main part of which essentially consists of two transmembrane helices (Figure 1. 4). Mic10 does not contain $\mathrm{N}$-terminal targeting peptide and is imported to mitochondria by utilising an internal targeting signal comprised in the loop region located between the two transmembrane domains. The overall predicted structure of Mic10 very much resembles the structure of reticulons (endoplasmic reticulum-based proteins which are known to mediate membrane curvature $)^{71}$. Two independent studies showed that Mic10's transmembrane domains are not identical. The first transmembrane domain is 
several amino acids longer. To avoid a hydrophobic mismatch, this domain adopts tilted orientation within the lipid bilayer. Thus, the Mic10 protein takes up more surface in the outer leaflet of the inner mitochondrial membrane, which results in membrane bending ${ }^{72,73}$. Mic10's ability to form homo-oligomers multiplies its membrane remodelling effects ${ }^{72}$.

Since then the opinion that functions of MICOS complex (contact sites creation and organising of $\mathrm{CJ}$ ) are performed by two different specialised core subunits became widely accepted. According to this idea, Mic60 plays the role of the MICOS interaction hub. By interacting with proteins of the outer mitochondrial membrane, MICOS contributes to the formation of contact sites and positioning of cristae junctions to optimise trafficking of the metabolites between mitochondrial compartments as well as along the mitochondrial inner membrane. As a second MICOS core component, Mic10 is responsible for the introduction of the membrane curvature, hence the active formation of CJs membrane ultrastructure. Although very elegant, this idea does not provide a reasonable explanation of the fact that yeast cells depleted of the Mic60 protein still lose a considerable amount of CJs despite unaffected levels of Mic10.

\section{5 MICOS IS EVOLUTIONARY CONSERVED}

Shortly after the discovery of MICOS complex in Saccharomyces cerevisiae, its homologues were also found in worms ${ }^{74,75}$, and mammals ${ }^{60}$. Therefore it became evident that this complex is evolutionary conserved. This notion was further supported by the recent phylogenetic study of the distribution of the putative MICOS subunits throughout the evolutionary tree of life $^{76}$. This study showed that homologues of MICOS subunits could be attributed to all organisms of major eukaryotic lineages. The "complete" MICOS complex, consisting of all six subunits (Mic10, Mic12, Mic19, Mic26, Mic27 and Mic60), was systematically represented only among the kingdoms of fungi and animals. Other eukaryotic lineages such as alveolates and stramenopiles were found to comprise MICOS consisting of only two subunits (namely Mic10 and Mic60) and excavates, amoebozoans and archeplastids of 3 subunits (Mic10, Mic60 and Mic19) ${ }^{76,77}$. This finding strongly supported the already existing opinion that Mic10 and 
Mic60 are the core subunits of the yeast as well as the mammalian MICOS. Moreover, it further suggested that these subunits might play an equally important and central role in all other eukaryotic organisms. The "auxiliary" MICOS subunits (Mic12, Mic19, Mic25, Mic26 and Mic27) show rather sporadic distribution. For example, Mic12 is restricted to fungi, Mic26 is restricted for fungi and animals, and Mic25 - only to vertebrates.

Taken together, it seems that the last eukaryotic common ancestor most probably would utilise a so-called "minimal required" MICOS complex consisting of its core subunits Mic10, Mic60 and, perhaps, Mic1976. The other subunits could be independently acquired by different clades of eukaryotes during evolution. This process possibly could involve several cases of independent gene duplications followed by parallel retention, loss and further divergence of obtained paralogs $s^{76,77}$.

Remarkably, no MICOS subunits, apart from Mic60, were found to have homologues within prokaryotes. (Figure 1. 6). Mic60 homologues were found to be exclusively restricted to the group of alphaproteobacteria, which are believed to be ancestors of mitochondria ${ }^{76}$. Alphaproteobacterial Mic60 were predicted to share overall domain organisation with their eukaryotic homologues (Figure 1. 6).

Similarly to eukaryotic Mic60 proteins, they contain a single N-terminal transmembrane domain, a central coiled-coil domain and a C-terminal mitofilin domain. The comparison of sequence similarity revealed that only the C-terminal domain shares sequence homology with eukaryotic proteins, while the secondary structure predictions clearly showed the presence of an extensive central coiled-coil ${ }^{76}$. In this way, alphaproteobacterial Mic60 has not principally changed from bacteria to eukaryotes and combines two kinds of protein homology: sequence, as well as structural. Such similarity suggests that the functions of eukaryotic Mic60 could be already enclosed in its alphaproteobacterial homologues. 
A
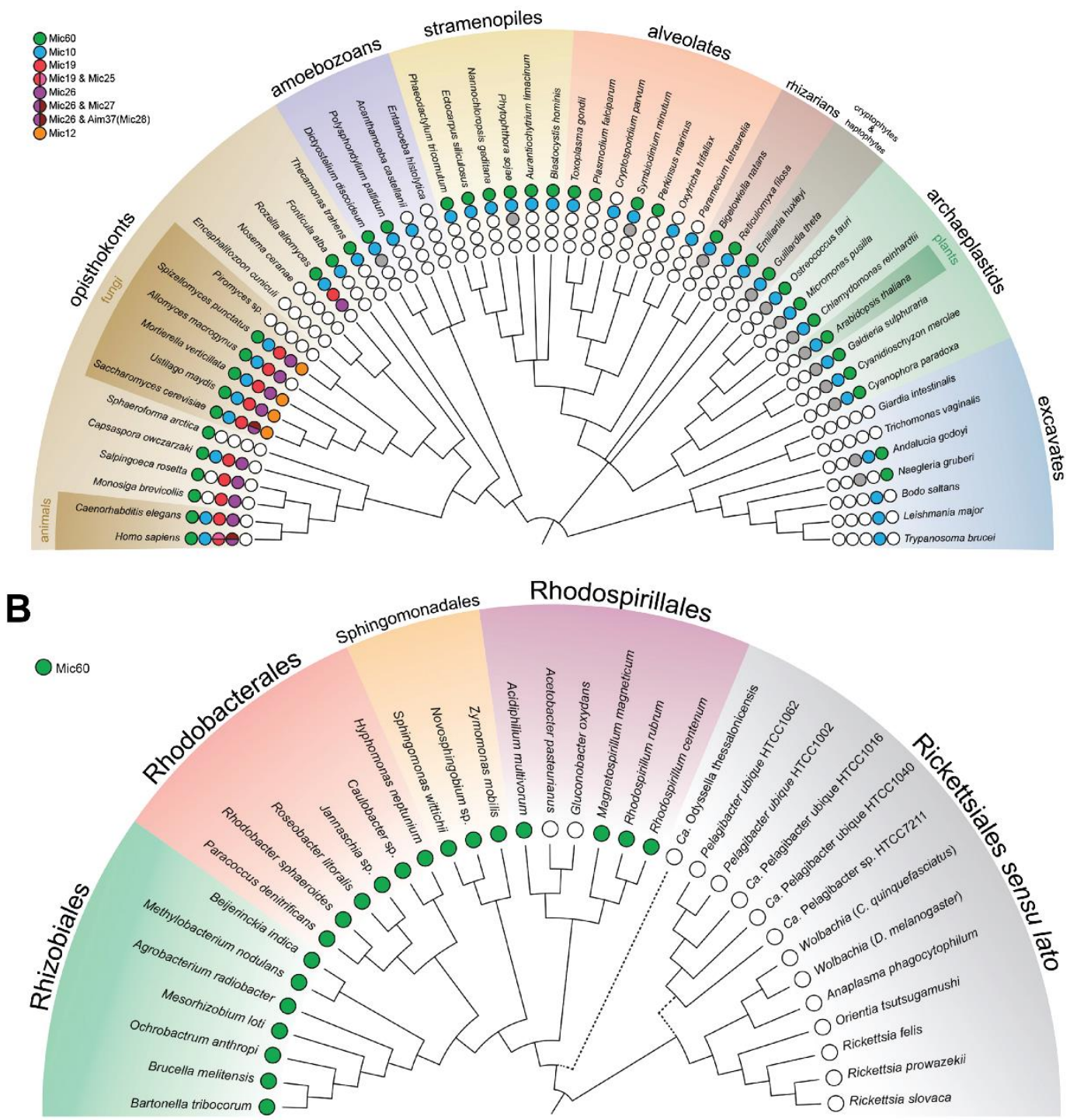

C

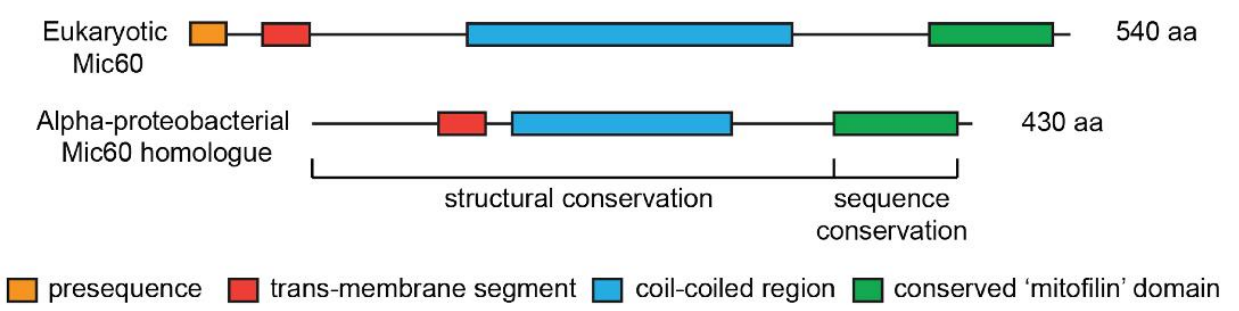

Figure 1. 6: Distribution of MICOS subunits across the evolutionary tree.

Distribution of MICOS subunits across the eukaryotic evolutionary tree (A). Distribution of the Mic60 protein across alphaproteobacteria (B). Comparison of the domain structure of eukaryotic and alphaproteobacterial Mic60 proteins (C); Modified from [76]. 


\section{6 ROLE OF PROKARYOTIC MIC60 HOMOLOGUES IN ALPHAPROTEOBACTERIA}

The class of alphaproteobacteria is represented by highly diverse members, which differ from each other to a great extent with regards to their morphology, metabolism and physiology. For example, alphaproteobacteria unite free-living, endosymbiotic mutualistic and even parasitic bacteria of various nutrition modes such as organotrophs, phototrophs and chemotrophs (including methanotrophs and nitrifiers). Despite such immense diversity, alphaproteobacteria share several features in common: All of them are Gram-negative, are enclosed by a double membrane and are characterised by the ability to develop intracytoplasmic membranes (ICMs) of various morphologies (Figure 1. 7) ${ }^{78}$. Although the precise mechanism of ICMs formation is not completely understood, it is known that functionally ICMs are devoted to increase the surface of the bacterial cytoplasmic membrane to accommodate higher
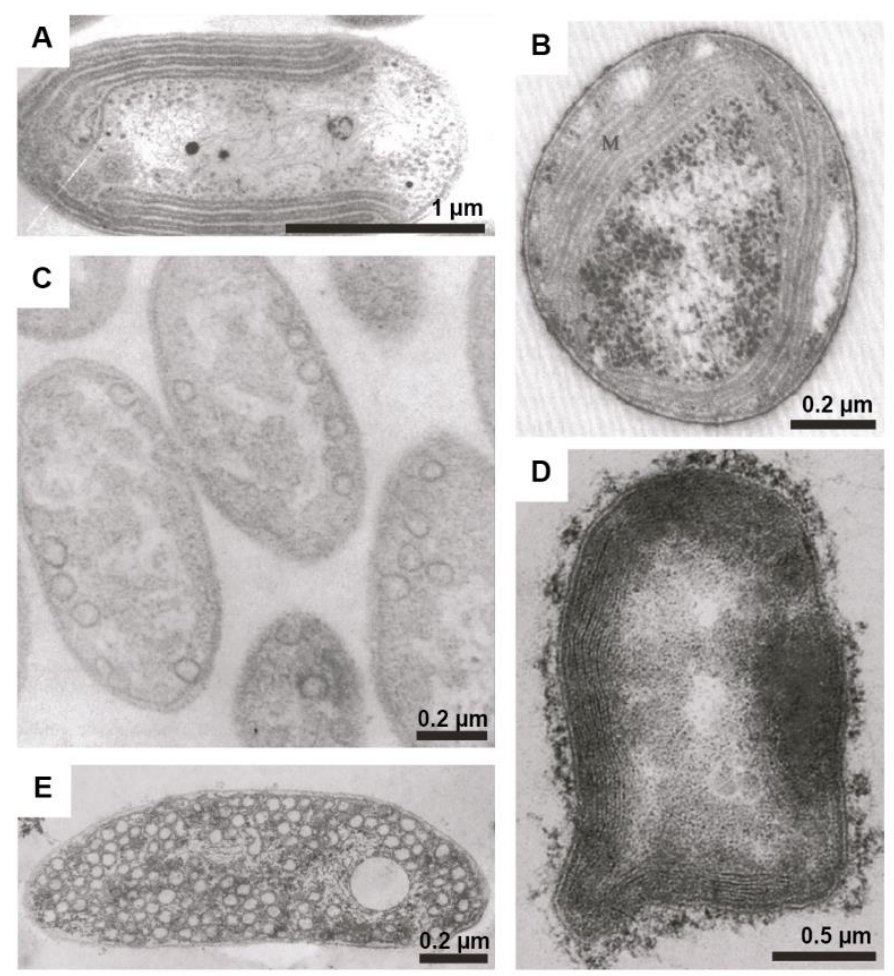

Figure 1. 7: Intracytoplasmic membranes of modern alphaproteobacteria.

TEM microphotograph of the cross sections obtained from Nitrobacter winogradski NB-255 (A), Methylosinus trichosporium OB3b (B), Erythrobacter sp. OCh114 (C) and Rhodoblastus sphagnicola (D); taken and modified from [77] 
amounts of photosynthetic machinery components ${ }^{78}$, nitrification ${ }^{79,80}$ or methanol oxidation enzymes ${ }^{78,81-83}$ in order to meet the energetic demands of the cell. Very often such intracytoplasmic membranes remain connected to the bacterial cytoplasmic membrane via thin membranous tubules. These tubules are believed to be important for establishing a diffusion barrier between the cytoplasmic and intracytoplasmic membranes as well as between periplasm and intravesicular lumen ${ }^{84-87}$. It is worth noticing that such morphological and functional organisation of alphaproteobacterial intracytoplasmic membranes very much resembles the organisation of mitochondrial cristae. Comparative analysis of the protein expression profiles of Rhodobacter sphaeroides under aerobic and photosynthetic (ICM formation-promoting) conditions, identified the alphaproteobacterial homologue of mitochondrial Mic60 among others ORFs which are uniquely expressed in photosynthetic Rhodobacter sphaeroides culture $^{88}$. Additionally, proteomic studies of the isolated Rhodobacter sphaeroides $\mathrm{ICMs}^{89,90}$, as well as ICMs isolated from other alphaproteobacterial species such as Rhodospirillum rubrum ${ }^{91}$ and Rhodopseudomonas palustris ${ }^{92}$ determined Mic60 homologues as one of the ICM-localized proteins. These results, in combination with the reported evolutionary and biochemical evidences of mitochondrial Mic60 being a core component of MICOS complex, indicate towards a high possibility of alphaproteobacterial Mic60 exerting analogous functions. Particularly, the alphaproteobacterial Mic60 protein could be involved in the process of ICMs biogenesis as well as in the formation and maintenance of tubular membrane segments, which interconnect them with the cytoplasmic membrane. Furthermore, the fact that Mic60's interaction partners within the mitochondrial outer membrane such as $\mathrm{SAM}^{93}$ and $\mathrm{TOM}^{94}$ also have identified bacterial homologues, as well as the evolutionary structural preservation of Mic60's functional domains, allow us to assume that similar types of interactions might also occur between the prokaryotic proteins. Such protein interaction might partake in the formation of contact sites between bacterial outer envelope and cytoplasmic membrane also known as Bayer's junctions ${ }^{95}$. Similarly to mitochondrial contact sites, Bayer's junctions are thought to be involved in coupling protein transport processes, as well as lipid transfer. If these assumptions are 
experimentally confirmed, it will re-establish a long-forgotten idea of the preendosymbiotic origin of mitochondrial cristae membranes, according to which mitochondrial cristae are not a purely eukaryotic invention but were inherited from the ancient bacterial relatives. Moreover, drawing such evolutionary parallels can help us to re-evaluate our current interpretations of the already known as well as broaden our outlook onto possible new roles of eukaryotic MICOS in general and its core component Mic60 in particular. 


\section{AIMS OF THIS WORK}

Proper and efficient execution of mitochondrial functions relies on the tight orchestration of multiple concurrent metabolic pathways. Highly complex ultrastructure of mitochondrial membrane underlays its compartmentalisation, which provides the structural basis for the spatial separation of various biochemical processes. Cristae junctions are the central sites of mitochondrial membrane ultrastructure organisation and coordination. Recently discovered MICOS complex was shown to be of prime importance for formation and stabilisation of CJ sites. These functions are fulfilled by the dual properties of MICOS. Such duality is provided by two structurally distinct MICOS core components namely Mic60 and Mic10: Mic60 bridges outer and inner mitochondrial membranes while Mic10 stabilises membrane curvature at the sites of CJs. This idea was strongly supported by recent studies, which functionally characterized Mic10 as a membrane-bending protein. Accumulating data nevertheless could not provide sufficient evidence to explain the reasons for massive $\mathrm{CJ}$ loss and drastic disturbances of mitochondrial inner membrane morphology of mic $60 \Delta$ cells in which Mic10 levels remained unaffected. Proper in vivo and in organello characterisation of individual MICOS subunits and their direct effects on CJ morphology remained very challenging due to the difficulties with differentiation between primary and secondary morphological effects. Therefore, I decided to employ an in vitro-based bottom-up experimental approach in order to functionally characterise the Mic60 protein with regard to its importance for the formation and maintenance of CJs and mitochondrial inner membrane morphology. There are several points which I planned to address during this study.

Firstly, I intended to reconstitute purified full-length Mic60 into model membranes of different types. This would allow investigating whether Mic60 is able to affect the morphology of lipid bilayer.

Secondly, if the membrane-remodelling property of Mic60 is confirmed, I aimed to allocate it to the specific domain and investigate its mechanism. 
Lastly (taking to consideration, that Mic60 is only MICOS subunit with homologues in prokaryotes) I intended to investigate whether high conservation of domain organisation leads to conservation of Mic60's functions. Specifically, by employing bottom-up in vitro reconstitution strategy in combination with in organello experiments I planned to check whether the bacterial Mic60 homologues can overcome the phenotypic consequences in mic60 $\Delta$ eukaryotic cells. 


\section{MATERIALS AND METHODS}

\subsection{MATERIALS}

\subsubsection{Chemicals and reagents}

Chemicals, as well as laboratory consumables, were ordered from Roth (Karlsruhe, Germany), Sigma Aldrich (Taufkirchen, Germany) and Sarstedt (Nürmbrecht, Germany).

The more specific materials and devices used in this study listed in the tables below.

Table 3. 1: Chemicals and reagents used in this study

\begin{tabular}{|c|c|}
\hline Item & Supplier \\
\hline Acyl-N-methylglucamine 9 (Mega 9) & Glycon \\
\hline Ampicillin & Roth \\
\hline Bio-Beads ${ }^{\circledast}$ SM-2 Adsorbent & Bio-Rad Laboratories \\
\hline Bio-Rad protein assay & Bio-Rad Laboratories \\
\hline $\begin{array}{l}\text { 3-[(3-Cholamidopropyl)dimethylammonio]- } \\
\text { 1-propanesulfonate (CHAPS) }\end{array}$ & Glycon \\
\hline Chloroform & Merk \\
\hline $\begin{array}{l}\text { Complete amino acid supplement mixture } \\
\text { without histidine }\end{array}$ & MP Biomedicals \\
\hline n-Decyl- $\beta$-D-maltopyranoside (DM) & Glycon \\
\hline Deoxynucleotide triphosphate mix & 5 PRIME \\
\hline Deoxyribonuclease I (DNase I) & Sigma Aldrich \\
\hline Digitonin & Calbiochem/Merk \\
\hline Dithiothreitol (DTT) & Thermo Scientific \\
\hline n-Dodecyl- $\beta$-D-maltoside (DDM) & Glycon \\
\hline Enhanced chemiluminescence (ECL) & Thermo Scientific \\
\hline Western Blotting Substrate & \\
\hline Ethidiumbromide $0.07 \%$ & AppliChem \\
\hline GeneRuler DNA Ladder $1 \mathrm{~kb}$ & Thermo Scientific \\
\hline Herring Sperm DNA & Promega \\
\hline Histodenz & Sigma Aldrich \\
\hline Imidazole & Roth \\
\hline $\begin{array}{l}\text { Isopropyl- } \beta \text {-D-1thiogalactopyranoside } \\
\text { (IPTG) }\end{array}$ & Roth \\
\hline Kanamycin & Roth \\
\hline L-Glutathione reduced & Roth \\
\hline Lysozyme & Sigma Aldrich \\
\hline Phenylmethylsulfonylfluoride (PMSF) & Sigma Aldrich \\
\hline Polyethylene glycol (PEG) 400 & Merk \\
\hline
\end{tabular}


Polyvinylidene difluoride (PVDF) transfer membrane

Proteinase inhibitor cocktail (EDTA-free)

Proteinase K (PK)

PageRuler Prestained Protein Ladder

Phusion DNA Polymerase

Restriction endonucleases

Triton X-100

Tween-20

T4 DNA Ligase

Urea

$X$-ray films

Zymolyase 20T
Maine Manufacturing LCC

Roche

Roche

Thermo Scientific

Thermo Scientific

Thermo Scientific

Sigma Aldrich

Roth

Thermo Scientific

Roth

GE Healthcare

Seikagaku Biobusiness Corporation

Table 3. 2: Commercial kits used in this study

\begin{tabular}{ll}
\hline Item & Supplier \\
\hline & \\
Fluorescence Labelling Kit & invitrogen \\
High Pure PCR Template Preparation Kit & Roche \\
Wizard SV Gel and PCR Clean-UP & Promega \\
Wizard SV Mini-Prep & Promega
\end{tabular}

Table 3. 3: List of lipids used in this study

\begin{tabular}{ll}
\hline Item & Supplier \\
\hline Cardiolipin (CL) & Avanti Polar Lipids \\
1,2-dioleoyl-s-glycero-3 phosphoethanolamine (DOPE) & Avanti Polar Lipids \\
L- $\alpha$-Phosphatidylcholine (PC) & Avanti Polar Lipids \\
L- $\alpha$-Phosphatidylethanolamine (PE) & Avanti Polar Lipids \\
L- $\alpha$-Phosphatidylethanolamine-N-(lissamine & Sigma Aldrich \\
rhodamine B sulphonyl) (Rhodamine PE) & \\
L- $\alpha$-Phosphatidylinositol (PI) & Avanti Polar Lipids \\
L- $\alpha$-Phosphatidylserine (PS) & Avanti Polar Lipids \\
& \\
\hline
\end{tabular}




\subsubsection{Antibodies}

Rabbit antisera produced at Gramsch laboratories (Schwabhausen, Germany) was routinely used as a primary antibody to detect mitochondrial inner membrane proteins. Monoclonal antibodies produced in mouse were used for detection of fusion tags and proteins other from mitochondrial inner membrane. All primary and secondary antibodies, as well their manufacturers, used in this study are listed in the table below.

Table 3. 4: List of primary antibodies used for immunodetection

\begin{tabular}{lll}
\hline Antigen & Antibody type & Manufacturer \\
\hline Mic10 & Rabbit polyclonal & Gramsch Laboratories \\
Mic60 & Rabbit polyclonal & Gramsch Laboratories \\
Tim23 & Rabbit polyclonal & Gramsch Laboratories \\
Tim44 & Rabbit polyclonal & Gramsch Laboratories \\
Tim50 & Rabbit polyclonal & Gramsch Laboratories \\
Tom22 & Rabbit polyclonal & Gramsch Laboratories \\
Maltose binding & Mouse monoclonal & Sigma-Aldrich \\
protein (MBP) & & \\
Mcr1 & Rabbit polyclonal & Gramsch Laboratories \\
Poly His tag & Mouse monoclonal & Sigma-Aldrich \\
FLAG tag & Mouse monoclonal & Sigma-Aldrich \\
$\beta$-lactamase & Mouse monoclonal & Abcam \\
GroEL & Mouse monoclonal & Abcam \\
ATPb & Mouse monoclonal & Abcam
\end{tabular}

Table 3. 5: List of secondary antibodies

\begin{tabular}{ll}
\hline Antibody & Manufacturer \\
\hline Goat anti-mouse & Dianova \\
Goat anti-rabbit & Dianova \\
& \\
\hline \hline
\end{tabular}




\subsubsection{Microorganisms}

E.coli and S. cerevisiae strains used in this study are listed below

Table 3. 6: List of E.coli strains used in this study

\begin{tabular}{lll}
\hline Strain name & Genetic background & Supplier \\
\hline \multirow{2}{*}{ BL21(DE3) } & recA1 endA1 gyrA96 thi-1 hsdR17 supE44 & Stratagene \\
& relA1 lac [F' proAB laclq $\Delta M 15$ Tn10 (Tetr)] & \\
XL1 Blue & F-dcm ompT hsdS (rB-mB)gal & Stratagene \\
& & \\
\hline
\end{tabular}

Table 3. 7: List of S. cerevisiae strains used in this study

\begin{tabular}{|c|c|c|}
\hline Strain name & Genetic background & Reference \\
\hline BY4742 & $\begin{array}{l}\text { Mat a, his3- } \Delta 1 \text { leu } 2 \Delta 0 \text { met } 15 \Delta 0 \text { ura3 } \Delta 0 \\
\text { [p413 MET25] }\end{array}$ & $\begin{array}{l}\text { (Sikorski and Hieter, } \\
\text { 1989) }\end{array}$ \\
\hline BY4741 + p413 & Mat a, his3- $\Delta 1$ leu $2 \Delta 0$ met $15 \Delta 0$ ura $3 \Delta 0$ & \\
\hline \multicolumn{3}{|c|}{ 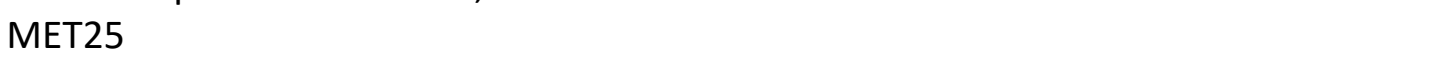 } \\
\hline$\Delta$ mic60 & $\begin{array}{l}\text { Mat a, his3- } \Delta 1 \text { leu } 2 \Delta 0 \text { met } 15 \Delta 0 \text { ura3 } \Delta 0 \text {; } \\
\text { mic60::kanMX4 }\end{array}$ & \\
\hline $\begin{array}{l}\Delta \operatorname{mic} 60+\mathrm{p} 413 \\
\mathrm{MET} 25\end{array}$ & $\begin{array}{l}\text { Mat a, his3- } \Delta 1 \text { leu } 2 \Delta 0 \text { met } 15 \Delta 0 \text { ura3 } \Delta 0 \text {; } \\
\text { mic60::kanMX4 [p413 MET25] }\end{array}$ & This study \\
\hline $\begin{array}{l}\Delta \text { mic60 }+ \text { Mic60 in } \\
\text { p413 MET25 }\end{array}$ & $\begin{array}{l}\text { Mat a, his3- } \Delta 1 \text { leu } 2 \Delta 0 \text { met } 15 \Delta 0 \text { ura3 } \Delta 0 \text {; } \\
\text { mic60::kanMX4 [p413 MET25-MIC60] }\end{array}$ & This study \\
\hline $\begin{array}{l}\Delta \operatorname{mic} 60+ \\
\text { Mic60FLAG in p413 }\end{array}$ & $\begin{array}{l}\text { Mat a, his3- } \Delta 1 \text { leu } 2 \Delta 0 \text { met } 15 \Delta 0 \text { ura3 } \Delta 0 \text {; } \\
\text { mic60::kanMX4 [p413 MET25- }\end{array}$ & This study \\
\hline MET25 & MIC60FLAG] & \\
\hline $\begin{array}{l}\Delta \text { mic60 + } \\
\text { P.d.Mic60FLAG in } \\
\text { p413 MET25 }\end{array}$ & $\begin{array}{l}\text { Mat a, his3- } \Delta 1 \text { leu } 2 \Delta 0 \text { met } 15 \Delta 0 \text { ura3 } \Delta 0 \text {; } \\
\text { mic60::kanMX4 [p413 MET25- } \\
\text { P.D.MIC60FLAG] }\end{array}$ & This study \\
\hline $\begin{array}{l}\Delta \text { mic60 + } \\
\text { R.s.Mic60FLAG in } \\
\text { p413 MET25 }\end{array}$ & $\begin{array}{l}\text { Mat a, his3- } \Delta 1 \text { leu } 2 \Delta 0 \text { met } 15 \Delta 0 \text { ura3 } \Delta 0 \text {; } \\
\text { mic60::kanMX4 [p413 MET25- } \\
\text { R.S.MIC60FLAG }\end{array}$ & This study \\
\hline
\end{tabular}




\subsubsection{Plasmids}

All plasmids generated for and used in this study are listed in the table below

Table 3. 8: List of bacterial plasmids used in this study

\begin{tabular}{|c|c|c|c|c|}
\hline $\begin{array}{l}\text { Name of the } \\
\text { plasmid }\end{array}$ & $\begin{array}{l}\text { Vector } \\
\text { backbone }\end{array}$ & Insert & $\begin{array}{l}\text { Selection } \\
\text { marker }\end{array}$ & Source \\
\hline MM 67 & pGEX-6P-1 & - & Amp & AG Meinecke \\
\hline MM 74 & pET-28a(+) & - & Kan & AG Meinecke \\
\hline MM 89 & pGEX-6P-1 & Mic60 & Amp & This study \\
\hline MM 106 & pET-28a(+) & Mic60 & Kan & This study \\
\hline MM 112 & pPROEXHTc & - & Amp & AG Meinecke \\
\hline MM 113 & pPROEXHTc & Mic60 & Amp & This study \\
\hline MM 210 & pMALp2x & - & Amp & AG Schwappach \\
\hline MM 214 & pMALp2x & Mic60 & Amp & This study \\
\hline MM 226 & pMALp2x & Tim50 & Amp & This study \\
\hline MM 227 & pMALp2x & $\operatorname{Tim} 23$ & Amp & This study \\
\hline MM 232 & pPROEXHTc & Mic60 IMS & Amp & This study \\
\hline MM 240 & pPROEXHTc & Tim50 & Amp & This study \\
\hline MM 246 & pMALp2x & Mic60 P.d & Amp & This study \\
\hline MM 247 & pMALp2x & Mic60 R.s & Amp & This study \\
\hline MM 248 & pMALp2x & Mic60 IMS & Amp & This study \\
\hline MM264 & pPROEXHTc & Mic60 P.d & Amp & This study \\
\hline MM 265 & pPROEXHTc & Mic60 R.s & Amp & This study \\
\hline MM 269 & pMALp2x & Tom20 & Amp & This study \\
\hline
\end{tabular}

Table 3. 9: List of yeast plasmids used in this study

\begin{tabular}{|c|c|c|c|c|}
\hline $\begin{array}{l}\text { Name of the } \\
\text { plasmid }\end{array}$ & $\begin{array}{l}\text { Vector } \\
\text { backbone }\end{array}$ & Insert & $\begin{array}{l}\text { Selection } \\
\text { marker }\end{array}$ & Source \\
\hline MM 235 & P413 MET25 & - & Amp/HIS & AG Rehling \\
\hline MM 249 & P413 MET25 & Mic60 & Amp/HIS & This study \\
\hline MM 253 & P413 MET25 & Mic60 FLAG & Amp/HIS & This study \\
\hline MM 257 & P413 MET25 & Mic60 ${ }^{P . d}$ FLAG & Amp/HIS & This study \\
\hline MM 259 & P413 MET25 & Mic60 R.s FLAG & Amp/HIS & This study \\
\hline
\end{tabular}




\subsubsection{Instruments and software}

All specific devices and equipment, as well as software, used in this study are listed in the tables below.

Table 3. 10: List of the specific devices and equipment used in this study

\begin{tabular}{|c|c|}
\hline Instrument/device & Manufacturer \\
\hline ÄKTA prime plus & GE Healthcare \\
\hline Carbon-coated grids & Agar Scientific \\
\hline Formvar-coated grids & Agar Scientific \\
\hline (Centrifuge) $5415 \mathrm{R}$ & Eppendorf \\
\hline (Centrifuge) 5424 & Eppendorf \\
\hline (Centrifuge) $5810 \mathrm{R}$ & Eppendorf \\
\hline (Centrifuge) F45-24-11 & Eppendorf \\
\hline (Centrifuge) Optima MAX-XP & Beckman Coulter \\
\hline (Centrifuge) Sorvall RC 6 Plus & Thermo Scientific \\
\hline (Centrifuge) Sorvall RC 12BP & Thermo Scientific \\
\hline (Centrifuge) TL-100 & Beckman Coulter \\
\hline Confocal microscope SP8 & Leica Microsystems \\
\hline Cryo immuno diamond knife & DiATOME \\
\hline Cryo-ultramicrotome UC6 & Leica Microsystems \\
\hline Desiccator & Vacuubrand \\
\hline EmulsiFlex C5 homogeniser & Avestin \\
\hline Hamilton syringe & Avanti polar lipids, Inc \\
\hline iMark Microplate Absorbance reader & Bio-Rad \\
\hline (Osmometer) Osmomat 3000 & Gonotech \\
\hline (Dounce homogenizer) Potter S & Sartorius \\
\hline (Rotor) JA-10 & Beckman Coulter \\
\hline (Rotor) JA-20 & Beckman Coulter \\
\hline (Rotor) Sorvall F10S-6x500Y & Thermo Scientific \\
\hline (Rotor) Sorvall F10S-6x250Y & Thermo Scientific \\
\hline (Rotor) Sorvall H-1200 & Thermo Scientific \\
\hline (Rotor) Sorvall SS-34 & Thermo Scientific \\
\hline (Rotor) Sorvall F10S-6x250Y & Thermo Scientific \\
\hline Cell disruptor sonicator W-220F & Heatsystems Ultrasonics Inc \\
\hline SpeedVac concentrator & Savant \\
\hline Superdex 75 16/600 gel-filtration column & GE Healthcare \\
\hline $\begin{array}{l}\text { Superdex } 200 \text { 16/600 gel-filtration } \\
\text { column }\end{array}$ & GE Healthcare \\
\hline Thermomixer comfort & Eppendorf \\
\hline TPersonal 48 thermocycler & Biometra \\
\hline TEM JEOL JEM -1011 & JEOL, Ltd \\
\hline TEM Philips CM 120 & FEl Europe \\
\hline
\end{tabular}


TEM EM900

Biometra Geldokumentation UV Solo

Vesicle Prep Pro

Zetasizer Nano

Chirascan Circular Dichroism

Spectrometer
ZEISS

Biometra

Nanion Technologies

Malvern Panalytical

Applied Photophysics

Table 3. 11: List of software used in this study

\begin{tabular}{ll}
\hline Software & Provider \\
\hline Adobe Illustrator CS5.1 & Adobe Systems \\
Adobe Photoshop CS5.1 & Adobe Systems \\
ImageJ & Wayne Rasband \\
Microsoft Office 2010 & Microsoft \\
OriginPro 8.5G & OriginLab Corporation \\
Serial cloner & SerialBasics \\
UNICORN & GE Healthcare \\
Gatan Microscopy Suite Software & Gatan, Inc. \\
Image Studio Software & LI-COR Biosciences \\
Volocity 6.3 & Perkin Elmer \\
\hline
\end{tabular}

\subsection{METHODS}

\subsubsection{Microbial culture and sample preparation}

\subsubsection{Cultivation of E.coli}

Broth cultures of XL1-blue and BL21DE3 strains of E.coli cells were propagated in LB lysogeny broth - $(1 \% \mathrm{NaCl}, 1 \%$ tryptone, $0.5 \%$ yeast extract $)$ or TB - terrific broth (1.2\% tryptone, $2.4 \%$ yeast extract, $0.5 \%$ glycerol, $89 \mathrm{mM}$ phosphate buffer) supplemented with $100 \mathrm{mg} / \mathrm{L}$ of ampicillin. Growing cultures were contained in upright glass flasks and incubated in an orbital shaker-incubator at $37^{\circ} \mathrm{C}, 220 \mathrm{rpm}$.

For propagation of bacterial cultures in a Petri dishes, liquid media was supplemented with $15 \mathrm{~g} / \mathrm{L}$ of agar-agar. 


\subsubsection{Transformation of chemically competent E.coli cells}

Chemically competent XL1-blue and BL21DE3 strains of E.coli were handled on ice. For single transformation $50 \mu \mathrm{L}$ of cell suspension and up to $100 \mathrm{ng}$ of purified plasmid DNA were used. Bacterial cell suspension and plasmid DNA were gently mixed, incubated on ice for 10 minutes and consequently subjected to a heat-shock for $45 \mathrm{sec}$ at $42^{\circ} \mathrm{C}$. Following the heat-shock, bacterial suspension was first placed on ice for 2 min and then incubated for $1 \mathrm{~h}$ in $250 \mu \mathrm{L}$ of LB media at $37^{\circ} \mathrm{C}, 220 \mathrm{rpm}$. Obtained recovered bacterial culture was seeded onto ampicillin-supplemented LB Petri dish and incubated at $37^{\circ} \mathrm{C}$ overnight.

\subsubsection{Preparation of E.coli total cell lysate}

For preparation of the cell lysate suitable to use for SDS-PAGE, broth culture was harvested for $2 \mathrm{~min}$ at $2300 \times \mathrm{g}, 4^{\circ} \mathrm{C}$. Resulting bacterial pellet was washed in cold $50 \mathrm{mM}$ Tris, $100 \mathrm{mM} \mathrm{NaCl}$ buffer, $\mathrm{pH} 8$ and resuspended in the same buffer supplemented with $1 \mathrm{mM}$ PMSF. The obtained cell suspension was subjected to sonication for $30 \mathrm{sec}$ to disrupt bacterial cells. Sonicated bacterial lysate was ultimately mixed with sample loading buffer.

\subsubsection{Fractionation of E.coli cells}

Protein-expressing cultures of E.coli were harvested for $20 \mathrm{~min}$ at $6000 \times \mathrm{g}, 4^{\circ} \mathrm{C}$. Obtained pellets were washed in $0.7 \mathrm{M}$ Sucrose, $20 \mathrm{mM}$ HEPES, $150 \mathrm{mM} \mathrm{NaCl}, 10 \mathrm{mM}$ EDTA, pH 7.4 and resuspended again in $0.7 \mathrm{M}$ Sucrose, $20 \mathrm{mM}$ HEPES, $150 \mathrm{mM} \mathrm{NaCl}, 5$ $\mathrm{mM} \mathrm{MgSO}_{4}, \mathrm{pH} 7.4$ supplemented with $1 \mathrm{mg} / \mathrm{ml}$ DNase I, $1 \mathrm{mg} / \mathrm{ml}$ lysozyme and EDTAfree protease inhibitors cocktail. The suspension was gently agitated at room temperature for $30 \mathrm{~min}$. After the incubation, four volumes of distilled water was added to the agitating suspension to form spheroplasts. Obtained spheroplasts were pelleted by centrifugation for $45 \mathrm{~min}$ at $20,000 \times \mathrm{g}, 4^{\circ} \mathrm{C}$. The supernatant contained the periplasmic fraction of E.coli cells, and the pellet contained membranes cytoplasmic cylinders. The pellet was further resuspended in $50 \mathrm{mM}$ HEPES, $200 \mathrm{mM} \mathrm{NaCl}, 5 \mathrm{mM}$ EDTA, 0.5 mM DTT, pH 7.4 supplemented with EDTA-free protease inhibitors cocktail and subjected to high-pressure lysis by EmulsiFlex C5 tissue homogeniser. Large cellular debris was spun down by centrifugation for $15 \mathrm{~min}$ at $3,000 \mathrm{rpm}, 4^{\circ} \mathrm{C}$. The supernatant 
was used for crude membrane fraction isolation by ultracentrifugation for $3 \mathrm{~h}$ at 53,000 rpm, $4^{\circ} \mathrm{C}$ (Type $70 \mathrm{Ti}$ rotor, Beckman Coulter). The resulting supernatant contained the cytosolic fraction of E.coli, and the pellet contained crude membranes. The membranous pellet was washed in the same buffer and carefully resuspended in 20 mM HEPES, $150 \mathrm{mM} \mathrm{NaCl}, 5 \mathrm{mM}$ EDTA, $0.5 \mathrm{mM}$ DTT, pH 7.4 and homogenised using tissue homogeniser (Schuett Homgenplus). Homogenised membranes sample was supplemented with $1 \% \mathrm{DDM}$ and centrifuged for $30 \mathrm{~min}$ at $150,000 \times \mathrm{g}, 4^{\circ} \mathrm{C}$. The supernatant contained enriched bacterial cytoplasmic membrane protein fraction.

\subsubsection{Cultivation of $S$. cerevisiae}

Liquid yeast cultures were propagated in selective media $(0.67 \%$ yeast nitrogen base without amino acids, $0.07 \%$ His dropout complete supplement mixture lacking histidine and $2 \%$ Glucose or $3 \%$ Glycerol, $\mathrm{pH} 5.0$ ) at $30^{\circ} \mathrm{C}, 220 \mathrm{rpm}$ using upright glass flasks and an orbital shaker-incubator.

Solid media for propagation of yeast cultures in Petri dishes was prepared by supplementing liquid media with $2.5 \%$ of agar-agar. For the growth test, serial dilutions of the liquid yeast cultures were spotted onto selective glycerol dishes and incubated at $18^{\circ} \mathrm{C}$ for several days until the growth is observed.

\subsubsection{Transformation of $S$. cerevisiae cells}

S. cerevisiae competent cells were prepared according to the previously published protocol $^{96}$. Briefly, $50 \mathrm{~mL}$ of $2 \times$ YPAD liquid media (1\% yeast extract, $2 \%$ tryptone, $10 \%$ adenine hemisulfate, $2 \%$ glucose) were inoculated with a single colony of $S$. cerevisiae and grown at $30^{\circ} \mathrm{C}$ in an up-right flasks in an orbital shaker-incubator at $120 \mathrm{rpm}$ until $\mathrm{OD}_{600}$ reached $1.5-2$. After the cells reached required optical density, they were collected by centrifugation for $5 \mathrm{~min}$ at $5000 \times \mathrm{g}, 4^{\circ} \mathrm{C}$. The cellular pellet was washed in $10 \mathrm{~mL}$ of cold, sterile distilled water. The washed pellet was subsequently resuspended in $10 \mathrm{~mL}$ of cold Lithium acetate buffer (5mM Tris, $0.1 \mathrm{M} \mathrm{C}_{2} \mathrm{H}_{3} \mathrm{LiO}_{2}, 0.1 \mathrm{mM}$ EDTA, pH 8) and incubated at $4^{\circ} \mathrm{C}$ for $30 \mathrm{~min}$ under gentle agitation. After the incubation, yeast cells were collected by centrifugation at $5,000 \times \mathrm{g}, 4^{\circ} \mathrm{C}$ and again resuspended in $500 \mu \mathrm{L}$ of the same buffer. 
For single transformation $100 \mu \mathrm{L}$ of competent cells, $500 \mathrm{ng}$ of plasmid DNA and $100 \mu \mathrm{g}$ of denatured herring sperm DNA were used. Plasmid and herring sperm DNA were gently mixed with competent yeast cells and were further incubated for $30 \mathrm{~min}$ at $30^{\circ} \mathrm{C}$ under gentle agitation. After $30 \mathrm{~min}, 600 \mu \mathrm{L}$ of $40 \%$ PEG 4000 in Lithium acetate buffer were added to the transformation mixture and were further incubated for $1 \mathrm{~h}$ in a thermomixer at $30^{\circ} \mathrm{C}$ and $1,000 \mathrm{rpm}$. Afterwards, $68 \mu \mathrm{L}$ of DMSO were added to the transformation and mixed until homogeneous. The cells were subjected to a heat-shock at $42^{\circ} \mathrm{C}$ for $15 \mathrm{~min}$ and collected by centrifugation for $1 \mathrm{~min}$ at $400 \times \mathrm{g}$. The cellular pellet was resuspended in $200 \mu \mathrm{L}$ of sterile distilled water and seeded onto selective Petri dishes and incubated at $30^{\circ} \mathrm{C}$ for two days.

\subsubsection{Preparation of $S$. cerevisiae total cell extract}

S. cerevisiae total cell extracts were prepared following the previously published protocol ${ }^{97}$. According to this protocol, cellular material of actively growing liquid yeast culture corresponding to $\mathrm{OD}_{600}$ of 3 was collected by centrifugation at $20,000 \times \mathrm{g}$ for 1 min and resuspended in $1 \mathrm{~mL}$ of sterile distilled water. Then, $148 \mu \mathrm{L}$ of $2 \mathrm{M} \mathrm{NaOH}$ and $12 \mu \mathrm{L}$ of $\beta$-mercaptoethanol were added, and cell suspension was further incubated for on ice for up to $30 \mathrm{~min}$. After the incubation, TCA was added to the mixture to the final concentration of $15 \%$, and the mixture was further incubated for 10 more min. The mixture was spun down for 2 min at maximal speed in the table-top centrifuge. The pellet was resuspended in the SDS-PAGE sample loading buffer. The $\mathrm{pH}$ value of the sample was adjusted with $1 \mathrm{M}$ Tris ( $\mathrm{pH} 11.5)$ when necessary.

\subsubsection{Isolation of crude mitochondria from S. cerevisiae}

Crude mitochondria from S. cerevisiae cells were isolated following the previously published protocol ${ }^{98}$. For this purpose, yeast cells were seeded onto selective galactose Petri dishes and incubated for 2 days at $30^{\circ} \mathrm{C}$. Afterwards, liquid selective galactose media was inoculated with a single colony and incubated at $30^{\circ} \mathrm{C}, 220 \mathrm{rpm}$ until $\mathrm{OD}_{600}$ reached 1.5 - 2. Then, growing yeast cultures were harvested by centrifugation for 10 $\min$ at $2,700 \times \mathrm{g}, 18^{\circ} \mathrm{C}$. The obtained cellular pellet was washed in sterile distilled water and resuspended in $2 \mathrm{~mL}$ of DTT buffer (100 mM Tris, $10 \mathrm{mM} \mathrm{DTT,} \mathrm{pH} \mathrm{9.4)} \mathrm{per} 1 \mathrm{~g}$ of the cellular pellet. When resuspended, the pellet was incubated in an orbital shaker- 
incubator for $30 \mathrm{~min}$ at $220 \mathrm{rpm}, 30^{\circ} \mathrm{C}$. After the incubation, yeast cells were spun down for $8 \mathrm{~min}$ at $2,700 \times \mathrm{g}, 18^{\circ} \mathrm{C}$ and washed in $200 \mathrm{~mL}$ of $1.2 \mathrm{M}$ Sorbitol. The washed pellet was resuspended in $100 \mathrm{~mL}$ of Zymolyase buffer (20 mM KPi, 1.2 M Sorbitol, pH 7.4 supplemented with $4 \mathrm{mg}$ of zymolyase per $1 \mathrm{~g}$ of cellular pellet) and was incubated in an orbital shaker-incubator at $220 \mathrm{rpm}, 30{ }^{\circ} \mathrm{C}$ for $1 \mathrm{~h}$. Following the incubation, zymolyase-treated cells were collected by centrifugation for $10 \mathrm{~min}$ at $1,500 \times \mathrm{g}, 18^{\circ} \mathrm{C}$, washed with $20 \mathrm{mM} \mathrm{KPi}, 1.2 \mathrm{M}$ Sorbitol, pH 7.4 and recollected by centrifugation for 10 min at $1,500 \times \mathrm{g}, 18^{\circ} \mathrm{C}$. The final pellet was resuspended in $7 \mathrm{~mL}$ per $1 \mathrm{~g}$ of cells of icecold Homogenization buffer (10 mM Tris, 600 mM sorbitol, 1 mM EDTA, 1 mM PMSF, 2 $\mathrm{g} / \mathrm{L}$ fatty-acids free BSA, $\mathrm{pH} 7.4$ ) and subjected to 20 homogenization cycles at $750 \mathrm{rpm}$ using Dounce homogeniser. The obtained homogenate was centrifuged for $5 \mathrm{~min}$ at $1,500 \times \mathrm{g}, 4^{\circ} \mathrm{C}$. The supernatant was separated from the pellet, centrifuged for $10 \mathrm{~min}$ at $2,700 \times$ g. Mitochondria were collected by additional round of centrifugation for 15 min at $17,000 \times \mathrm{g} 4^{\circ} \mathrm{C}$, washed in $10 \mathrm{~mL}$ of SEM buffer (10mM MOPS, $250 \mathrm{mM}$ sucrose, 1 mM EDTA, 1 mM PMSF, pH 7.2) and resuspended in $600 \mu \mathrm{L}$ of SEM buffer.

Total mitochondrial protein concentration was estimated by Bradford assay and subsequently brought to a final concentration of $10 \mathrm{mg} / \mathrm{mL}$ by dilution in SEM buffer. The adjusted mitochondrial suspension was aliquoted, snap-frozen in liquid nitrogen and stored at $-80^{\circ} \mathrm{C}$ until further use.

\subsubsection{Molecular cloning}

\subsubsection{Plasmid DNA isolation}

Plasmid DNA isolation from E.coli cells was performed using "Wizzard Plus SV Mini-prep DNA Purification System" (Promega), according to the manufacturer's instructions.

\subsubsection{Yeast genomic DNA isolation}

For the yeast genomic DNA isolation log-phase, S. cerevisiae liquid culture was used. Cell material from $1 \mathrm{~mL}$ of the culture was collected by centrifugation for $2 \mathrm{~min}$ at the maximum speed of the table-top centrifuge and resuspended in $1 \mathrm{~mL}$ of $50 \mathrm{mM}$ Tris, 10 $\mathrm{mM}$ EDTA, $0.3 \% \beta$-mercaptoethanol, $0.5 \mathrm{mg} / \mathrm{mL}$ zymolyase, $\mathrm{pH}$ 7.4. The resuspended 
pellet was incubated for $1 \mathrm{~h}$ at $30^{\circ} \mathrm{C}$. Further steps of genomic DNA isolation were performed using "High Pure PCR Template Preparation Kit" (Roche).

\subsubsection{Obtaining of alphaproteobacterial Mic60 coding sequences}

Coding DNA sequences of Mic60 homologues from $R$. sphaeroides and $P$. denitrificans were derived from their putative protein sequences. The protein sequences of both homologues were retrieved from NCBI GenBank ( $R$. sphaeroides: KD131, WP_015921743.1; P. denitrificans: PD1222, WP_041529918.1), and actual DNA sequences were synthesised from PCR fragments (GeneArt).

\subsubsection{PCR}

The required DNA fragments were amplified by polymerase chain reaction (PCR) ${ }^{99}$ from a plasmid DNA or S. cerevisiae genomic DNA used as the templates. Each reaction mixture of $50 \mu \mathrm{L}$ was performed in $1 \times$ Phusion HF buffer and contained $100 \mathrm{ng}$ of a DNA template, $0.3 \mu \mathrm{M}$ of each, forward and reverse, primer, $1 \mathrm{U}$ of Phusion DNA Polymerase (Thermofisher), $0.2 \mu \mathrm{M}$ dNTPs mix and 3\% DMSO. The PCR cycle steps' temperature and length were set according to the recommendations of the Phusion DNA Polymerase manufacturer (Thermofisher) based on the primers' and templates' properties.

\subsubsection{Agarose gel electrophoresis}

The success of PCR amplification was monitored by agarose gel electrophoresis ${ }^{100}$. The agarose gels were prepared by dissolving of $1 \%$ Agarose (Roth) in $1 \times$ TAE buffer (40 $\mathrm{mM}$ Tris, $20 \mathrm{mM}$ acetic acid, $1 \mathrm{mM}$ EDTA), and electrophoresis was conducted at $120 \mathrm{~V}$ for 30 min. Separated DNA fragments were visualised under UV light.

\subsubsection{Purification of PCR fragments}

Amplified PCR fragments were excised from the agarose gel and further cleaned-up using "Wizzard SV Gel and PCR CleanUP System" (Promega) following the manufacturers' instructions.

\subsubsection{Restriction}

PCR-amplified protein-coding DNA inserts, as well as vector DNA, were digested using restriction endonucleases (Thermo Scientific). Single digestion reaction of $20 \mu \mathrm{L}$ was 
carried out in appropriate restriction buffer and contained $1 \mu \mathrm{g}$ of DNA substrate as well as 2-4 $U$ of each endonuclease. The choice of restriction buffer, as well as the choice of the restriction enzymes, was made based on the availability of restriction sites within the vector and protein-coding inserts according to the manufacturer's Doubledigest guide. After digestion, the DNA products were subjected to agaroseelectrophoresis, excised from the gel and purified using "Wizzard SV Gel and PCR CleanUP System" (Promega) following the manufacturers' instructions.

\subsubsection{Ligation}

Protein-coding DNA inserts were ligated into appropriate vectors using T4 DNA Ligase (Thermo Scientific). Each ligation reaction $(20 \mu \mathrm{L})$ was performed in $1 \times$ T4 DNA Ligase buffer and contained $1.5 \mathrm{U}$ of T4 DNA Ligase, $50 \mathrm{ng}$ of linear vector, linear insert in different molar ratios $(1: 1,1: 3$ and $1: 5)$. Ligation reaction was carried out at $16^{\circ} \mathrm{C}$ for $18 \mathrm{~h}$.

\subsubsection{DNA sequencing}

All generated plasmids were sequenced at the GATC Biotech facilities (Constance, Germany).

\subsubsection{Protein biochemistry methods}

\subsubsection{SDS-PAGE}

Protein samples were separated by sodium dodecyl sulphate polyacrylamide gel electrophoresis (SDS-PAGE) ${ }^{101}$ using Mini PROTEAN Tetra cell (BioRad). Resolving gel consisted of $12.5 \%$ acrylamide/bisacrylamide, $386 \mathrm{mM}$ Tris/ $\mathrm{HCl}, 0.1 \%$ SDS, $0.1 \%$ APS, $0.08 \%$ TEMED, $\mathrm{pH}$ 8.8. Stacking gel consisted of $5 \%$ acrylamide/bisacrylamide, $126 \mathrm{mM}$ Tris/ $\mathrm{HCl}, 0.1 \%$ SDS, $0.1 \%$ APS, $0.2 \%$ TEMED, $\mathrm{pH}$ 6.8. SDS-PAGE was conducted in Laemmli running buffer (25 mM Tris, $191 \mathrm{mM}$ Glycine, 0.1\% SDS) and at constant 180 V. SDS-PAGE using precast NuPAGE gradient gels was conducted using Novex Mini cell (Invitrogen). Electrophoresis was conducted in MES buffer according to the manufacturer's instructions. For SDS-PAGE protein samples were prepared in sample loading buffer (2\% SDS, 10\% Glycerol, 60 mM Tris-HCl, 1\% $\beta$-mercaptoethanol, 0.01\% 
brompheol blue, $\mathrm{pH}$ 6.8). As a protein molecular weight standard PageRuler prestained protein marker (Thermo Scientific) was used.

\subsubsection{Coomassie brilliant blue staining}

Proteins separated on SDS-PAGE gels were visualised using Coomassie brilliant blue staining. For that, gels were incubated for several hours in staining solution $(25 \%$ ethanol, $10 \%$ acetic acid and $0.1 \%$ Coomassie brilliant blue R 250 ). The background stain was removed by incubation in destaining solution ( $25 \%$ ethanol, $10 \%$ acetic acid).

\subsubsection{Western blot and immunodetection}

Western blot analysis ${ }^{102}$ was performed using semi-dry transfer cell (PeqLab). After SDS-PAGE gels were equilibrated in western blot transfer buffer (20 mM Tris, 150 mM Glycine, $0.02 \%$ SDS, $20 \%$ methanol) and assembled into transfer sandwich (2 layers of soaked in transfer buffer blotting paper, pre-activated in methanol PVDF membrane on the bottom and two additional layers of soaked blotting paper on the top). The transfer was conducted for $1 \mathrm{~h}$ at $13 \mathrm{~V}, 125 \mathrm{~mA}$.

PVDF membrane with transferred proteins was blocked in 5\% skimmed milk powder in TBS-T buffer for $1 \mathrm{~h}$. After the blocking step, membrane was washed 3 times in fresh TBS-T buffer for $10 \mathrm{~min}$ and subsequently incubated in primary antibody for $1 \mathrm{~h}$. Following the primary antibody stain, membrane was washed 3 times in fresh TBS-T buffer for $10 \mathrm{~min}$ and transferred into appropriate secondary antibody diluted in 5\% skimmed milk powder dissolved in TBS-T buffer for $1 \mathrm{~h}$, washed 3 times for $10 \mathrm{~min}$, and subsequently developed using ECL (Thermo Scientific). Luminescence signal was captured by exposing to the x-ray films. Films were developed using CAWOMAT developing machine.

\subsubsection{Recombinant protein expression and purification}

\subsection{Protein targeting to the cytoplasmic membrane of E.coli}

Protein targeting into bacterial cytoplasmic membrane was performed according to previously published protocol with a slight modifications ${ }^{103}$. Mic60, Mic60 ${ }^{\mathrm{MMS}}$, and all control proteins (Tim50, Tim23 and Tom20) were expressed as periplasm-targeted MBP fusions in $\mathrm{BL21}(\mathrm{DE} 3)$ E. coli cells. Bacteria were grown in $\mathrm{TB}$ media at $37^{\circ} \mathrm{C}$ in an orbital 
shaker-incubator to $\mathrm{OD}_{600} 0.6-0.7$, and protein expression was induced with $0.5 \mathrm{mM}$ IPTG. The expression cultures were transferred to $18^{\circ} \mathrm{C}$ and were further grown for 18 h. Cells were harvested by centrifugation at $6,000 \times \mathrm{g}$ for $20 \mathrm{~min}$.

\subsection{Isolation of inclusion bodies}

Inclusion bodies were isolated following previously published protocol ${ }^{104}$. Expression E.coli cultures were harvested by centrifugation for $20 \mathrm{~min}$ at $7,000 \times \mathrm{g}, 4^{\circ} \mathrm{C}$. The cellular pellet was washed in ice-cold Wash buffer $(50 \mathrm{mM}$ Tris, $100 \mathrm{mM} \mathrm{NaCl}, \mathrm{pH}$ 8), resuspended in ice-cold Lysis buffer (50 mM Tris, $100 \mathrm{mM} \mathrm{NaCl}, 1 \mathrm{mM}$ PMSF, $0.1 \mathrm{mg} / \mathrm{mL}$ lysozyme, $10 \mu \mathrm{g} / \mathrm{mL}$ DNase I, $\mathrm{pH}$ 8) and subjected to 5 consecutive lysis cycles using high-pressure homogenizer EmulsiFlex-C5 (Avestin). Obtained cell lysate was supplemented with $4 \mathrm{mg}$ per $1 \mathrm{~g}$ of cellular pellet of deoxycholic acid and incubated at room temperature for 30 min while stirring. After incubation, the lysate was spun down for $1 \mathrm{~h}$ at $4,200 \times \mathrm{g}, 4^{\circ}$. The supernatant was discarded and the inclusion bodies containing pellet was resuspended in Triton X-100 buffer $(50 \mathrm{mM}$ Tris, $100 \mathrm{mM} \mathrm{NaCl}$, 2\% Triton X-100, $1 \mathrm{mM}$ EDTA, $10 \mathrm{mM} \mathrm{DTT}, \mathrm{pH}$ 8), incubated for $30 \mathrm{~min}$ at $4^{\circ} \mathrm{C}$ while stirring and spun down for $30 \mathrm{~min}$ at $4,200 \times \mathrm{g}, 4^{\circ} \mathrm{C}$. The supernatant was discarded, the pellet was thoroughly resuspended in TEN buffer $(50 \mathrm{mM}$ Tris, $100 \mathrm{mM} \mathrm{NaCl}, 1 \mathrm{mM}$ EDTA, $10 \mathrm{mM} \mathrm{DTT}, \mathrm{pH} 8$ ), incubated for $30 \mathrm{~min}$ at $4^{\circ} \mathrm{C}$ while stirring and spun down again for $30 \mathrm{~min}$ at $4,200 \times \mathrm{g}, 4^{\circ} \mathrm{C}$. The final pellet was resuspended in Wash buffer, centrifuged for $30 \mathrm{~min}$ at $4,200 \times \mathrm{g}, 4^{\circ} \mathrm{C}$. The supernatant was discarded and the pellet contained purified inclusion bodies.

\subsection{Affinity His-tag chromatography}

The inclusion bodies were resuspended in Buffer A $(10 \mathrm{mM}$ Tris, $150 \mathrm{mM} \mathrm{NaCl}, 8 \mathrm{M}$ Urea, $40 \mathrm{mM}$ Imidazole, $2 \mathrm{mM}$ DTT, $\mathrm{pH} 8$ ) and further incubated at room temperature for $1 \mathrm{~h}$ stirring. When completely dissolved, the inclusion bodies were spun down for 20 min at $17,400 \times g$ and the supernatant was subsequently filtered using PVDF filter of the pore size $0.45 \mu \mathrm{m}$ (Roth). Such pre-cleared, solubilized inclusion bodies were applied onto pre-equilibrated with Buffer A pre-packed HisTrap column (GE Healthcare) using ÄKTA Prime plus (GE Healthcare). The column was subsequently washed with 10 
column volumes of Buffer $A$, and the protein was eluted with 3 column volumes of Buffer B (10 mM Tris, 150 mM NaCl, 8 M Urea, 500 mM Imidazole, 2 mM DTT, pH 8).

\subsection{Affinity GST-tag chromatography}

Soluble ENTH domain protein used in this study was expressed as GST-fusions in BL21DE3 E.coli strain. The expression culture was harvested by centrifugation for 20 min at $7000 \times \mathrm{g}, 4^{\circ} \mathrm{C}$. The cellular pellet was washed in cold Lysis buffer (50 mM HEPES, $150 \mathrm{mM} \mathrm{NaCl}, 1 \mathrm{mM}$ PMSF, 2mM EDTA, pH 7,4) and subjected to 5 consecutive lysis cycles using high-pressure homogenizer EmulsiFlex-C5 (Avestin). The total E.coli lysate was pre-cleared of large cellular debris and not soluble particles by centrifugation for 1 h at $200,000 \times g, 4^{\circ} \mathrm{C}$. The supernatant was additionally filtered using PVDF filter of the pore size $0.45 \mu \mathrm{m}$ (Roth). The supernatant was applied onto pre-equilibrated with Lysis buffer GSTrap pre-packed column (GE Healthcare) using ÄKTA Prime plus (GE Healthcare). After this, the column was washed with 10 column volumes of Lysis buffer, and bound protein was eluted with 3 column volumes of Elution buffer (50 mM HEPES, $150 \mathrm{mM} \mathrm{NaCl}, 10 \mathrm{mM} \mathrm{L-glutathione} \mathrm{reduced).} \mathrm{The} \mathrm{GST} \mathrm{affinity} \mathrm{tag} \mathrm{fused} \mathrm{to} \mathrm{the}$ expressed protein was enzymatically removed using PreScission protease. Free GST as well as PreScission protease were separated from the protein by additional round of affinity GST-tag chromatography, when the flow-through of the loading step contained protein of interest.

\subsubsection{Size-exclusion chromatography}

The proteins from 3.2.3.4.2 Affinity His-tag chromatography" and 3.2.3.4.3 Affinity GSTtag chromatography" were further purified using size-exclusion chromatography methods. The gel-filtration columns were pre-equilibrated with appropriate Running buffer using ÄKTA Prime plus (GE Healthcare). Protein samples, prior lading were spun down for $10 \mathrm{~min}$ at the maximal speed of a table-top centrifuge, $4^{\circ} \mathrm{C}$, and maximum 5 $\mathrm{mL}$ were loaded on the chromatography column.

\subsubsection{Protein refolding}

Urea-solubilised proteins were refolded using several different detergents. The denatured protein solution was transferred to the dialysis tubing membrane of $3.5 \mathrm{kDa}$ size cut off (Spectrum Laboratories, Inc.) and dialysed against Refolding buffer ( $20 \mathrm{mM}$ 
HEPES, $150 \mathrm{mM} \mathrm{NaCl}$, pH7.4) supplemented with detergent in the concentration of $4 \times$ $\mathrm{CMC}$ for $2 \mathrm{~h}$ at room temperature. For the detergents, which form micelles bigger than the membrane cut off, an equal concentration of the detergent was added directly into the membrane tubing. Afterwards, the dialysis tubing was transferred to the fresh portion of detergent-supplemented Refolding buffer and further dialysed at $4^{\circ} \mathrm{C}$ overnight. The next day, the refolded protein solution was transferred into ultracentrifuge tubes and spun down for $30 \mathrm{~min}$ at $125,000 \times \mathrm{g}, 4^{\circ} \mathrm{C}$. The supernatant contained soluble, properly refolded protein fraction while the pellet contained aggregated non-refolded protein fraction. The supernatant was transferred to a fresh tube, and the pellet was resuspended in an equal to the initial volume of $1 \times$ SDS-PAGE sample loading buffer. Equal volumes of supernatant and pellet were loaded onto an SDS-PAGE to estimate the refolding efficiency.

\subsubsection{Protein labelling}

Mic60 fluorescent labelling with Alexa Fluor 488 used for the GUVs experiments was performed using Alexa Fluor 488 Protein labelling kit (Invitrogen) in accordance with the manufacturer's guidelines. Labelled protein fraction was separated from the dye excess by size-exclusion chromatography using a G-25 gravity column (GE Healthcare).

\subsubsection{TCA precipitation}

TCA protein precipitation was performed by addition of ice-cold trichloracetic acid (TCA) to the protein sample so that final concentration was $10 \%$. The samples were mixed and left incubating on ice for at least $30 \mathrm{~min}$. Afterwards, the precipitated samples were spun down in the table-top centrifuge at maximal speed for $30 \mathrm{~min}$. The pellet was washed with ice-cold acetone and subsequently dried in SpeedVac concentrator. The dry pellet was resuspended in a suitable volume of $1 \times$ Sample loading dye for SDS-PAGE.

\subsubsection{CD measurements}

Spectra were obtained with Chirascan Circular Dichroism Spectrometer (Applied Photophysics) by measuring the denatured and DDM-refolded Mic60 protein at concentration of $0.4 \mathrm{mg} / \mathrm{mL}$ in $8 \mathrm{M}$ Urea, $300 \mathrm{mM} \mathrm{NaF}, 30 \mathrm{mM} \mathrm{NaH}_{2} \mathrm{PO}_{4}, 0.1 \% \mathrm{DDM}$, pH 7.4 and 300 mM NaF, $30 \mathrm{mM} \mathrm{NaH}_{2} \mathrm{PO}_{4}, 0.1 \%$ DDM, pH 7.4 buffer respectively. 


\subsubsection{Lipid membranes}

\subsubsection{Preparation of liposomes}

Lyophilised powders of I- $\alpha$-Phosphatidylcholine (PC), I- $\alpha$-Phosphatidylethanolamine (PE), I- $\alpha$-Phosphatidylinositol (PI), I- $\alpha$-Phosphatidylserine (PS), cardiolipin (CL) and 1,2dioleoyl-s-glycero-3-phosphoethanolamine (DOPE) were purchased from Avanti Polar Lipids, Inc. Lipid mixtures composed of $20 \%$ DOPE/80\% PC, $20 \%$ DOPE/65\% PC/15\% CL, $60 \% \mathrm{PC} / 20 \% \mathrm{PE} / 15 \% \mathrm{PI} / 5 \% \mathrm{PS}$ and $45 \% \mathrm{PC} / 20 \% \mathrm{PE} / 15 \% \mathrm{PI} / 5 \% \mathrm{PS} / 15 \% \mathrm{CL}$ were dried under constant nitrogen gas flow until thin lipid films were formed and further incubated in a desiccator for $3 \mathrm{~h}$. Dry lipid films were re-hydrated in Refolding buffer (20mM HEPES, $150 \mathrm{mM} \mathrm{NaCl}, \mathrm{pH}$ 7.4). LUVs were formed by performing repeating freeze-thaw cycles and subsequent extrusion through polycarbonate filter with pores' diameter of $100 \mathrm{~nm}$ (Whatman).

\subsubsection{Detergent-mediated incorporation}

Proteoliposomes were prepared following detergent-mediated incorporation protocol. Refolded protein was added to pre-solubilized in 0.1\% DDM LUVs and incubated for 1 $\mathrm{h}$ at room temperature while gently agitating. Protein was incorporated into lipid bilayer by DDM depletion. DDM was depleted using detergent-adsorbing Bio-Beads SM-2 (Bio-Rad Laboratories) following manufacturer's guidelines.

\subsubsection{DLS}

Size distribution of various liposomal populations was analysed on Zetasizer Nano S system (Malvern Instruments). Single measurements consisted of 20 repetitions over 10 min time span. The error was calculated as the standard error of averaged values from at least three independent measurements.

\subsubsection{Flotation assay}

Flotation assay was performed in non-ionic Histodenz density gradient. LUV sample was placed at the bottom of the ultracentrifugation tubes, and the non-continuous Histodenz gradient was built up from high density towards low (40\%/20\%/10\%/5\%/2\%). The gradient was subjected to ultracentrifugation for $1 \mathrm{~h}$ at $150,000 \times \mathrm{g}, 4^{\circ} \mathrm{C}$. Afterwards, the gradient was dissected into fractions. Each fraction 
was TCA-precipitated and further analysed by SDS-PAGE and Coomassie brilliant blue staining.

\subsubsection{Sodium carbonate extraction}

LUVs-containing bands from the interfaces of the Histodenz gradient centrifugation were collected and incubated with cold $20 \mathrm{mM} \mathrm{Na}_{2} \mathrm{CO}_{3}$ for $30 \mathrm{~min}$ on ice. After the incubation, sodium carbonate-treated samples were subjected to ultracentrifugation for $30 \mathrm{~min}$ at $150,000 \times \mathrm{g}, 4^{\circ} \mathrm{C}$. The supernatant was further TCA-precipitated. The total fraction of pellets and TCA-precipitated supernatants were analysed by SDS-PAGE and Coomassie brilliant blue staining.

\subsubsection{Preparation of GUVs}

GUVs were produced following the electroformation protocol ${ }^{105}$. Proteoliposomes were collected by ultracentrifugation for $30 \mathrm{~min}$ at 150,000 $\times \mathrm{g}$ and resuspended in 10 mM HEPES, $5 \mathrm{mM} \mathrm{NaCl} \mathrm{pH} 7.4$ buffer to final lipid concentration $0.5 \mathrm{mg} / \mathrm{mL}$. Small droplets of resuspended proteoliposomes were spotted onto indium tin oxide (ITO)coated glass slides. The proteoliposomes were further incubated for $2 \mathrm{~h}$ in a desiccator under the saturated vapour pressure of $\mathrm{KCl}$ solution. Afterwards, the GUV-generation chamber was assembled by mounting of thin rubber spacer between two ITO-coated slides containing proteoliposomes films overlaid with $300 \mathrm{mM}$ glucose solution. Pulse generator was connected to the glass slides and an alternating current electric field created was applied across the chamber for $3 \mathrm{~h}$ and incremented gradually from $20 \mathrm{mV}$ to $1.1 \mathrm{~V}$ at $12 \mathrm{~Hz}$. Afterwards the alternating current frequency was lowered to $4 \mathrm{~Hz}$ at $2 \mathrm{~V}$ for $30 \mathrm{~min}$. Lowering of current frequency lead to detachment of the formed GUVs from the surface of glass slides.

\subsubsection{Visualization techniques}

\subsubsection{Electron microscopy of LUVs}

LUV samples were transferred onto carbon-coated grids (Agar Scientific) and negatively stained with 5\% Uranyl Acetate solution. Electron microphotographs were obtained with a transmission electron microscope (JEM 1011, JEOL). Images were captured with 
an Orius SC1000 A charge-coupled device camera using image processing software Gatan.

\subsubsection{Light microscopy of GUVs}

Images of GUVs were obtained with a spinning-disk confocal setup (Ultraview, PerkinElmer) using VOLOcity 6.3 software (PerkinElmer). The setup consisted of an inverted microscope (Ti-E Eclipse, Nikon) with a 14-bit electron-multiplying chargecoupled device camera (C9100, Hamamatsu).

\subsubsection{Electron microscopy for E.coli cells}

E. coli cells expressing MBP-Mic60 fusion protein were collected by centrifugation and fixed with $0.2 \%$ glutaraldehyde for $1 \mathrm{~h}$ on ice. The cells were washed, resuspended in small amount of $10 \%$ molten gelatine, and quickly spun down before solidified. Solid cellular pellet was cut into small blocks and infiltrated with $2.3 \mathrm{M}$ sucrose overnight. Single sucrose-infiltrated blocks were mounted onto aluminium pins and frozen in liquid nitrogen. Ultrathin cryosections were obtained using a cryo-ultramicrotome (UC6, Leica Microsystems) and a cryo immuno diamond knife (DiATOME). For Immunodetection primary anti-Mic60 antibodies produced in rabbit were used. These antibodies were subsequently detected with 1:50 dilution of $10 \mathrm{~nm}$ protein A gold (Cell Microscopy Core, Department of Cell Biology, University Medical Centre Utrecht, Netherlands). The $E$. coli cryosections were investigated using a transmission electron microscope (EM900, ZEISS), and microphotographs were captured with the aid of a wide-angle dual-speed $2 \mathrm{k}$ charge-coupled device camera using ImageSP software. To analyse where the protein of interest (Mic60) is localised, the relative distribution (RD) of the gold particles was evaluated. The RD represents the percentage the total gold particles located to the membrane and the cytosol. For that, gold particles in 27 bacterial cells $(n=27)$ were counted using ImageJ software. The number of specific gold particles was derived by extraction of the number of background labels (gold particles from 27 bacterial cells incubated with protein A gold omitting primary antibody step) from the total number of labels. Standert deviation (SD) was calculated to estimate the dispersion of the immuno labelling results. 


\subsubsection{Electron microscopy for S. cerevisiae cells}

First, S. cerevisiae cells were propagated in liquid selective media $(1.7 \mathrm{~g} / \mathrm{L}$ yeast nitrogen base, $2 \mathrm{~g} / \mathrm{L}$ His dropout mix, $5 \mathrm{~g} / \mathrm{L}$ ammonium sulphate) suplemented with $2 \%$ glucose at $30^{\circ} \mathrm{C}$, and then they were transferred into same selective media containing $3 \%$ glycerol instead of $2 \%$ glucose. The cells were cultured untill they reached the logarithmic growth phase and harvested by centrifugation. The cells were chemically fixed with $2 \%$ glutaraldehyde for $30 \mathrm{~min}$. The cell wall of fixed cells was digested with Zymolyase $(0.1 \mathrm{mg} / \mathrm{ml}$ Zymolyase and $0.5 \% \beta$-mercaptoethanol in $1 \times \mathrm{PBS} / 10 \%$ sorbitol $\mathrm{w} / \mathrm{v}$ ) for $15 \mathrm{~min}$ at room temperature. The cells were additionally fixed with $1 \%$ osmium tetroxide for $30 \mathrm{~min}$ and contrasted with $1 \%$ uranyl acetate for $2 \mathrm{~h}$. The samples were dehydrated by incubation in graded ethanol series and propylene oxide, and subsequently embedded in epoxide resin (Agar 100, Plano). Ultrathin sections were examined using a transmission electron microscope (CM 120, Philips), and microphotographs were captured with a CMOS camera (TemCam F416, TVIPS)

\subsubsection{Light microscopy for S. cerevisiae cells}

S. cerevisiae cells transformed with pVT100U-mitoGFP were propagated in in liquid selective media $(1.7 \mathrm{~g} / \mathrm{L}$ yeast nitrogen base, $2 \mathrm{~g} / \mathrm{L}$ His-Ura dropout mix, $5 \mathrm{~g} / \mathrm{L}$ ammonium sulphate) supplemented with $2 \%$ glucose. Confocal images of live $S$. cerevisiae cells were captured using SP8 confocal microscope (Leica Microsystems). Z image series were acquired, and maximum projections of stacks were used for display. 


\section{RESULTS}

During this study functional characterisation of the second core component of MICOS complex, namely Mic60, was performed. Using bottom-up in vitro reconstitution experimental strategy, it was investigated whether Mic60 possesses a membrane remodelling activity and contributes to the cristae junctions' formation and stabilisation. For this purpose, the full-length Mic60 protein was recombinantly expressed and purified. Different types of artificial model membranes were used to examine the effects of Mic60 on the morphology of lipid bilayer. Obtained results were additionally proved by utilising biological membranes of living cells. Since Mic60 is only MICOS complex with homologues in prokaryotes, the same experimental strategy was employed to learn whether the membrane remodelling properties of Mic60 are evolutionary conserved. Additionally, it was investigated whether the prokaryotic homologues are able to efficiently substitute the functions of eukaryotic Mic60 protein in living cells.

\subsection{THE FULL-LENGTH MATURE FORM OF THE MIC60 PROTEIN CAN BE SUCCESSFULLY EXPRESSED IN E. COLI}

To be able to express and isolate recombinant Mic60 in a heterologous host, its coding sequence was cloned into an appropriate expression vector. Despite being a mitochondrial protein, Mic60 is synthesised on cytosolic ribosomes, and hence it must be transported into mitochondria post-translationally. For this reason, Mic60 is expressed in the form of a pre-protein containing a mitochondrial targeting sequence on its N-terminus. After the Mic60 pre-protein is successfully imported into mitochondria, the targeting sequence is cleaved off while the mature form of Mic60 remains inserted in the inner mitochondrial membrane. In order to perform in vitrobased experiments, it was essential to obtain the recombinant form of Mic60, which corresponds to the mature form of the protein found in mitochondria (Figure 4. 1, A). On this account, a set of primer pairs were designed in the way that the forward primer of each pair bound to the mic60 gene directly downstream of the mitochondrial targeting sequence cleavage site. In combination with the reverse primer, PCR 
amplification yielded DNA fragments coding for the mature form of Mic60. The obtained DNA fragments were successfully cloned into several bacterial expression vectors (pGEX6p2, pET28a(+) and pPROEXHTc), which are regulated by different promoters (tac, T7/lac and trc respectively). As a next step of getting recombinant Mic60, I aimed to find out its optimal expression conditions. Expression constructs were transformed into E. coli BL21DE3 cells (a robust strain specifically optimised for recombinant protein expression). For each construct, a list of expression conditions (various combinations of expression temperature and time) were tested to determine the one giving the highest protein yields (Figure 4. 1, B). Mic60 expression levels appeared to be low since the protein signal could be detected only by means of immunoblotting. All expression samples were additionally subjected to a solubility test in order to check if any of them bear a soluble fraction of the protein (Figure 4. 1, C) Mic60 was expressed as an insoluble form (inclusion bodies), regardless of the conditions. Taking into consideration both of the above-mentioned results, as well as the experimental purposes, I defined the expression from the pPROEXHTc vector, performed at $37^{\circ} \mathrm{C}$ for three hours in the presence of $1 \mathrm{mM}$ IPTG as the optimal conditions for obtaining recombinant Mic60.

\subsection{THE FULL-LENGTH MATURE FORM OF THE MIC60 PROTEIN CAN BE PURIFIED RECOMBINANTLY}

The following task was to purify the recombinant Mic60 protein in sufficient amounts for in vitro experiments and in its native conformation. Based on the results of the expression test, it was realised that in order to obtain significant amounts of Mic60 the volume of the expression culture had to be increased to a great extent. After several rounds of scale up and yield estimation, it was determined that 12 litres of the expression culture (approx. $20 \mathrm{~g}$ of the cellular pellet) made the optimal volume for a single round of protein purification. Such culture volume yielded sufficient amounts of Mic60 inclusion bodies, which could be handled without losing a substantial part of the material after each step of the inclusion bodies clean-up protocol. When purified, the inclusion bodies were successfully solubilised in the urea-containing buffer, and then immobilised metal affinity chromatography (IMAC) using Ni-NTA agarose resin was 
performed to purify Mic60. Although the quantity of Mic60 eluted from the affinity column was considerable, its purity was not yet optimal. Apart from the Mic60 protein, the elution fraction contained multiple co-purified background proteins (Figure 4. 1, A). In order to refine Mic60 purity, we subjected the total elution to size-exclusion chromatography. The Mic60 protein was eluted in the void volume of the gel-filtration column, while the impurities were eluted in the later fractions. Mic60-containing fractions were pooled, and the protein concentration was determined. The total yield of Mic60 was $1.5 \mathrm{mg}$ per litre of expression culture which was enough to proceed with the next task - folding of Mic60 to its native conformation. Up to this moment, Mic60 was handled in high concentrations of urea - a chaotropic compound which prevented the protein from aggregation and kept it in a denatured state. To study Mic60's function, it was essential to be able to recover its native structure. Therefore urea was gradually removed and concurrently substituted with detergent by dialysis. In these conditions, detergent micelles provided a membrane-like environment, so that the Mic60 protein could successively refold and adopt its native conformation. To screen for the most effective refolding conditions, I tested several detergents (Figure 4. 2, B). After careful considerations of the detergent test results with regard to the further experimental strategies $0.1 \%$ DDM was selected as the most favourable refolding agent for Mic60. The quality of the refolding was controlled by circular dichroism (CD) spectroscopy, a method which enables the monitoring of protein secondary structure. The CD spectrum profile, obtained for the Mic60 protein refolded in $0.1 \%$ DDM, indicated the prevalence of $\alpha$-helical structures (Figure 4. 2, C). This result was in line with the predicted structure of Mic60, which mainly consists of a coiled-coil motif. By these means, it was possible to confirm the purification of full-length Mic60 in its native form and amounts suitable for functional studies. 
A

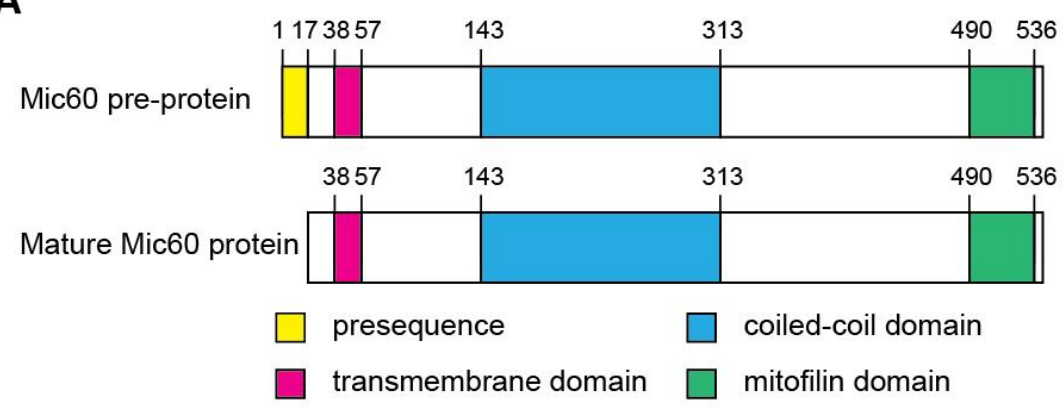

B

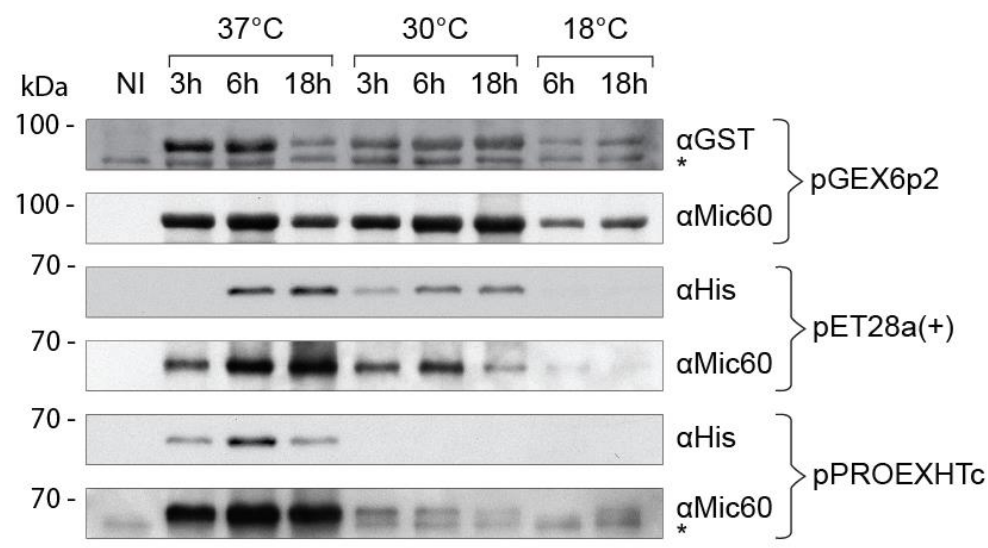

C

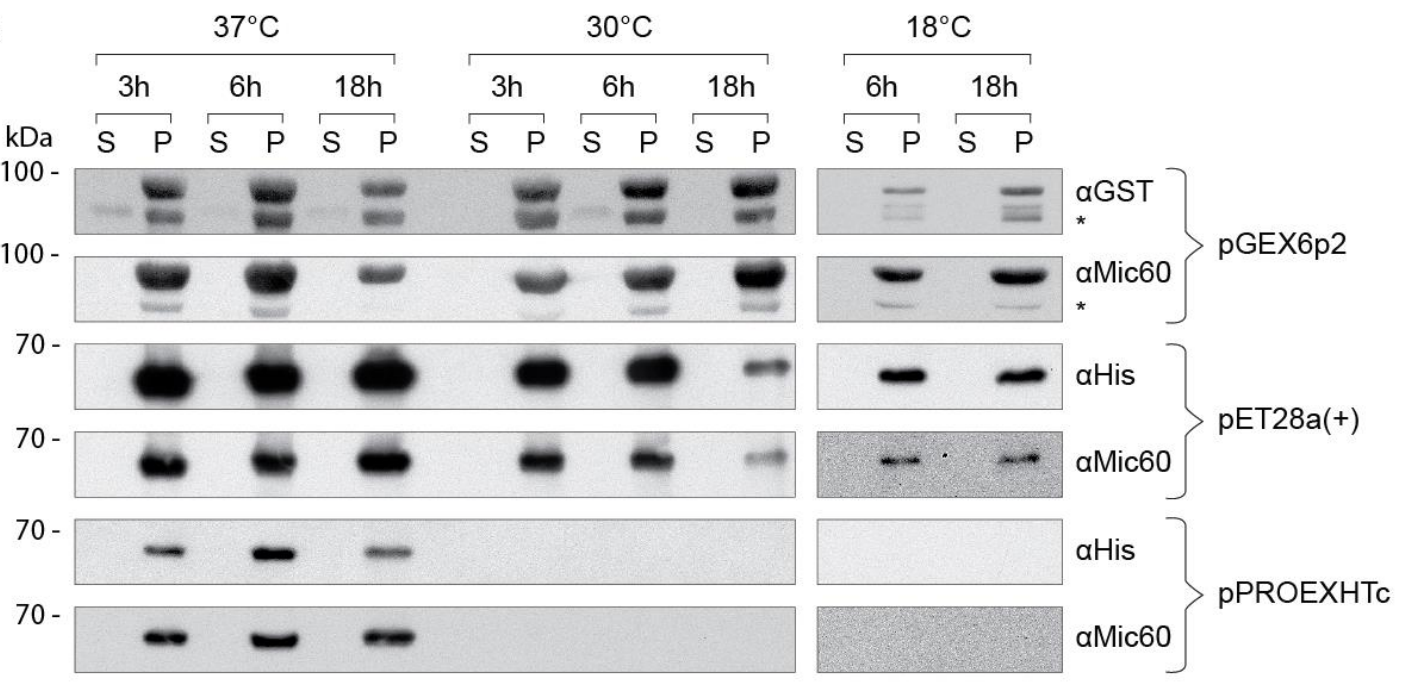

Figure 4. 1: Expression of full-length mature Mic60 protein in E.coli.

The DNA sequence coding for the mature Mic60 protein without mitochondrial targeting sequence $(A)$ was cloned into various bacterial expression vectors such as pGEX6p2, pET28a(+) and pPROEXHTc. The Mic60 protein was expressed in LB medium, and in the presence of $1 \mathrm{mM}$ IPTG. Different expression conditions such as time and temperature were tested. Mic60 levels were monitored by western blot analysis (B). Mic60-expressing culture samples were additionally subjected to a solubility test. The results of the solubility test were visualised by western blot analysis (C). "S" stands for "Supernatant", and "P" stands for "Pellet". Asterisks indicate unspecific bands. 
A

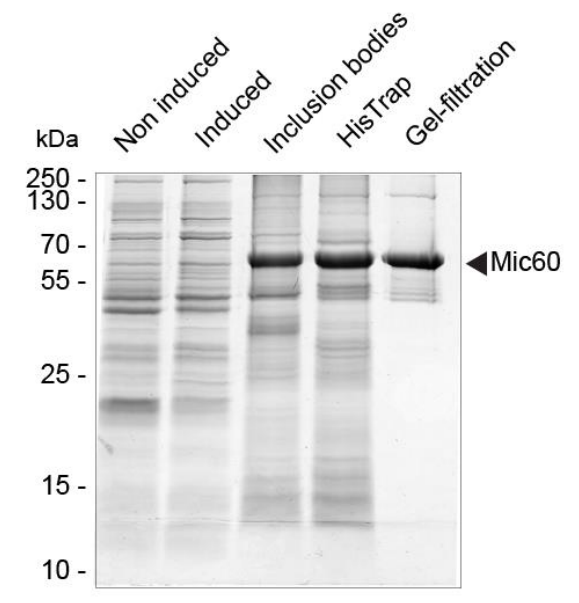

B

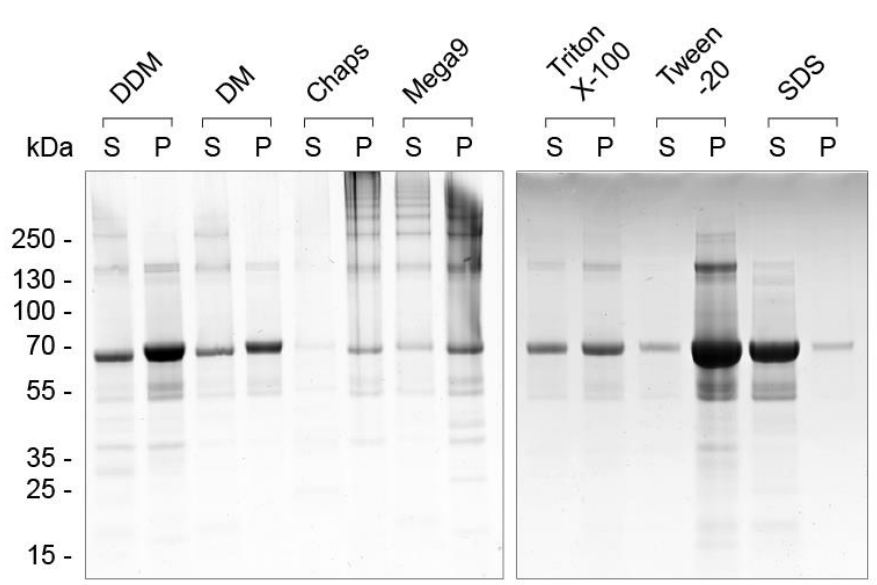

C

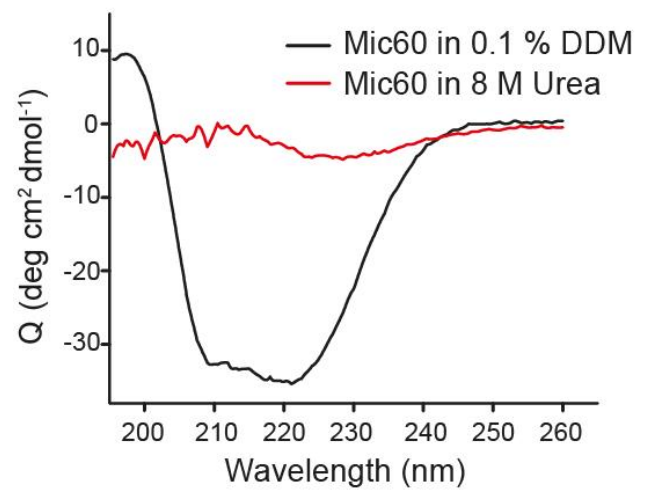

Figure 4. 2: Purification of the recombinant full-length mature form of the Mic60 protein.

Mic60 inclusion bodies were solubilised in $8 \mathrm{M}$ urea. The Mic60 protein was further enriched and purified via a two-step chromatography protocol, which comprised of metal affinity chromatography followed by gel-filtration (A). Mic60 optimal refolding conditions were determined by a small-scale detergent screen, and $0.1 \%$ DDM was determined to be the most experimentally convenient option (B). " $S$ " stands for "Supernatant", and "P" stands for "Pellet". The efficiency of Mic60 refolding in 0.1\% DDM was monitored by CD spectroscopy (C).

\subsection{THE RECOMBINANTLY EXPRESSED MIC60 PROTEIN CAN BE INCORPORATED INTO MODEL MEMBRANES}

In order to study the effects of Mic60 on membranes in vitro, it was necessary to transfer the protein from detergent into a lipid environment, which was provided by model membranes (in this instance, large unilamellar vesicles also referred to as LUVS or liposomes). To carry out this transition I made use of the so-called detergent- 
mediated reconstitution protocol. First liposomes were pre-solubilized in $0.1 \%$ DDM and then incubated together with the Mic60 protein. This allowed a facilitated insertion of the Mic60 transmembrane helix into the detergent-perturbed lipid bilayer. Afterwards, DDM molecules were depleted from the system, and, reconstituted via its transmembrane helix, Mic60 remained in the liposomes (for details see the Materials and methods section 3.2.4.2 Detergent-mediated incorporation). Success and efficiency of this process were estimated by the flotation assay and subsequent sodium carbonate extraction (Figure 4. 3). The flotation assay results clearly showed that Mic60 co-migrated with liposomes within the density gradient, indicating that the protein bound to the lipid bilayer (Figure 4. 3, A and B). In order to discriminate whether this binding was a result of a mere peripheral attachment (due to rather weak electrostatic or hydrophobic interactions), or actual incorporation of the protein's transmembrane helix into the lipid bilayer, sodium carbonate extraction was performed (Figure 4. 3, C). Treatment with the alkaline solution of concentrated sodium carbonate did not disrupt the Mic60-lipid interaction since the Mic60 protein was found solely in the liposomal fraction. Together, these assays confirmed that Mic60 was successfully and efficiently reconstituted into model membranes.

\subsection{MIC60 INDUCES HIGH DEGREES OF CURVATURE WHEN INCORPORATED INTO MODEL MEMBRANES}

The main reason to reconstitute Mic60 into the liposomes was to investigate whether it possesses an intrinsic ability to induce membrane curvature. In fact, I began to observe the first hints of membrane curving properties at the very early stages of this study. For instance, when performing the flotation assay, it was already noticed that the flotation pattern of Mic60 proteoliposomes looked quite different from the flotation pattern of control vesicles (Figure 4. 3, A). Both Tim50 proteoliposomes and empty liposomes migrated within the density gradient as single bands, while Mic60 proteoliposomes migrated to the interface of each gradient layer and arranged in a ladder-like pattern. Tim50 protein was selected as an experimental control since it is an 
A

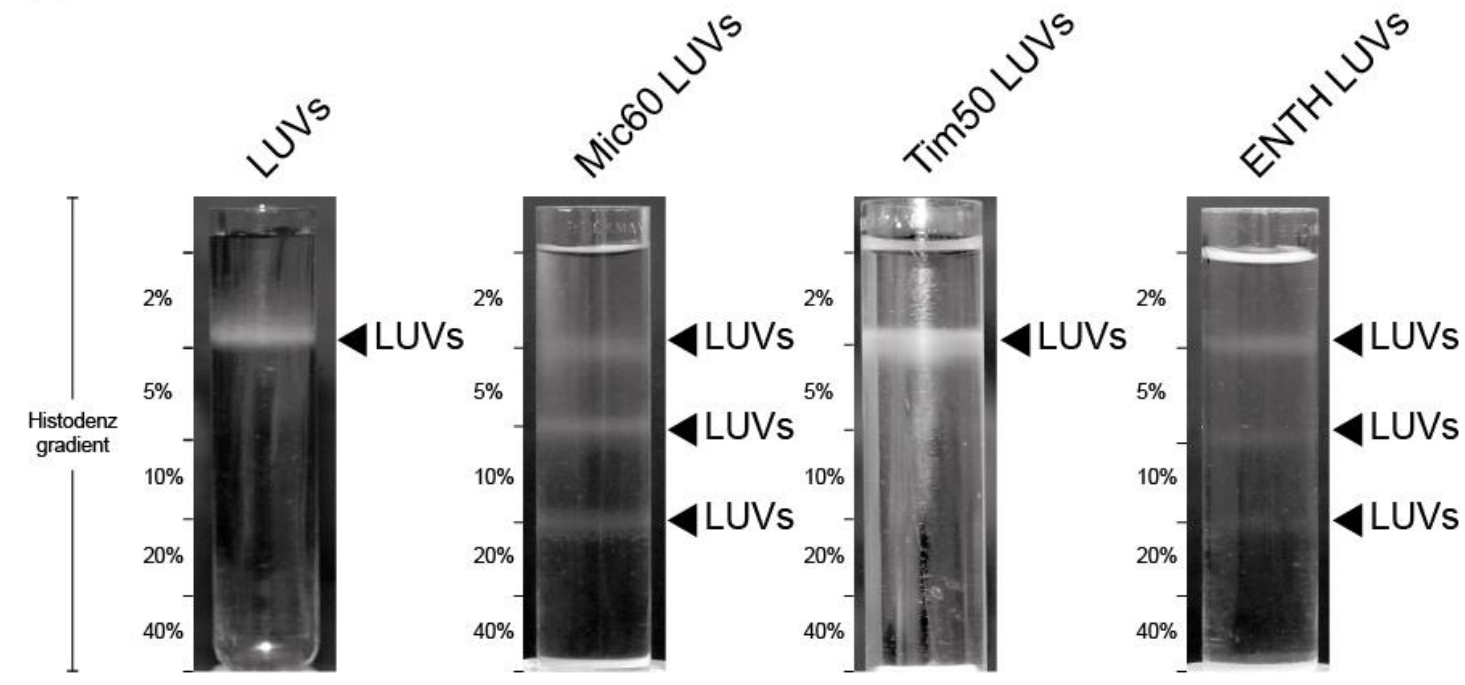

B

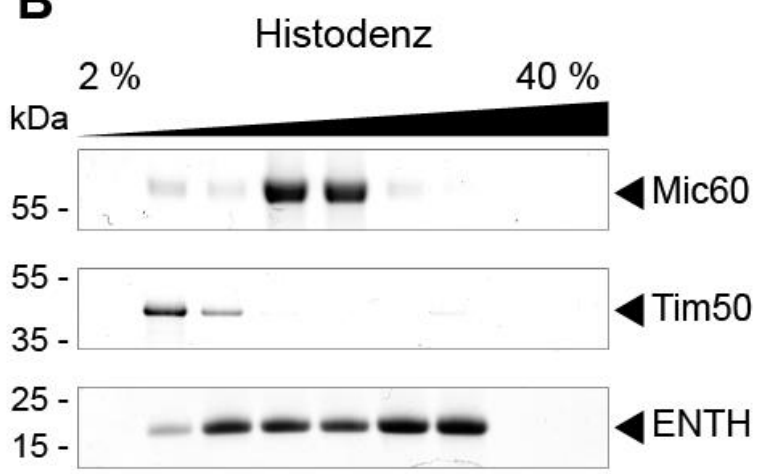

C

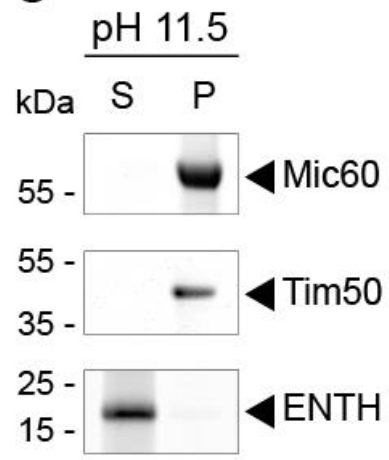

Figure 4. 3: The full-length, mature form of the recombinant Mic60 protein can be successfully and efficiently reconstituted into model membranes.

Mic60 reconstitution success was monitored by the flotation assay (A, B) and sodium carbonate extraction (C). Mic60-containing LUVs, empty LUVs and LUVs containing the control proteins Tim50 and ENTH domain were separated on the discontinuous histodenz density gradient by ultracentrifugation (A). The gradients were further fractionated and analysed by SDS-PAGE and Coomassie brilliant blue staining (B). The LUVs-containing bands from (A) were isolated, treated with concentrated sodium carbonate solution, $\mathrm{pH}$ 11.5, and subjected to ultracentrifugation. The supernatant, "S", and the pellet, " $\mathrm{P}$ ", fractions were analysed by SDS-PAGE and Coomassie brilliant blue staining (C). 
inner mitochondrial membrane protein which resembles the size, topology, and the mode of membrane insertion (via single $\mathrm{N}$-terminal transmembrane domain) of Mic60, but is not involved in membrane remodelling processes. Interestingly enough, when the flotation assay was performed with the well-characterised curvature-inducing endocytic protein ENTH domain, the same ladder-like arrangement of multiple proteoliposomal bands, as in the case of Mic60, was observed. Therefore these observations provided us with a premise that Mic60 could potentially affect membrane morphology by inducing membrane curvature. To further test this assumption, the homogeneity and size distribution of such proteoliposomes were assessed in bulk by dynamic light scattering (DLS) spectroscopy (Figure 4. 4, A). Tim50-containing proteoliposomes and empty liposomes appeared to constitute rather monodisperse phases of uniformly sized vesicles which is reflected by a single smooth DLS peak around the $100 \mathrm{~nm}$ mark (size obtained by the extrusion during liposome preparation protocol). However, Mic60- and ENTH-containing proteoliposomes exhibited substantial shifts in the particle size distribution, which resulted in multiple DLS peaks corresponding to a wide range of liposomal diameters. To directly visualise these effects, I subjected these proteoliposomes to transmission electron microscopy (Figure 4. 4, B). The imaging results revealed that the underlying reason of the observed heterogeneity was not a mere change of the liposomes' size, but rather significant alteration of their overall morphology. Mic60- and ENTH domain-containing proteoliposomes adopted predominantly tubular shapes when compared to the control (empty and Tim50containing) vesicles. Although I was already quite confident to claim that the Mic60 protein is able to induce membrane curvature, I could not completely dismiss the existing conception that the liposomes, owing to their small size of $50 \mathrm{~nm}-200 \mathrm{~nm}$, exert some degree of intrinsic membrane curvature which is potentially strong enough to influence the process of protein-induced membrane remodelling. Therefore, to make sure that the effects were Mic60 specific, it was decided to make use of another type of model membrane, namely giant unilamellar vesicles (GUVs). In contrast to liposomes, the size of GUV is usually of micrometre range, which is comparable to the size of the cell. Hence the lipid bilayer of GUV's more closely resemble the cellular 
plasma membranes, whereby nearly no membrane curvature is exerted when considered on the scale of a single protein molecule. These features make GUVs a good model system to test Mic60 membrane curvature properties. For this purpose, GUVs were formed from empty LUVs, as well as from Tim50- and Mic60-containing proteoliposomes, and subjected to confocal fluorescence microscopy (Figure 4. 5, A). The majority of GUVs grown from empty liposomes (85 \%), as well as from Tim50containing proteoliposomes (70\%), adopted a normal, unilamellar round-shaped morphology, while the majority (92 \%) of GUVs grown from Mic60-containing proteoliposomes formed multiple intraluminal vesicles and sheet-like structures (60\% and $32 \%$ respectively)(Figure $4.5, \mathrm{~B})$. Essentially, the obtained results were consistent with the results from the experiments performed on LUVs. In conclusion, I could confidently determine that Mic60 is able to induce high degrees of membrane curvature when incorporated into various in vitro model membranes of different physical properties.

A

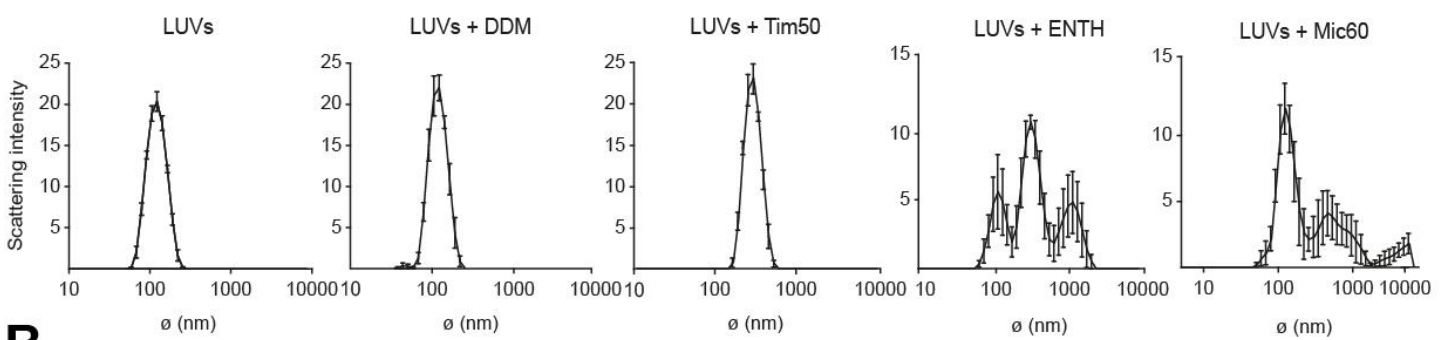

B

LUVs

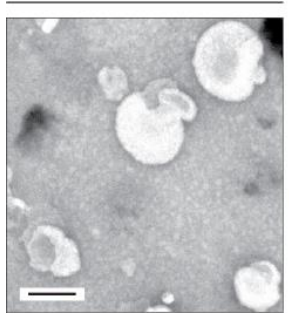

LUVs + DDM

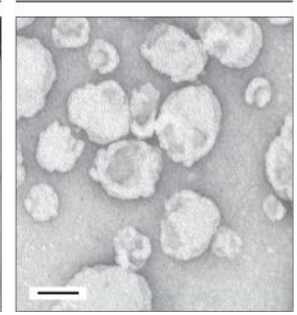

LUVs + Tim50

LUVs + ENTH

LUVs + Mic60
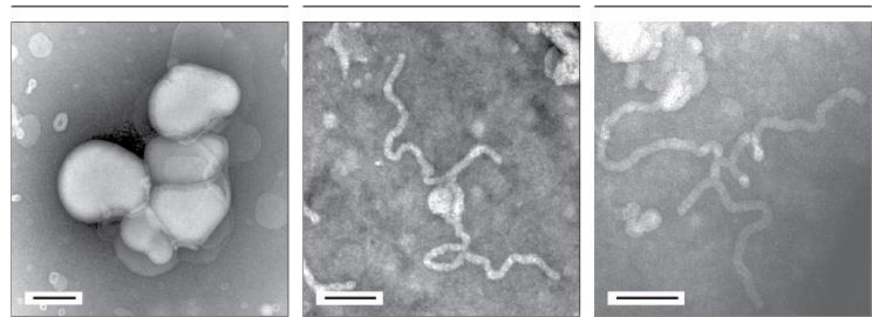

Figure 4. 4: The Mic60 protein is able to induce curvature in the model LUV membranes.

The overall size homogeneity of Mic60-containing LUVs as well as of the control LUVs (as indicated) was evaluated by dynamic light scattering analysis (A). The error bars represent SEM. The morphology of the lipid bilayer of such LUVs was directly visualised by transmission electron microscopy (B). Scale bars are equal $100 \mathrm{~nm}$. 


\subsection{MIC60 IS ABLE TO INTRODUCE MEMBRANE CURVATURE IN REAL BIOLOGICAL MEMBRANES DE NOVO}

When Mic60-induced membrane bending was proven to occur in vitro, the foremost aim became to investigate whether Mic60 also contributes to the curvature of the inner mitochondrial membrane in situ. Following the logic of the bottom-up experimental approach, I decided to check whether Mic60 is able to induce curvature of a real biological membrane de novo. When looking for a membrane which would suit this purpose the most, an ideal option was the inner membrane of $E$. coli. It resembles the overall organisation of a mitochondrion, but with the one important exception being that the inner membrane of $E$. coli is flat. To test if Mic60 is able to cause changes in the morphology of a biological membrane, the full-length Mic60 protein, as well as control proteins (Tim50, Tim23, Tom20), were targeted to the inner membrane of $E$. coli by using an N-terminal maltose binding protein (MBP) tag. The efficiency of targeting was monitored by subcellular fractionation, followed by immunoblotting (Figure 4. 6, D-F). By means of fractionation, the main compartments of bacterial cells (cytosol, periplasm, total membranes) could be resolved to a great extent. The degree of resolution was monitored by decorating the obtained fractions with antibodies against compartment-specific marker proteins (anti- $\beta$-lactamase for periplasm, antiGroEL chaperone for cytosol and anti-ATP synthase subunit ATPb for membrane) (Figure 4. 6, F). According to the immunoblotting results, Mic60 was found in the membranous fraction (Figure 4. 6, D), which confirmed successful membrane targeting. As a next step, I assessed these membranes for the presence of curvature. To do so, ultrathin cryosections of the $E$. coli cells expressing the proteins of interest were prepared and subsequently examined under a transmission electron microscope (Figure 4. 6, A-C). The cells expressing free MBP tag as well as cells expressing other control proteins (Tim50, Tim23, and Tom20), did not exhibit any changes in their membrane morphology and looked the same as uninduced E. coli. In contrast, the Mic60-expressing cells contained numerous membrane-bound, as well as free, cytosolic vesicular structures. 


\section{A}

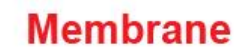

Protein
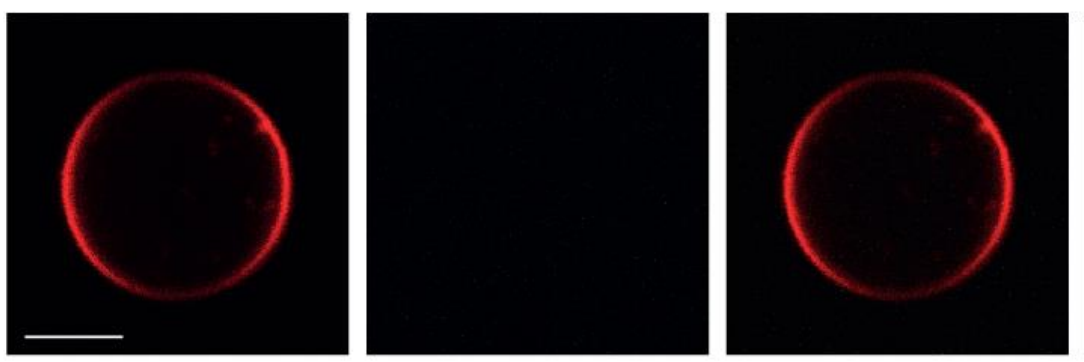

GUV
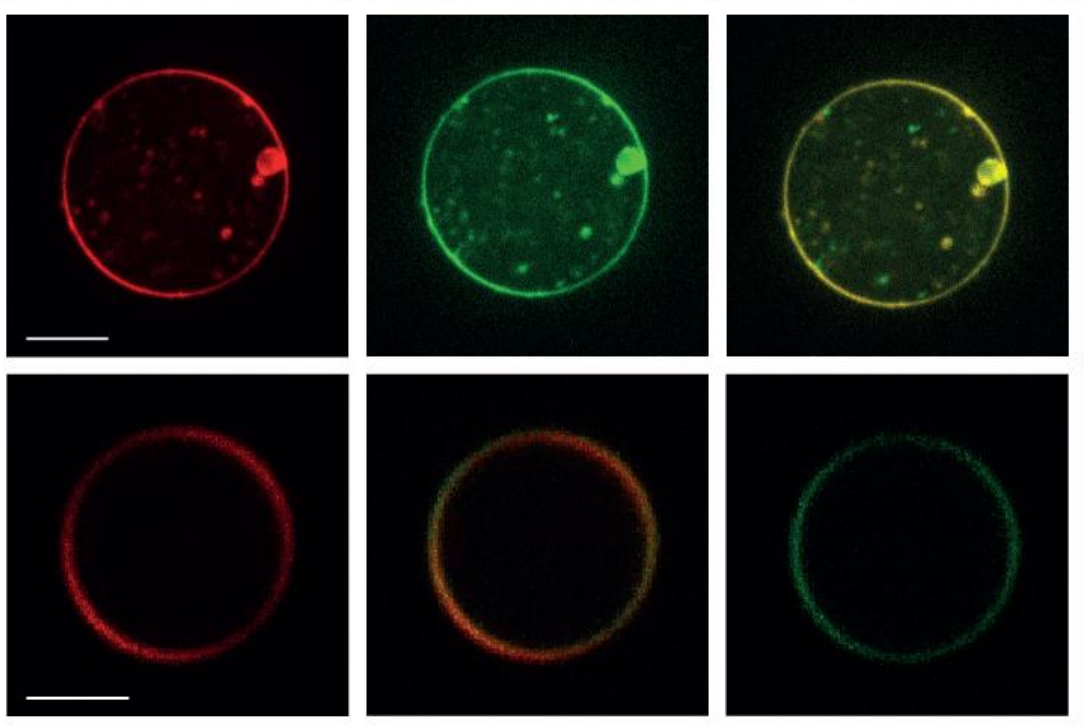

GUV+Mic60

GUV+Tim50

B

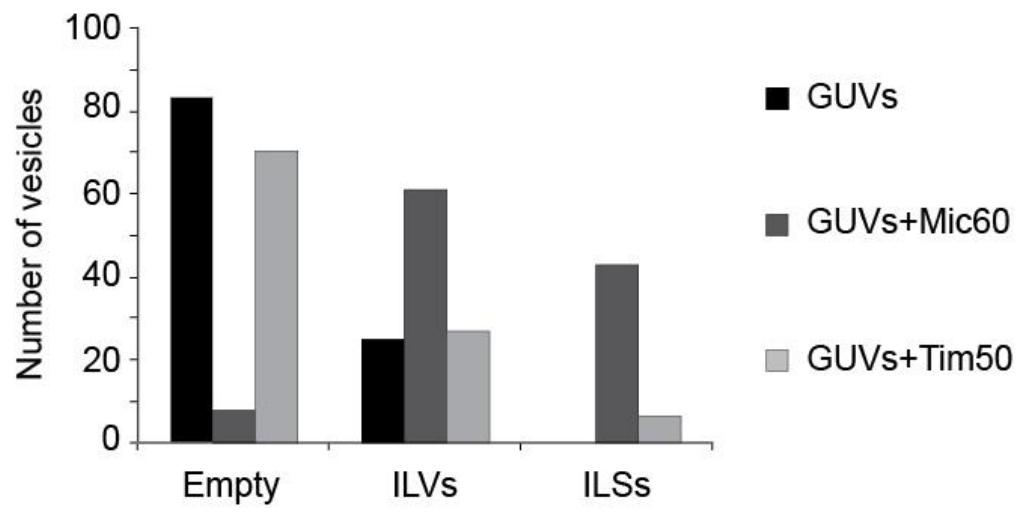

Figure 4. 5: The Mic60 protein is able to induce curvature of the model GUV membranes.

The morphology of GUVs grown in the presence of Mic60 protein, control Tim50 protein, as well as the morphology of empty GUVs, was examined using a confocal fluorescence microscope (A). The membrane was labelled by rhodamine-PE, and the proteins were labelled with Alexa 488 fluorophore, scale bars are equal $10 \mu \mathrm{m}$. The observed effects were quantitatively evaluated (B). For each sample, a minimum of 100 GUVs from three independent preparations was analysed. "ILVs" stands for intraluminal vesicles, and "ILSs" stands for intraluminal sheets. The histogram represents absolute numbers. 


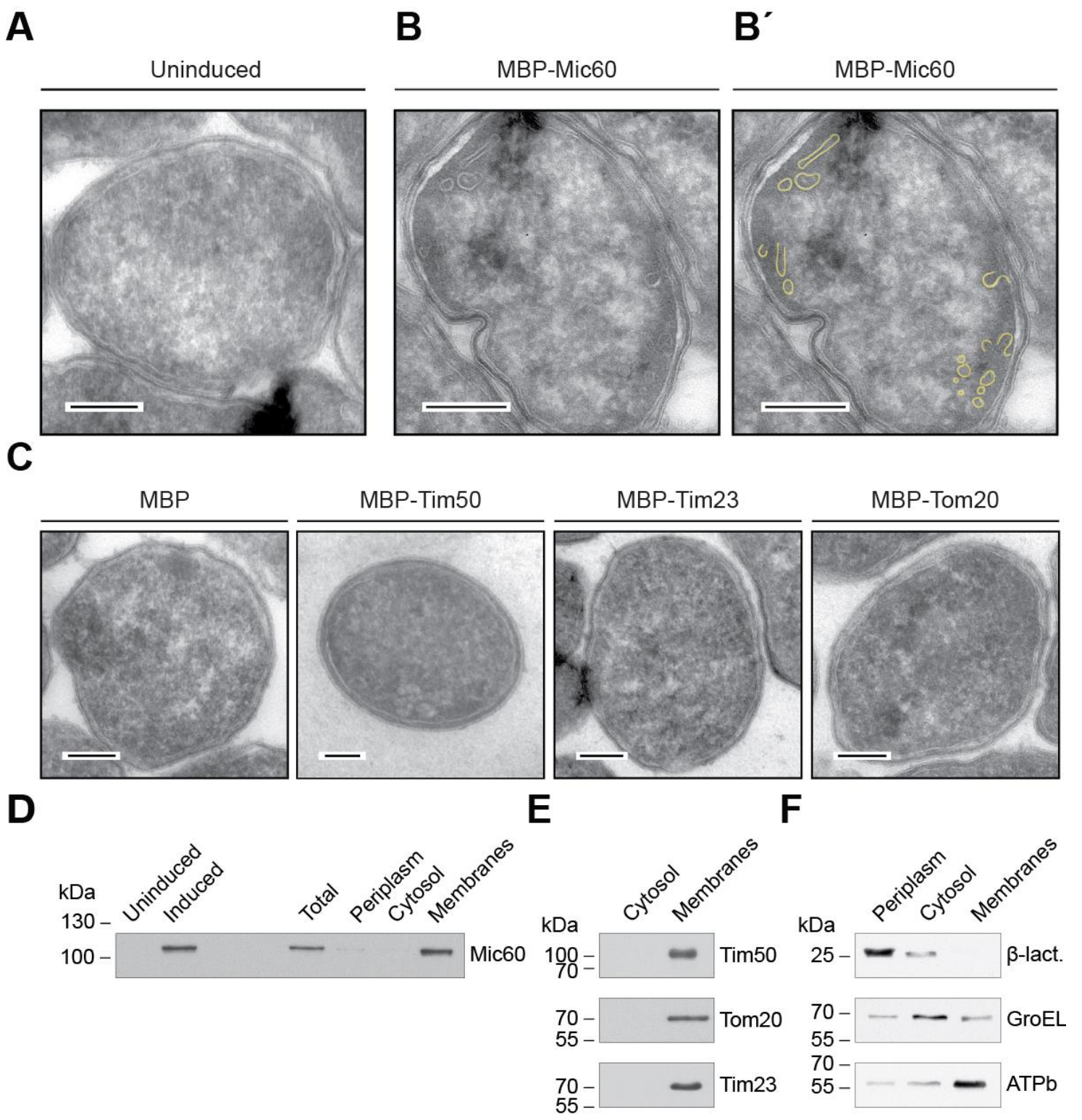

\section{Figure 4. 6: Mic60 is able to bend biological membranes in vivo and to induce membrane curvature in a living cell de novo.}

Mic60 ( $B$ and $\left.\mathrm{B}^{\prime}\right)$, as well as the control proteins $(C)$, were targeted to the plasma membrane of $E$. coli using the MBP fusion tag. The morphology of plasma membrane of these, as well as of uninduced $(A) E$. coli cells were visualised by transmission electron microscopy of the negatively stained cryosections. Scale bars are equal $100 \mathrm{~nm}$. Targeting efficiency was monitored by subcellular fractionation followed by Western blot analysis of obtained fractions using anti-MBP antibody (D) and antibody against the proteins of interest $(E)$. Targeting specificity was monitored by Western blot analysis of the fractions using antibodies against compartment-specific marker proteins such as $\beta$-lactamase for periplasm, GroEL for cytosol and ATPb for plasma membrane (F). 


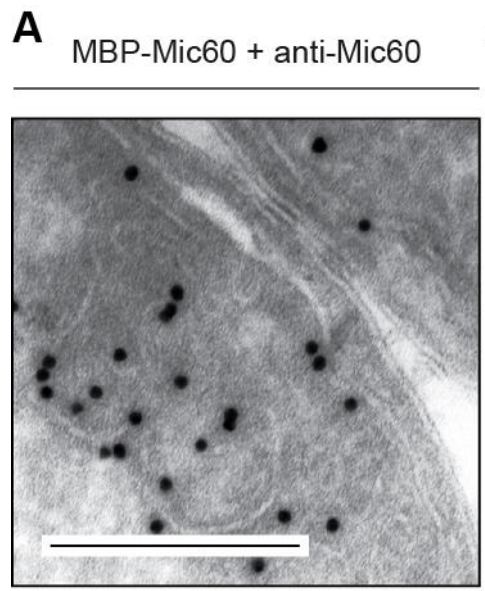

A' $^{\prime}$ MBP-Mic60 + anti-Mic60

B

Labeling control
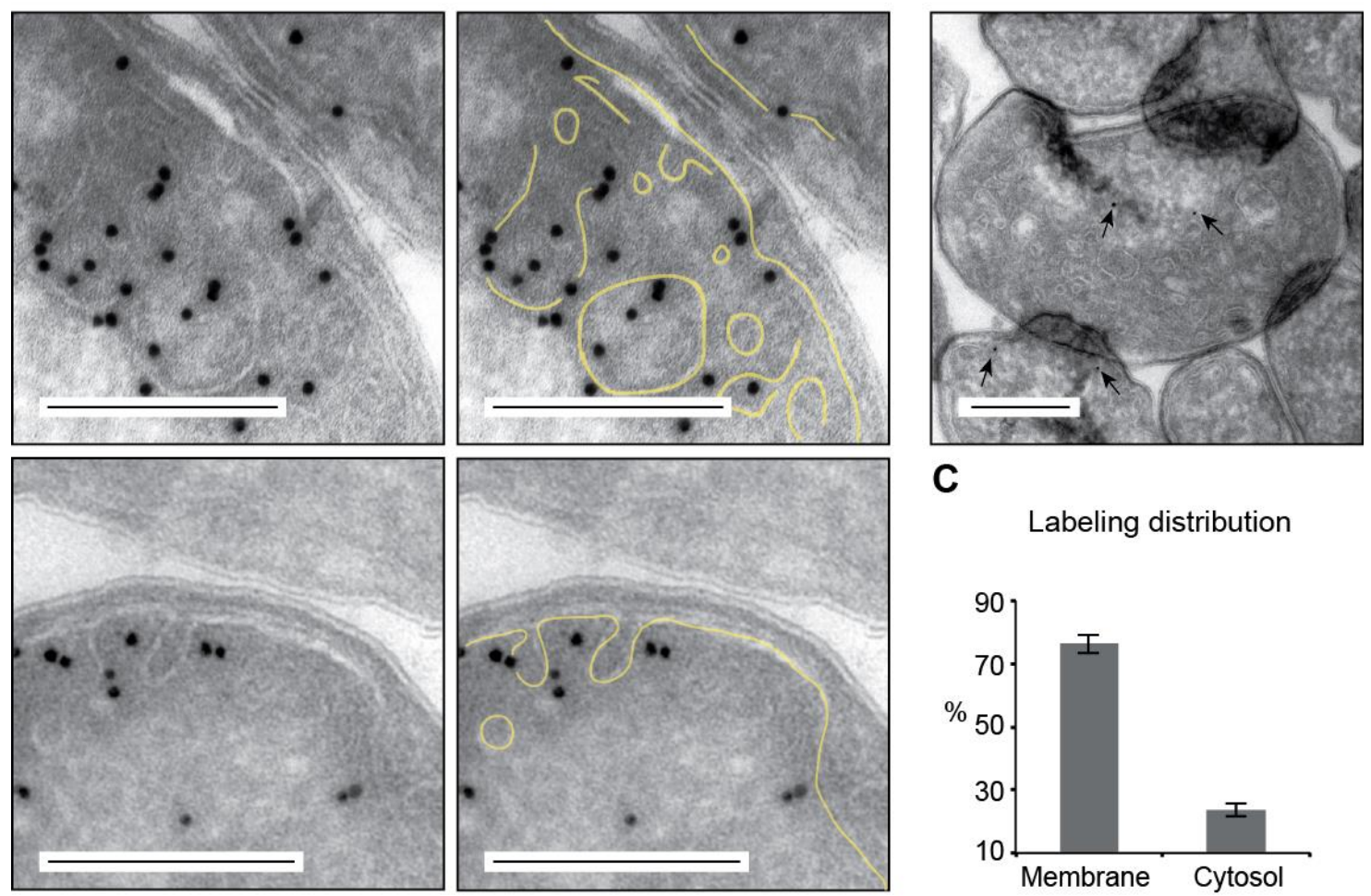

C

Labeling distribution

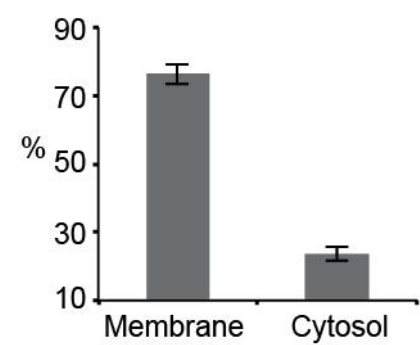

Figure 4. 7: Immunogold labelling of $E$. coli cells expressing the MBP-Mic60 fusion protein.

The cryosections were incubated with primary anti-Mic60 antibodies and, subsequently, with protein A coupled to the gold particles. The labelling signal was visualised by transmission electron microscopy (A and $A^{\prime}$ ), and labelling distribution was quantified by counting the number of gold particles (1481) in 27 E. coli cells $(n=27)(C)$. The error bars represent SD. The signal specificity was monitored by performing the labelling protocol omitting the step of primary antibody incubation (B). Scale bars are equal $100 \mathrm{~nm}$.

To make sure that the emergence of these structures was related to the presence of Mic60, immunogold staining of the samples was performed using anti-Mic60 antibodies (Figure 4. 7, $A$ and $A^{\prime}$ ).

A thorough visual and statistical evaluation of the immunogold imaging results revealed that the majority of the gold particles $(76.1 \%)$ localised around the internal membranes (Figure 4. 7, B and C) further confirming the assumption that these structures were Mic60-specific. Together, all these experiments demonstrated that the Mic60 membrane remodelling properties are potent enough to bend biological membranes in vivo and to induce membrane curvature in a living cell de novo. 


\subsection{THE MIC60 IMS DOMAIN IS RESPONSIBLE FOR THE MEMBRANE REMODELLING FUNCTION OF THE MIC60 PROTEIN}

At this point, the data was quite convincing that Mic60 is a membrane remodelling protein, but the mechanism by which Mic60-mediated membrane remodelling occurs remained unknown. To gain a deeper insight, I investigated which domain of Mic60 is responsible for lipid binding and membrane curvature induction respectively. To begin with, a truncated version of Mic60 lacking the transmembrane domain (further referred to as Mic60 ${ }^{\mathrm{IMS}}$ ) was expressed and purified (Figure 4. 8, A). Afterwards, I investigated whether the Mic60 ${ }^{\mathrm{IMS}}$ lipid binding properties differ from the lipid binding properties of the full-length protein using the flotation assay (Figure 4. 8, B). We noted that, although missing the transmembrane domain, Mic60 ${ }^{\mathrm{IMS}}$ consistently co-migrated with liposomes along the density gradient. This observation suggested that the transmembrane domain is not essential for Mic60 membrane binding and that the Mic60 IMS domain might possess an intrinsic affinity to lipids. To test whether Mic $60^{\mathrm{IMS}}$ can also induce curvature in lipid bilayers, Mic60 ${ }^{\mathrm{IMS}}$-containing liposomes were visualised under the transmission electron microscope (Figure 4. 8, C). Similarly to the full-length protein, Mic60 ${ }^{\mathrm{IMS}}$ converted round liposomes to tubules, indicating that it has a membrane remodelling capacity. To investigate it further, Mic60 ${ }^{\mathrm{MMS}}$ was targeted to the periplasm of $E$. coli via an MBP tag to analyse whether it is able to affect the morphology of the bacterial inner membrane (Figure 4. 8, D and $D^{\prime}$ ). Surprisingly, Mic60 IMs induced morphological changes of the inner membrane to an even greater extent than the fulllength protein. While full-length Mic60 induced the formation of vesicular structures, Mic60 ${ }^{\mathrm{IMS}}$ induced the formation of tubule-like membrane invaginations extending towards the cytosol and resembling the appearance of mitochondrial cristae. When compared to the Mic60-induced internal vesicular structures, Mic60 ${ }^{\mathrm{IMS}}$-induced tubules appeared more regular and morphologically uniform. 
A

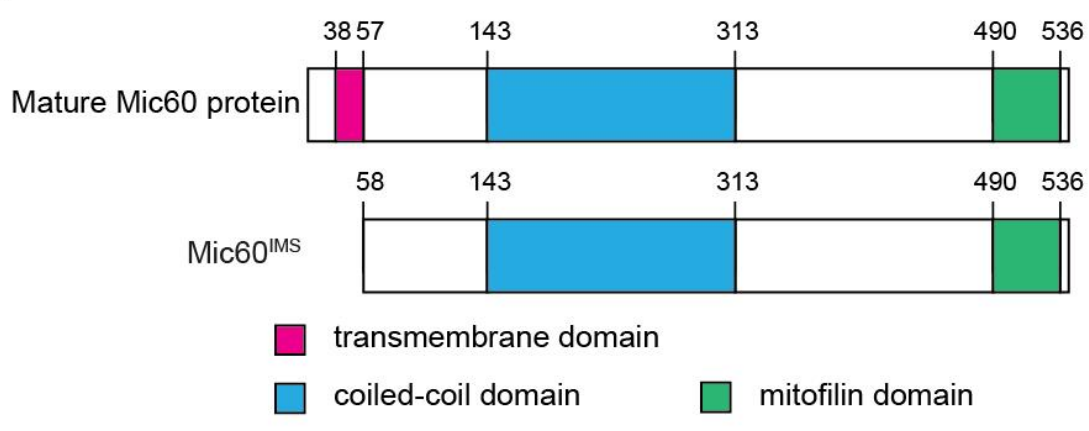

B

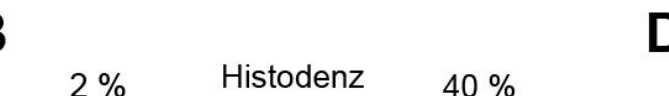

D

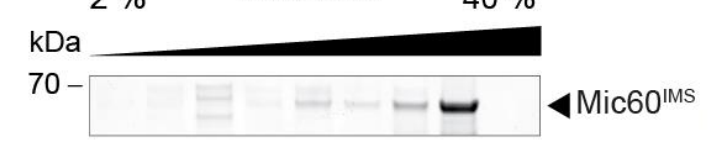

C
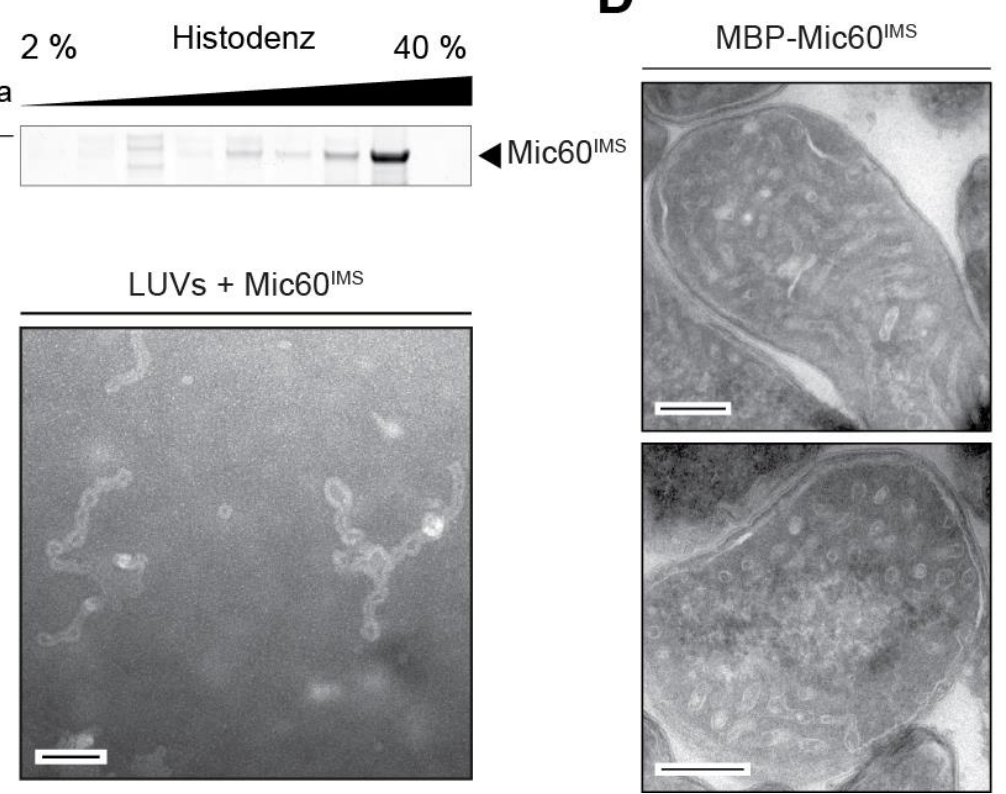

D'

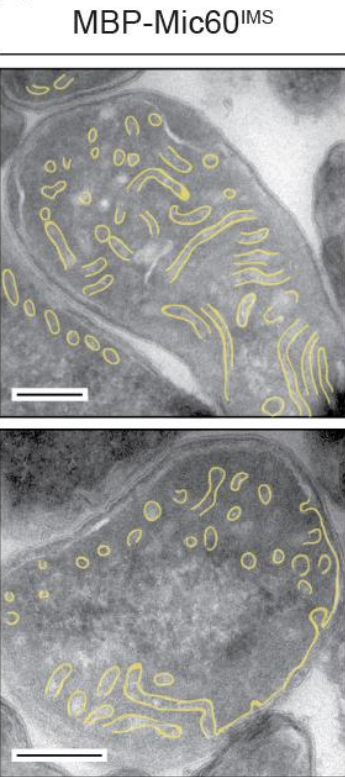

Figure 4. 8: The IMS domain of Mic60 possesses an affinity to lipids and bends model membranes in vitro as well as real biological membranes in vivo.

$\operatorname{Mic60}^{\mathrm{IMS}}(\mathrm{A})$ affinity to lipids was monitored by the flotation assay in discontinuous histodenz gradient. LUVs were incubated with Mic60 IMS protein and separated on the histodenz gradient by ultracentrifugation. The density gradient was fractionated, and all fractions were analysed by SDS-PAGE and subsequent Coomassie brilliant blue staining (B). The effect of Mic60 IMs on the membrane morphology of LUVs was assessed by transmission electron microscopy imaging of negatively stained LUVs incubated together with Mic60 IMS $(C)$. Scale bar is $100 \mathrm{~nm}$. The Mic60 ${ }^{\mathrm{MS}}$ effect on the plasma membrane of $E$. coli was evaluated by transmission electron microscopy imaging of negatively stained cryosections of $E$. coli cells expressing Mic60 ${ }^{\mathrm{IMS}}$ as a fusion protein with MBP (D and $\left.D^{\prime}\right)$. Scale bars are equal to $100 \mathrm{~nm}$. 
When the cryosections of $E$. coli expressing Mic60 ${ }^{\mathrm{IMS}}$ were subjected to immunogold labelling and examined using the transmission electron microscope (Figure 4. 9), the gold particles (corresponding to the Mic60 protein signal) were seen to be distributed throughout the length of the membranous structures. Based on these results it can be concluded that Mic60's IMS domain has an inherent affinity to lipids and is most probably responsible for the membrane remodelling activity of the Mic60 protein, both in model membranes in vitro, as well as in biological membranes in vivo.

\section{MBP-Mic60IMs + anti-Mic60}
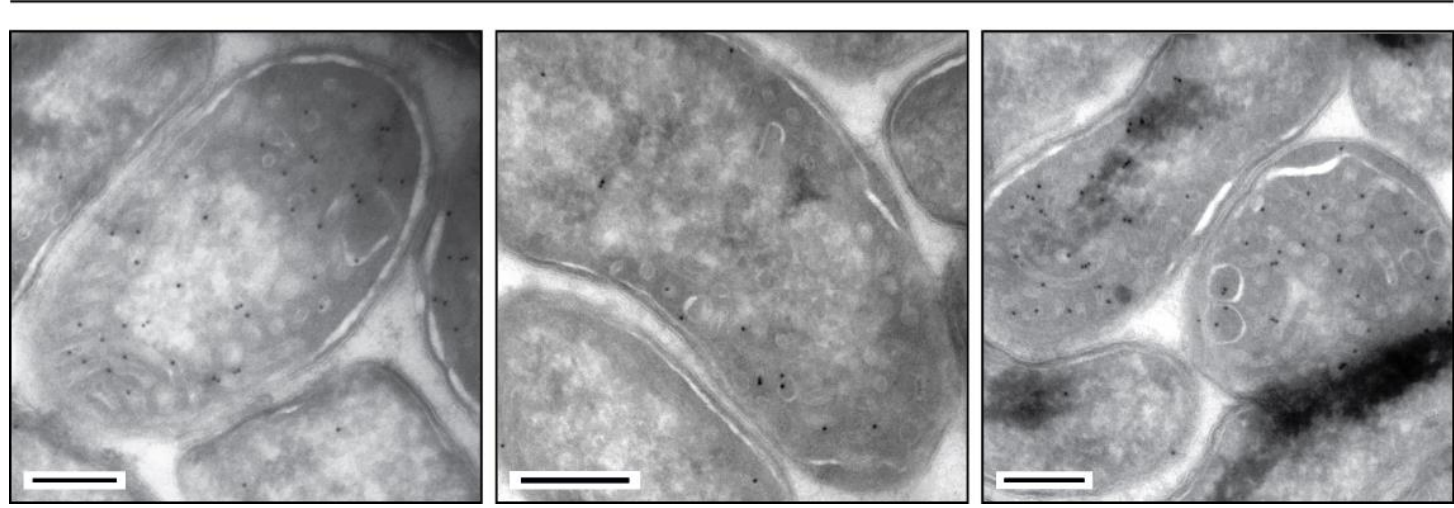

Figure 4. 9: Immunogold labelling of $E$. coli cells expressing the MBP-Mic60 ${ }^{\mathrm{MS}}$ fusion protein.

The cryosections of E.coli cells expressing Mic60 IMS domain were incubated with primary anti Mic60 antibodies and, subsequently, with protein A coupled to the gold particles. The labelling signal was visualised by transmission electron microscopy. Scale bars are equal to $100 \mathrm{~nm}$.

\subsection{MEMBRANE REMODELLING ACTIVITY OF THE MIC60 PROTEIN IS EVOLUTIONARY CONSERVED}

Mic60 is the only MICOS subunit which has homologues amongst prokaryotes. These homologues are exclusively found in the class of alphaproteobacteria and share structural, as well as sequence, similarity with eukaryotic Mic60 proteins. Following the principle of structure-to-function relationships, it can be speculated that the tendency of Mic60 to interact with a lipid bilayer, as well as its membrane remodelling activity, could also be attributed to its alphaproteobacterial homologues. To experimentally test this idea, I employed the in vitro as well as the in vivo membrane bending assays, which 
I previously used in order to characterise these properties of the yeast Mic60. I selected two of the identified alphaproteobacterial Mic60 homologs: from Rhodobacter sphaeroides (Mic60 ${ }^{R . s}$ ) and Paracoccus denitrificans (Mic60 ${ }^{P . d}$ ). R. sphaeroides is a wellcharacterized model organism for studies on photosynthetic systems, while $P$. denitrificans is known for its resemblance to mitochondrion with regards to the biochemistry of respiratory chain and oxidative phosphorylation ${ }^{106}$. The DNA coding sequences of both homologues were acquired, cloned into the $6 \times$ His-tag pPROEXHTc bacterial expression vector, and the proteins were recombinantly expressed and purified. Next, I proceeded to in vitro experiments in order to monitor the effects of Mic60 R.s and Mic60 P.d on the morphology of model membranes (Figure 4. 10, A). Both homologues were successfully incorporated into liposomes and then examined using the transmission electron microscope. The imaging results revealed that similar to the yeast Mic60, Mic60 R.s and Mic60 ${ }^{P . d}$ significantly affected the morphology of liposomal membranes by reshaping them into tubules. To further check the effects of Mic60 R.s and Mic60 ${ }^{P . d}$ in vivo, the proteins were targeted to the inner membrane of $E$. coli (Figure 4. $10, B, C, D$ and $\left.D^{\prime}\right)$. Here it was observed, that they were able to effectively remodel biological membranes as well. Mic60 R.s induced formation of diverse, mostly membrane-attached vesicles and tubules, and Mic60 P.d induced formation of morphologically uniform, free cytoplasmic vesicles, which often completely filled up the entire volume of the $E$. coli cells. All these observations strongly supported the assumption that the alphaproteobacterial Mic60 homologues indeed have inherent membrane remodelling activity 
A

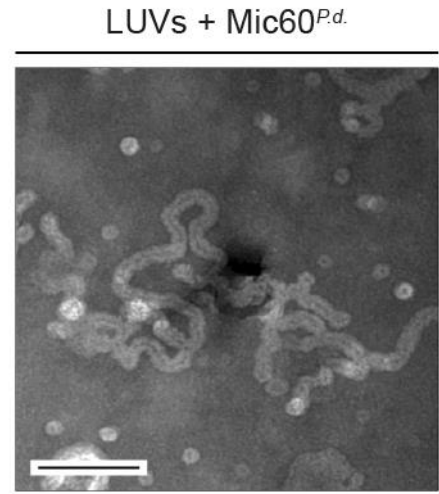

B<smiles>[14CH3]</smiles>

Histodenz $\mathrm{kDa}$
LUVs + Mic60R.s.

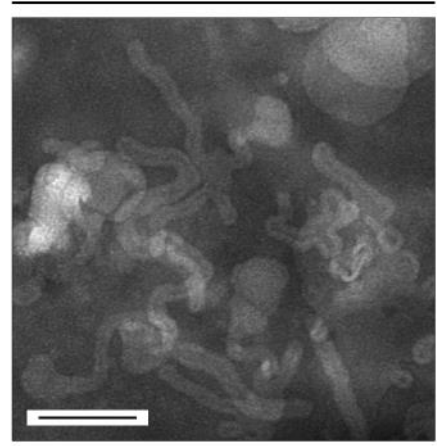

LUVs

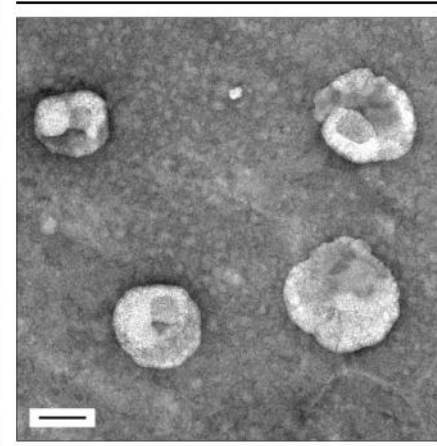

is

C

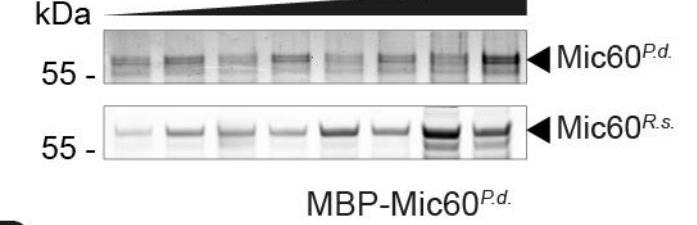

D
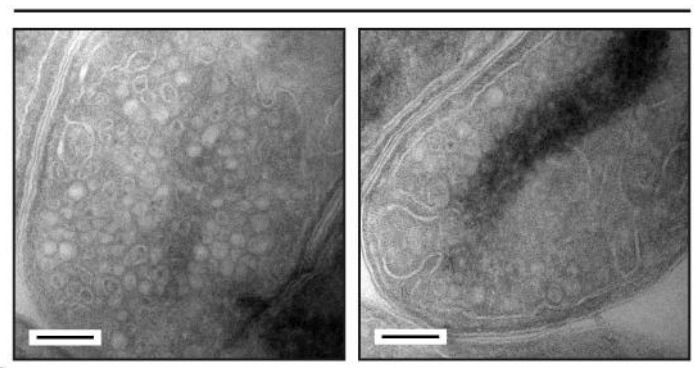

$\mathrm{kDa}$ 130 100 - $=$
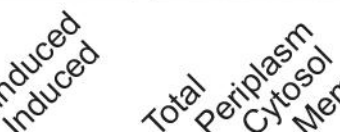

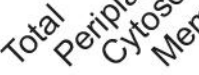
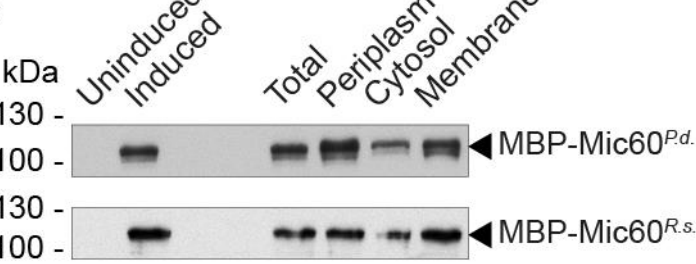
100

MBP-Mic60 R.s.

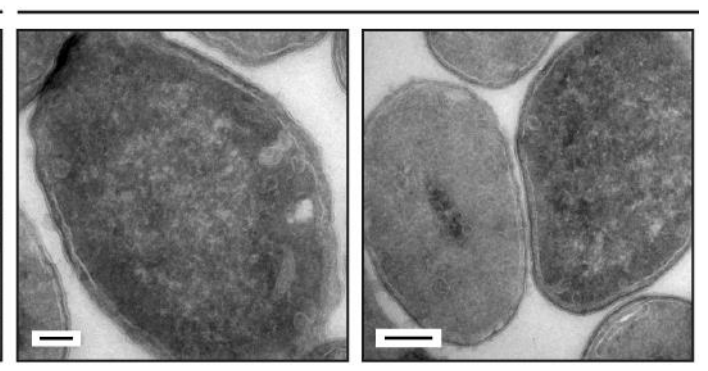

D
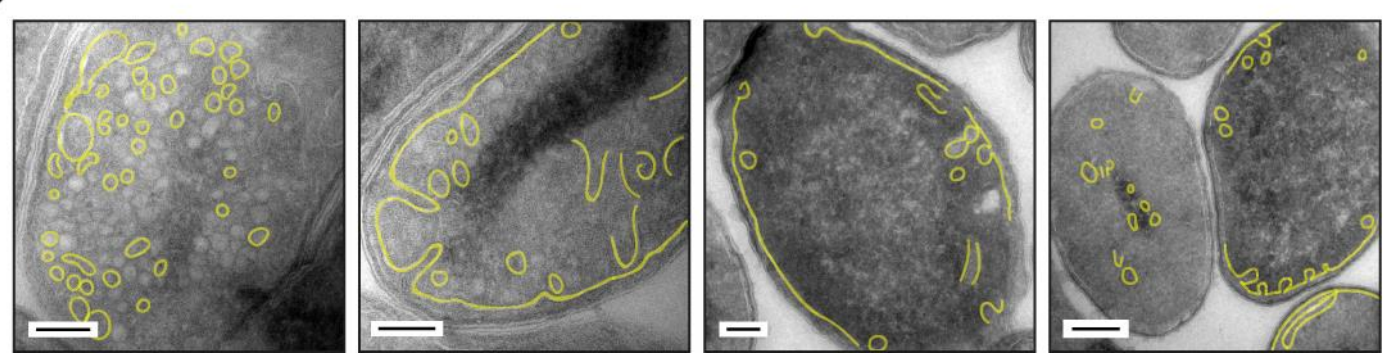

Figure 4. 10: Alphaproteobacterial Mic60 homologues possess an inherent membrane remodelling activity.

The effect of Mic60 $0^{P . d}$ and Mic60 ${ }^{R . S}$ on the morphology of the lipid bilayer of LUVs in vitro was assessed using transmission electron microscopy of negatively stained Mic60 $6 .{ }_{\text {- }}$ and Mic $60^{\text {R.S }}$-containing LUVs and their comparison to the morphology of the control empty LUVs (A). Mic60 ${ }^{\text {P.d }}$ and Mic $60^{\text {R.s integration }}$ success into LUVs was monitored by the flotation assay (B). Mic $60^{P . d}$ and Mic $60^{R . s}$ were targeted to the plasma membrane of E.coli. Targeting efficiency was monitored by subcellular fractionation followed by western blot analysis of obtained fractions using anti-MBP antibody (C). Mic60 P.d and Mic60 R.s effects on the real biological membranes in vivo were monitored by transmission electron microscopy imaging of negatively stained cryosections of $E$. coli cells expressing Mic $60^{P . d}$ and Mic $60^{\text {R.s }}$ as a fusion with the MBP protein ( $D$ and $\left.D^{\prime}\right)$. Scale bars (A, D and $\left.D^{\prime}\right)$ are equal to $100 \mathrm{~nm}$. 


\subsection{ALPHAPROTEOBACTERIAL HOMOLOGUES OF MIC60 ARE ABLE TO COMPLEMENT ITS EUKARYOTIC FUNCTIONS}

The fact that alphaproteobacterial homologues of Mic60 are able to remodel membranes led to the assumption that Mic60's ability to shape and maintain mitochondrial cristae junctions is evolutionary conserved and is driven by an ancient mechanism of prokaryotic origin. To further test this idea, I decided to investigate whether the alphaproteobacterial Mic60 homologues are able to take over the functions of eukaryotic Mic60 in mitochondria of a living cell. For this purpose, Mic60 R.s and Mic60 ${ }^{P . d}$ were expressed in the mic60 $\Delta$ yeast strain, which lacks the endogenous Mic60 protein and targeted into the inner membrane of mitochondria (Figure 4. 11, A). I assessed mitochondrial fitness of the obtained strains by growing them on a nonfermentable carbon source, glycerol, which requires active respiration, hence extensive proliferation and use on mitochondria (Figure 4. 11, B). Expression of the Mic60 homologues led to an only mild restoration of the cell growth when compared to the control mic60 $\Delta$ strain. Therefore, I decided to investigate whether the expression of Mic $60^{R . S}$ and Mic60 P.d proteins can mend morphological defects of the inner mitochondrial membrane by restoring the normal ultrastructure of cristae junctions in cells lacking the endogenous Mic60 protein.

In collaboration with the group of Prof. Dr Stefan Jakobs we analysed S. cerevisiae mic60 $\Delta$ cells expressing Mic60 R.s and Mic60 P.d protein variants by TEM, as well as by live cell fluorescence microscopy (Figure 4. 11, C). Upon deletion of Mic60, nearly half of the cellular mitochondria lost cristae junctions exhibiting altered, concentric, or stacked cristae membranes (Figure 4. 11, C, lower panel, and D). Expression of the alphaproteobacterial Mic60 homologues in such cells restored the normal cristae junctions, as well as normal cristae membranes, in more than $70 \%$ of affected mitochondria. Although this effect was not as strong as the effect obtained in rescue experiments using the wild-type yeast Mic60, it was consistent and reproducible. We observed a similar trend when visualising the overall mitochondrial network of yeast cells expressing Mic60 homologues using live cell fluorescence microscopy 
A

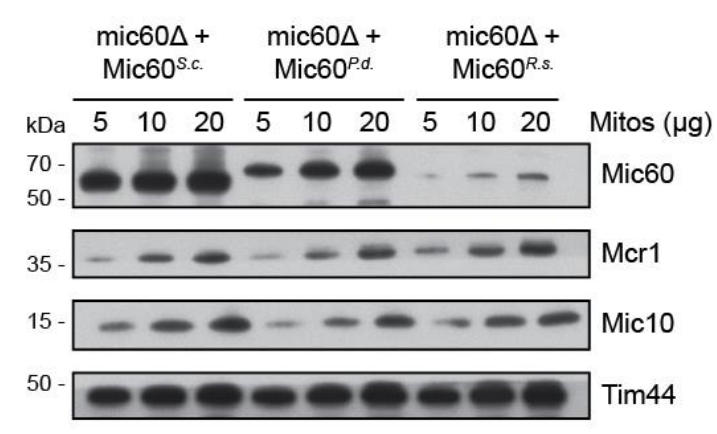

B

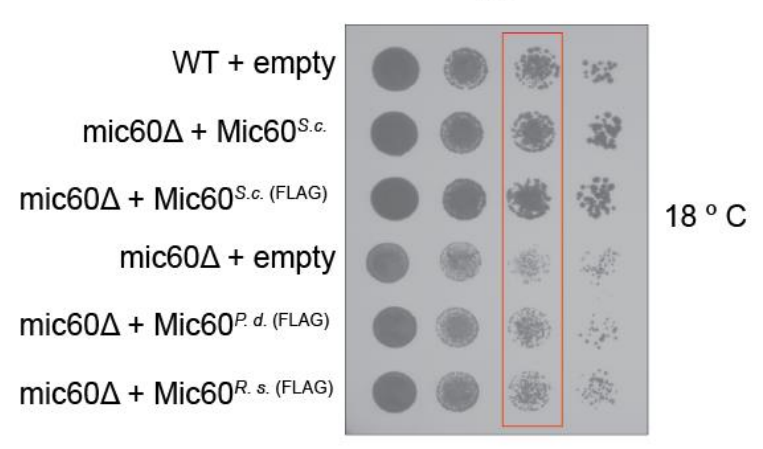

C

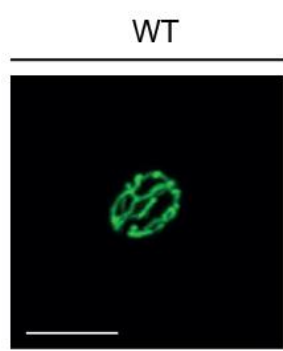

$\operatorname{mic} 60 \Delta+$ Mic $60^{\text {S.c. }}$

$\operatorname{mic} 60 \Delta$

$\operatorname{mic} 60 \Delta+$ Mic60 $0^{\text {P.d. }}$

$\operatorname{mic} 60 \Delta+\mathrm{Mic} 60^{\text {R.s. }}$
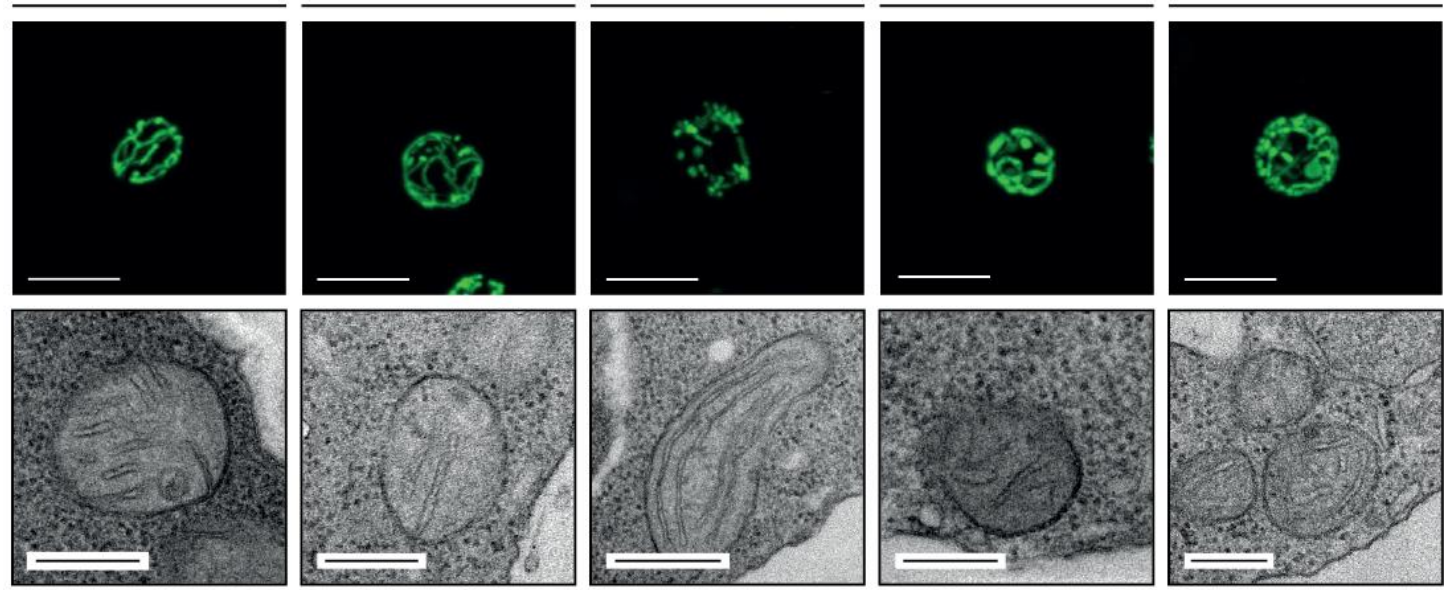

D

Mitochondria with changed IM morphology

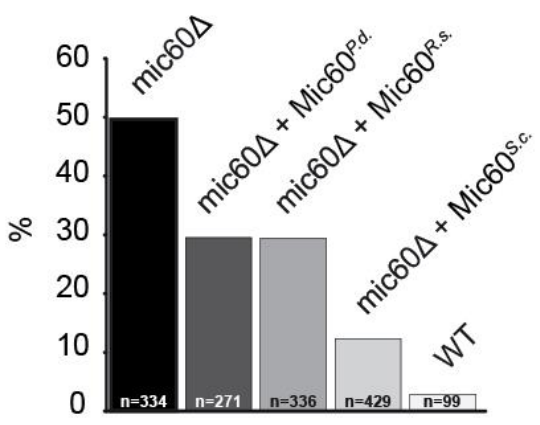

Figure 4. 11: Mic60's membrane remodelling function evolved in an alphaproteobacterial progenitor of mitochondria before the endosymbiotic event and is essential for cristae junction formation.

Mic60 R.s and Mic60 $0^{P . d}$ were cloned into yeast expression vectors and targeted into mitochondria of mic $60 \Delta$ S. cerevisiae cells (A). Mitochondrial fitness of the mic $60 \Delta$ yeast strains expressing Mic60 R.S and Mic60 ${ }^{P . d}$ instead of the endogenous Mic60 protein was assessed by growing them at low temperatures and on non-fermentable, glycerol-containing (SG), medium (B). Mic60 R.S and Mic60 P.d effects on the restoring of the normal morphology of total mitochondrial network of mic $60 \Delta$ yeast strain were assessed by live cell confocal microscopy of the yeast cells (C, upper panel). Mic60 R.S and Mic60 ${ }^{\text {P.d }}$ effects on the 
restoring of the normal ultrastructure of cristae junctions of mic60 $\Delta$ yeast strain were assessed by transmission electron microscopy imaging of the mitochondrial ultrastructure in ultra-thin sections of the yeast cell ( $C$, lower panel). The results of transmission electron microscopy imaging were quantitatively assessed (D). Mitochondria with at least one clear cristae junction were considered as unchanged. Mitochondria with stacked or concentric cristae membranes, and without visible cristae junctions, were counted as changed. The histogram represents absolute numbers. Scale bars are $2.5 \mu \mathrm{m}$ (C, upper panel) and $300 \mathrm{~nm}$ (C, lower panel).

(Figure 4. 11, C, upper panel). The mitochondrial network of wild-type yeast looked like a continuous system of interconnected tubules, while the mitochondrial network of the cells lacking the Mic60 protein looked rather shrunk and fragmented. Although slightly less pronounced in comparison to wild-type yeast Mic60 expression, the expression of the Mic60 homologues restored the mitochondrial network to a great extent. These results confirmed the assumption that Mic60-dependent membrane deformation started to develop very early on in the evolutionary timeline and is essential for cristae junctions' formation. 


\section{DISCUSSION}

During my doctorate research, I was able to pinpoint an unexpected function of the core component of MICOS complex known as Mic60. Previously Mic60 was considered as a protein-protein interaction hub of the complex, while the function of membrane bending at the cristae junctions' sites was assigned to the second core component Mic10. By employing a bottom-up in vitro experimental approach based on the use of purified proteins and model membranes of different physical properties, I was able to show that Mic60 itself exhibits a strong membrane remodelling activity. Furthermore, I could determine that Mic60's membrane remodelling activity is independent of the $\mathrm{N}$-terminal transmembrane domain and enclosed in its peripheral IMS domain. The experimental results observed in vitro were also successfully confirmed in in vivo systems. My findings helped to finally answer a question that kept scientists of the mitochondrial field puzzled for several years: What is the underlying reason for the massive loss of cristae junction number and accumulation of cristae membrane stacks in mic60 Saccharomyces cerevisiae strain, while Mic10 protein levels remained unaffected? Additionally, I could show that the Mic60 membrane remodelling activity is evolutionary conserved and can be found already in its alphaproteobacterial homologues. This finding not only provides a structural basis for the mechanism of alphaproteobacterial intracytoplasmic membranes formation and maintenance but also reinvigorates the long-forgotten idea of the pre-endosymbiotic origins of cristae membranes of modern mitochondria.

\subsection{PURIFICATION OF THE RECOMBINANT FULL-LENGTH MIC60 PROTEIN}

Mic60 is an integral membrane protein. Although Mic60's major part is constituted of the soluble intermembrane space domain, the presence of the $\mathrm{N}$-terminal transmembrane helix significantly increases the total hydrophobicity score of the protein. Therefore, when recombinantly expressed in E.coli, Mic60 aggregates and forms insoluble protein agglomerates within bacterial cytoplasm also known as inclusion bodies. In order to be able to implement the bottom-up approach and reconstitute Mic60 functions in vitro, as the first step of my investigation I established 
efficient protocols for purification, solubilisation and refolding of recombinant fulllength form.

Handling of in-vitro-refolded recombinant proteins often raises multiple questions regarding the degree of their nativity and possible effects of the detergent molecules used for facilitation of refolding on the outcome of downstream assays. Being aware of these concerns, I aimed to make sure that none of the experimental results is influenced by the abovementioned artefacts. Therefore, every stage of the in vitro reconstitution experiments was performed under intense scrutiny and in parallel with every required experimental control.

To minimise the possibility of detergent-induced artefacts from the very initial steps, I aimed to find the conditions in which Mic60 would be efficiently renatured while using as little concentration of detergent as possible. Thus, after performing the detergent screen, I opted for the $0.1 \%$ DDM as the most suitable milieu for Mic60 refolding. DDM is a mild lipid-like non-ionic detergent which is able to stabilise hydrophobic membrane proteins while preserving their native conformation and functional activity more efficient than other commonly used detergents such as CHAPS or OG. As an illustration, DDM was successfully utilised before in in vitro enzymatic assays without distortion of enzymatic activity of the protein specimen ${ }^{107}$. Also, it was successfully used for handling of solubilised functional receptor molecules ${ }^{108}$ and structural studies of membrane proteins $^{109-111}$.

To ensure that Mic60 was properly renatured, the process of DDM-mediated refolding was monitored by circular dichroism (CD) spectroscopy. This method allows for estimation of secondary structure elements based on the spectra produced by the interaction between protein molecules and circular polarised far UV light. The pattern of CD spectra obtained from Mic60 before refolding suggested an irregular or disorganized structure of the protein, while the CD spectra of Mic60 refolded in $0.1 \%$ DDM Mic60 matched the signature pattern of the $\alpha$-helical fold. Thus, we assessed the outcome of Mic60 refolding as successful. This observation was strongly supported by the results of the theoretical predictions of Mic60 structural organisation: All structural 
domains of Mic60 (transmembrane, extensive central coiled-coil as well as mitofilin) are assigned as $\alpha$-helical-based.

Despite such supportive evidence in favour of proper folding, it was still impossible to prove that our protocol yields Mic60 protein of native conformation (equivalent to the one it adopts within mitochondrial inner membrane) since the actual information on the Mic60 structure remains unavailable. Thus, I decided on using the soluble Mic60 IMs (part of Mic60 protein without its transmembrane domain) as a reference of successful refolding during $C D$ measurements. In this way, Mic $60^{\mathrm{IMS}}$ would retain the major part of the structural information enclosed within its sequence and would not require the use of detergent during the course of purification. Unfortunately, Mic60 ${ }^{\mathrm{IMS}}$, similarly to the full-length protein, appeared to be quite hydrophobic and was sorted into inclusion bodies when expressed recombinantly. In the same fashion, different $\mathrm{N}$-terminal truncation variants of Mic60 $\mathrm{IMS}$ also proved to be insoluble. Only single structural domains of Mic60 such as coiled-coil and mitofilin could be purified as soluble proteins. However, due to the low percentage of original sequence coverage, I considered single domains as not ideal reference molecules. Another, but more challenging, way to obtain Mic60 protein in the close to a native state suitable for quality control of the refolding procedure would be to isolate a small amount of this protein directly from mitochondria. Although this method would still require the use of mild detergent to extract Mic60 from the mitochondrial inner membrane, the detergent properties would be employed to maintain an in vivo generated the native tertiary structure of the protein rather than the formation of such de novo.

Possible unspecific detergent-induced effects were monitored not only with regards to protein refolding but also with regards to the morphology of a lipid bilayer. The protocol for Mic60 incorporation into the model membranes was designed to assure the complete substitution of the detergent by lipid molecules. Nevertheless, to guarantee specificity of the Mic60 effects on the membrane morphology, every incorporation experiment was accompanied by additional negative "detergent" control. The main intention of such control was to perform so-called mock incorporation when liposomes undergo full detergent-mediated reconstitution protocol omitting the step of protein 
addition. Performance of this control allowed for monitoring of the possible effect of the residual amount of detergent or even the detergent removal procedure itself on the morphology of model membranes. Such detergent-treated liposomes were always analysed in parallel to the protein-containing liposomes and did not exhibit a change in size distribution as well as in the overall morphology in comparison to non-treated vesicles.

Moreover, the in vivo experiments on the bending of biological membranes showed identical effects despite the absence of detergent as well as unnecessity of refolding. Since Mic60 was expressed as a fusion protein with MBP, a tag known to enhance protein solubility and targeted to its native membrane environment, Mic60 did not accumulate in the form of inclusion bodies and most probably adopted its native conformation. In this way, refolded and native proteins showed similar effects when incorporated into the lipid bilayer of model or biological membranes. Therefore, all in vitro and in vivo effects observed for Mic60 can be with confidence assigned to the presence of the protein.

\subsection{MECHANISM OF MIC60-MEDIATED MEMBRANE BENDING}

To make sure that observed membrane remodelling is specific to Mic60 and is not induced by simple protein crowding in a lipid bilayer ${ }^{112,113}$, I searched for an additional negative "protein" control. For this purpose, I selected the mitochondrial inner membrane protein Tim50. This $55 \mathrm{kDa}$ protein is not only similar to Mic60 in size but also has only one transmembrane domain and large $\alpha$-helical domain exposed to the intermembrane space of mitochondria ${ }^{114}$. Tim50 is a part of TIM23 complex and plays an important role in the facilitation of mitochondrial protein transport by directing transit peptides from TOM complex to the channel of TIM23 complex ${ }^{29,115}$ and, importantly, is not involved in membrane remodelling processes. These features made Tim50 an excellent control for the membrane remodelling assays. To monitor proteinrelated effects on the morphology of LUVs, I performed a parallel series of incorporations of the Mic60 and Tim50 proteins. Both of these proteins were incorporated into the LUVs in an equal molar concentrations. Several populations of 
LUVs containing increasing amounts of the corresponding protein were generated and subsequently analysed by DLS and electron microscopy. Such experimental design allowed us not only to observe different stages of protein-induced membrane deformation process but also to judge on its dependence on the essence of incorporated protein. While performing these experiments, I could observe that, in contrast to Mic60-containing LUVs, Tim50-containing LUVs remained spherical independently on the amount of incorporated protein. Therefore, I could specifically assign the observed effects to a Mic60-driven mechanism of membrane deformation. Together, these findings predicated that the MICOS core component Mic60 possesses an intrinsic membrane bending properties. Hence, Mic60 independently mediates membrane remodelling at cristae junctions' sites in addition to the second MICOS core component Mic10, the membrane bending properties of which were already described several years ago.

Clearly, Mic10's and Mic60's mode of action must be very different, since these two proteins have an explicitly distinct structural organisation and membrane topology. Mic10 is a small membrane protein essentially consisting of two transmembrane helices. First transmembrane helix is slightly longer. Thus when inserted into membrane bilayer it occupies the larger surface of the outer lipid leaflet of the membrane, which causes it to bend. Such an effect is amplified by the Mic10's ability to oligomerize through its glycine-rich motifs on both helices ${ }^{72,73}$. Mic60, however, has a single transmembrane helix and a large peripheral domain, which is exposed to the mitochondrial intermembrane space ${ }^{58}$. This peripheral part of the protein includes an extended central coiled-coil domain and a C-terminal mitofilin domain ${ }^{57,70}$. Up to this point, it was generally accepted that the main function of Mic60 is being an "interaction hub" of MICOS and mediating protein-protein interactions within the complex and with other machineries of both mitochondrial membranes through the large coiled-coil domain while Mic10 is being the main provider of membrane bending at cristae junctions' sites.

The initial results obtained during my doctoral research, however, revealed an unexpected membrane remodelling function of Mic60. This finding encouraged further 
studies, which were focused on localisation of the membrane remodelling activity within the Mic60 protein. Concomitantly, I could efficiently show that the transmembrane helix of Mic60 is dispensable for its membrane remodelling activity, while its IMS portion alone displays an affinity to lipids. These results suggested that the molecular mechanism of membrane remodelling by Mic60 could be similar to the mechanism of well-characterised peripheral membrane-bending proteins such as endophilins, amphiphysins and epsins. These proteins are involved in cellular membrane dynamics, specifically in the process of clathrin-mediated endocytosis. One of their characteristic features is the presence of amphipathic helices, which upon membrane binding induce a high degree of curvature $\mathrm{c}^{116-118}$.

Although apart from its transmembrane helix, no membrane-interacting domains were described for Mic60, I nevertheless subjected the primary sequence of Mic60 ${ }^{\mathrm{IMS}}$ to various bioinformatics tools for secondary structures prediction. Interestingly, one of them disclosed a probability of an amphipathic helix formation within the IMS part of Mic60. The existence of such helix could explain the lipid binding properties of Mic60 IMS observed in my experiments and, moreover, could provide some mechanistic explanation for the results of a previously published study regarding differential functions of Mic60 structural domains ${ }^{66}$. In this study, the authors discussed the matter that the C-terminal mitofilin domain is more critical for the function of Mic60 than its coiled-coiled domain. According to their results, the C-terminal domain is crucial for MICOS complex and cristae junctions' integrity, while the coiled-coil domain was shown to be particularly important for the interaction with the translocation machinery of the outer membrane TOM. Nevertheless, the expression of a Mic60 variant lacking the coiled-coil domain still led to cristae junction loss and accumulation of cristae membranes stacks in mitochondria even in the presence of fully functional C-terminal mitofilin domain. These results indicated a possible function of the coiled-coil domain of Mic60 in the maintenance of mitochondrial inner membrane morphology.

Presumably, the Mic60 amphipathic helix, when inserted into membranes competes with the head groups of lipid molecules for space which results in distortion of the bilayer. Such distortion, when introduced asymmetrically in only one leaflet of a lipid 
bilayer, consequently promotes membrane bending. In the case of Mic60, such amphipathic helix could facilitate keeping the peripheral part of Mic60, hence also a rather remote C-terminal domain in the proximity to the lipid bilayer of the mitochondrial inner membrane. By localising near cristae junction's site, the mitofilin domain can be more effectively engaged in protein-protein interaction with other MICOS components largely contributing to the complex stability and maintenance of cristae junction morphology. These ideas are strongly supported by the results of a parallel study performed on the Mic60 homologue from thermophilic fungus Chaetomium thermophilum, which identified the presence of two amphipathic helices just outside the coiled-coil domain, which was shown to be essential for membrane remodelling properties of this protein ${ }^{119}$. Such results strongly consolidated our assumption regarding the possible mechanism of Mic60-mediated membrane bending.

\subsection{THE NECESSITY OF TWO MEMBRANE BENDING PROTEINS AT THE SITES OF}

\section{CRISTAE JUNCTIONS}

According to the evolutionary studies, Mic60 is the oldest and only MICOS component with homologues in prokaryotes ${ }^{76}$. Distribution of prokaryotic Mic60 was shown to be restricted to the class of alphaproteobacteria (present-day relatives of the actual ancestors of eukaryotic mitochondria). Similarly to their modern representatives, ancient alphaproteobacteria were probably able to form various membrane invaginations and intracytoplasmic membranous structures. These mechanisms are devoted to increasing the surface area of their cytoplasmic membranes to harbour more units of energy converting machineries adjusting efficiency of metabolic pathways such as photosynthesis or fixation of nitrogen according to the environmental conditions. Previous studies linked the formation of such intracytoplasmic membranes to the presence of alphaproteobacterial Mic60 homologues ${ }^{90}$, and the results obtained during my doctoral research revealed that these homologues actually possess membrane remodelling properties. Since no homologues for other MICOS components were identified in prokaryotes ${ }^{76}$, it is very likely that the membrane curvature inducing activity of alphaproteobacterial Mic60 is sufficient to form and stabilise intracytoplasmic membranous structures. Furthermore, these proteins could very well 
be involved in protein-protein interactions, responsible for the formation of stable contacts between the bacterial cytoplasmic and the outer membranes. Therefore, the alphaproteobacterial Mic60 on its own might already fulfil all the basic functions of the MICOS complex. This raises the question about the underlining reason for the need to acquire another protein with membrane bending properties, namely Mic10.

The newly adopted endosymbiotic alphaproteobacteria during evolutional codevelopment with their host started to adopt novel, eukaryote-specific, functions. Thus, formerly dynamic intracytoplasmic membranes became permanent constituents of mitochondria and formed what we now know as cristae. Mitochondrial cristae membranes, apart from their main function of oxidative phosphorylation, gradually became involved in other processes such as the regulation of calcium signalling or the sequestering of cytochrome c molecules, which is important for the process of the intrinsic pathway of apoptosis. Clearly, such vital cellular functions required tighter and more reliable regulation mechanisms. The need to fulfil such demands might have led to the development of the second membrane-bending unit. In this way, two proteins could contribute to the maintenance and formation of membrane curvature at cristae junctions. Along with its direct membrane remodelling function, Mic60 kept its function as interaction hub, and Mic10 provided an additional, more rigid scaffold to the deformed mitochondrial inner membrane. Multiple proteins with seemingly redundant functions are rather often found in important biological processes such as clathrinmediated endocytosis ${ }^{120,121}$ and regulation of endoplasmic reticulum membrane organization ${ }^{71}$. Hence, with the increasing complexity of mitochondrial function and cristae membranes adopting a more active role in the regulation of cellular homeostasis, more proteins added up to cristae junction regulation. MICOS complexes of higher organisms consist of not just of Mic60 and Mic10 but two different multiprotein modules formed around these core subunits: Mic60/Mic19 and Mic10/Mic12/Mic26/Mic27. These modules are believed to be dynamically interconnected by Mic19 and/or Mic12 proteins ${ }^{122,123}$. Deletion of Mic12 results in loosening of the connection between the modules, which, in turn, leads to a mild distortion of the mitochondrial inner membrane morphology. Mic19 is a peripheral 
membrane protein, which appeared rather early in MICOS evolution and could provide reliable regulation leverage too. Being a cysteine-containing protein, it exerts higher affinity to the MICOS complex when oxidised ${ }^{124}$ and, similarly to Mic12, its dissociation from the complex leads to MICOS "loosening". Therefore, these subunits could potentially fine-tune cristae remodelling (widening and tightening of their diameter in response to the physiological state of the cell) by regulation of the interplay between the two MICOS modules

The discovery of an unexpected membrane bending activity of Mic60 finally provided the basis that could explain the cristae junction loss in Mic60-deficient cells with unaffected Mic10 protein levels. Mic60, apart from the contact sites maintenance, is also required for curvature induction at cristae junction's sites. Hence, the membrane remodelling capacity of only Mic10 is simply not enough to cover for the second core component of the complex. Alternatively, the membrane bending capacity of Mic10 could be additionally affected by compromised numbers of Mic10 molecules at cristae junction sites in mic60 $\Delta$ cells. The MICOS complex of Mic60-deficient mitochondria is destabilised but the overall level of Mic10 in such mitochondria remains high $^{58,66}$. Therefore, one can assume, that Mic10 dislocates from cristae junction's sites, which consequently contributes to cristae junction loss. This idea is in line with recently published studies which reported a free fraction of Mic10 protein which exists outside the MICOS complex and interacts with ATP synthase ${ }^{125}$. The further investigation of Mic10 behaviour in mic60 $\Delta$ mitochondria would require the performance of highly precise localisation studies, which would involve using a series of constructs expressing quantitatively labelled Mic60 and Mic10 possibly involving high-resolution light microscopy in combination with electron microscopy and double immune-gold staining.

\subsection{ALPHAPROTEOBACTERIAL MIC60 PROTEIN CAN RECOVER CRISTAE JUNCTIONS IN MIC60D EUKARYOTIC CELLS}

In my study, apart from yeast Mic60, I investigated its alphaproteobacterial homologues. I could show that these homologues, similarly to the yeast Mic60, are able 
to induce high degrees of membrane curvature: efficiently bend membranes of liposomes, transform them from spherical structures to tubules as well as remodel biological membranes and induce intracytoplasmic vesicles and cristae-like tubules when targeted to the bacterial cytoplasmic membrane in vivo. These experiments were driven by the results of the phylogenetic study which reported a high degree of evolutionary conservation of Mic60 domain organisation from prokaryotes to eukaryotes $^{76}$. In fact, alphaproteobacterial Mic60 homologues exhibit identical structural domain organisation to eukaryotic Mic60: one transmembrane domain, a central coiled-coil domain and a C-terminal mitofilin domain. Importantly, the coiledcoil domain exhibits only structural similarity, while the C-terminal domain displays a high degree of primary sequence similarity. To further investigate whether such structural conservation leads to functional conservation of these proteins in situ, I decided to express bacterial Mic60 homologues in eukaryotic cells lacking endogenous Mic60 and estimate if they would be able to rescue the function of its eukaryotic homologues in a living cell. Indeed, I observed significant restoration of the overall mitochondrial network organisation as well as a rescue of the normal mitochondrial ultrastructure, particularly, recovery of cristae junctions. Nonetheless, these effects were less pronounced when compared to the effects of rescue experiments using the wild-type variant of Mic60. Additionally, the growth recovery phenotype of cells expressing prokaryotic Mic60 variants on non-fermentable medium was rather poor, which suggested that their mitochondria are not fully functional. Such results could be explained by the functional duality of Mic60 and differences in the pace of the evolution between its C-terminal and coiled-coil domains. The membrane bending activity of Mic60 appears to be more conserved while protein-protein interaction hub function, hence the formation of contact sites in mitochondria, possibly was diverging much faster depending on evolution rates of its interaction partners in different organisms. To investigate this further, one could carry out co-isolation experiments on the mitochondria expressing tagged variants of alphaproteobacterial Mic60 homologues in order to learn which of already confirmed eukaryotic Mic60 interactions partners of the mitochondrial outer and inner membrane would be recovered. This can be achieved by 
performing a Western blot analysis using antibodies against MICOS components (Mic10, Mic12, Mic19, Mic27 and Mic26) which would provide additional information on the complex integrity as well as against known interaction partners from the mitochondrial outer membrane, such as VDAC, components of TOM machinery and, especially, components of SAM. Such co-isolation experiments could be analysed in more details by mass spectrometry. The functional aspect of this experiment could be further elaborated by performing in vitro import assays of the outer and inner mitochondrial membrane using isolated mitochondria expressing alphaproteobacterial Mic60 homologues. Evaluation of recovered interaction partners together with an evaluation of mitochondrial import efficiency could provide some insight into the general fitness of such mitochondria. 


\section{SUMMARY AND CONCLUSIONS}

During this study, an unexpected membrane-bending function of MICOS core component Mic60 was discovered. Using in vitro - based bottom-up experimental strategy Mic60 was shown to not only actively bend lipid bilayer of artificial model membranes of different physical and biochemical properties but also to induce the formation of cristae-like folds when targeted to the cytoplasmic membrane of a bacterial cell in vivo. Membrane-remodelling properties of Mic60 were allocated to its peripheral intermembrane space domain, which also displays an affinity to lipids.

Alphaproteobacterial homologues of Mic60 were not only shown to have identical domain organisation with the eukaryotic Mic60 proteins but also were shown to exert similar effects on the model and biological, membranes. Moreover, the alphaproteobacterial Mic60 proteins were shown to be able to partially restore normal mitochondrial inner membrane architecture and cristae junction formation when targeted to mitochondria of mic60 $\Delta$ yeast cells.

Thus, along with the previously characterised Mic10 protein, Mic60 is the second membrane-bending MICOS core subunit, which partakes in stabilisation and maintenance of cristae junctions and mitochondrial inner membrane morphology. In this way it was confirmed, that Mic60 exhibits dual function in the inner membrane of mitochondria: membrane remodelling on the one hand, and membrane contact sites/protein-protein interaction mediation on the other hand. According to the results presented in this thesis, one can conclude that both functions of the Mic60 protein are extremely conserved and evolved more than 1.5 billion years ago, prior the endosymbiotic event when ancient alphaproteobacteria became mitochondria. 


\section{BIBLIOGRAPHY}

1. Taylor, F. J. R. Implications and Extensions of the Serial Endosymbiosis Theory of the Origin of Eukaryotes. Taxon 23, 229 (1974).

2. Sagan, L. On the origin of mitosing cells. J. Theor. Biol. 14, 255-74 (1967).

3. Gray, M. W., Burger, G. \& Lang, B. Minireview The origin and early evolution of mitochondria. Genome Biol. Evol. 2, 1-5 (2001).

4. Martijn, J. \& Ettema, T. J. G. From archaeon to eukaryote: the evolutionary dark ages of the eukaryotic cell. Biochem. Soc. Trans. 41, 451-7 (2013).

5. Martin, W. \& Müller, M. The hydrogen hypothesis for the first eukaryote. Nature 392, 37-41 (1998).

6. Poole, A. M. \& Gribaldo, S. Eukaryotic Origins: How and When Was the Mitochondrion Acquired? Cold Spring Harb. Perspect. Biol. 6, a015990-a015990 (2014).

7. CAVALIER-SMITH, T. The Simultaneous Symbiotic Origin of Mitochondria, Chloroplasts, and Microbodies. Ann. N. Y. Acad. Sci. 503, 55-71 (1987).

8. Zaremba-Niedzwiedzka, K. et al. Asgard archaea illuminate the origin of eukaryotic cellular complexity. Nature 541, 353-358 (2017).

9. Gray, M. W. \& Doolittle, W. F. Has the endosymbiont hypothesis been proven? Microbiol. Rev. 46, 1-42 (1982).

10. Harsman, A. et al. Bacterial origin of a mitochondrial outer membrane protein translocase: new perspectives from comparative single channel electrophysiology. J. Biol. Chem. 287, 31437-45 (2012).

11. Hewitt, V., Alcock, F. \& Lithgow, T. Minor modifications and major adaptations: The evolution of molecular machines driving mitochondrial protein import. Biochim. Biophys. Acta-Biomembr. 1808, 947-954 (2011).

12. Alberts, B. et al. Molecular biology of the cell. (Garland Science, 2002).

13. Westermann, B. Bioenergetic role of mitochondrial fusion and fission. Biochim. Biophys. Acta - Bioenerg. 1817, 1833-1838 (2012).

14. Galloway, C. A., Lee, H. \& Yoon, Y. Mitochondrial morphology-emerging role in bioenergetics. Free Radic. Biol. Med. 53, 2218-2228 (2012).

15. Okamoto, K. \& Shaw, J. M. Mitochondrial Morphology and Dynamics in Yeast and Multicellular Eukaryotes. Annu. Rev. Genet. 39, 503-536 (2005).

16. Liesa, M. \& Shirihai, O. S. Mitochondrial dynamics in the regulation of nutrient utilization and energy expenditure. Cell Metab. 17, 491-506 (2013).

17. Mishra, P. \& Chan, D. C. Metabolic regulation of mitochondrial dynamics. J. Cell Biol. 212, 379-387 (2016).

18. Westermann, B. Molecular machinery of mitochondrial fusion and fission. J. 
Biol. Chem. 283, 13501-13505 (2008).

19. Hoppins, S. \& Nunnari, J. M. The molecular mechanism of mitochondrial fusion. Biochim. Biophys. Acta - Mol. Basis Dis. 1793, 20-26 (2008).

20. Blachly-Dyson, E. \& Forte, M. VDAC channels. IUBMB Life 52, 113-118 (2002).

21. Endo, T. \& Yamano, K. Transport of proteins across or into the mitochondrial outer membrane. Biochim. Biophys. Acta - Mol. Cell Res. 1803, 706-714 (2010).

22. Künkele, K.-P. et al. The Isolated Complex of the Translocase of the Outer Membrane of Mitochondria. Biochemistry 273, 31032-9 (1998).

23. Wiedemann, N. et al. Machinery for protein sorting and assembly in the mitochondrial outer membrane. Nature (2003). doi:10.1038/nature01753

24. Vogel, F., Bornhövd, C., Neupert, W. \& Reichert, A. S. Dynamic subcompartmentalization of the mitochondrial inner membrane. J. Cell Biol. 175, 237-247 (2006).

25. Wurm, C. A. \& Jakobs, S. Differential protein distributions define two subcompartments of the mitochondrial inner membrane in yeast. FEBS Lett. 580, 5628-5634 (2006).

26. Gilkerson, R. W., Selker, J. M. L. \& Capaldi, R. A. The cristal membrane of mitochondria is the principal site of oxidative phosphorylation. FEBS Lett. 546, 355-358 (2003).

27. Hoogenraad, N. J. \& Ryan, M. T. Translocation of proteins into mitochondria. IUBMB Life 51, 345-350 (2001).

28. Chacinska, A. et al. Essential role of Mia40 in import and assembly of mitochondrial intermembrane space proteins. EMBO J. 23, 3735-46 (2004).

29. Backes, S. \& Herrmann, J. M. Protein Translocation into the Intermembrane Space and Matrix of Mitochondria: Mechanisms and Driving Forces. Front. Mol. Biosci. 4, 83 (2017).

30. Hennon, S. W., Soman, R., Zhu, L. \& Dalbey, R. E. YidC/Alb3/Oxa1 Family of Insertases. J. Biol. Chem. 290, 14866-74 (2015).

31. Fawcett, D. W. (Don W. The cell. (W.B. Saunders Co, 1981).

32. Zick, M., Rabl, R. \& Reichert, A. S. Cristae formation-linking ultrastructure and function of mitochondria. Biochim. Biophys. Acta - Mol. Cell Res. 1793, 5-19 (2009).

33. Perkins, G. A. et al. Bcl-xL-mediated remodeling of rod and cone synaptic mitochondria after postnatal lead exposure: Electron microscopy, tomography and oxygen consumption. Molecular Vision 18, (2012).

34. Mannella, C. A. Structure and dynamics of the mitochondrial inner membrane cristae. Biochim. Biophys. Acta - Mol. Cell Res. 1763, 542-548 (2006).

35. Strauss, M., Hofhaus, G., Schröder, R. R. \& Kühlbrandt, W. Dimer ribbons of ATP 
synthase shape the inner mitochondrial membrane. EMBO J. 27, 1154-1160 (2008).

36. Davies, K. M. et al. Macromolecular organization of ATP synthase and complex I in whole mitochondria. Proc. Natl. Acad. Sci. 108, 14121-14126 (2011).

37. Mannella, C. A. et al. Topology of the mitochondrial inner membrane: Dynamics and bioenergetic implications. IUBMB Life 52, 93-100 (2002).

38. Mannella, C. A., Lederer, W. J. \& Jafri, M. S. The connection between inner membrane topology and mitochondrial function. J. Mol. Cell. Cardiol. 62, 51-57 (2013).

39. Olichon, A. et al. Loss of OPA1 perturbates the mitochondrial inner membrane structure and integrity, leading to cytochrome c release and apoptosis. J. Biol. Chem. 278, 7743-7746 (2003).

40. Frezza, C. et al. OPA1 Controls Apoptotic Cristae Remodeling Independently from Mitochondrial Fusion. Cell 126, 177-189 (2006).

41. Cogliati, S. et al. Mitochondrial cristae shape determines respiratory chain supercomplexes assembly and respiratory efficiency. Cell 155, 160-171 (2013).

42. Varanita, T. et al. The Opa1-dependent mitochondrial cristae remodeling pathway controls atrophic, apoptotic, and ischemic tissue damage. Cell Metab. 21, 834-844 (2015).

43. Mannella, C. A. The relevance of mitochondrial membrane topology to mitochondrial function. Biochim. Biophys. Acta - Mol. Basis Dis. 1762, 140-147 (2006).

44. Reichert, A. S. \& Neupert, W. Contact sites between the outer and inner membrane of mitochondria - Role in protein transport. Biochim. Biophys. Acta Mol. Cell Res. 1592, 41-49 (2002).

45. Perkins, G. et al. Electron Tomography of Neuronal Mitochondria: ThreeDimensional Structure and Organization of Cristae and Membrane Contacts. J. Struct. Biol. 119, 260-272 (1997).

46. Perkins, G. A. et al. The Micro-Architecture of Mitochondria at Active Zones: Electron Tomography Reveals Novel Anchoring Scaffolds and Cristae Structured for High-Rate Metabolism. J Neurosci. 30, 1015-1026 (2010).

47. Pardini, D. A., Byrd, A. L., McNamee, R., Lynam, D. \& Raine, A. Neurcognitive and Physiological Correlates in of Psychopathic Features in Adolescent Males. Pap. Present. 3rd Bienn. Soc. Sci. Study Psychopathy Conf. 1-5 (2009).

48. Nicastro, D., Frangakis, A. S., Typke, D. \& Baumeister, W. Cryo-electron Tomography of Neurospora Mitochondria. J. Struct. Biol. 129, 48-56 (2000).

49. Schülke, N., Sepuri, N. B. \& Pain, D. In vivo zippering of inner and outer mitochondrial membranes by a stable translocation intermediate. Proc. Natl. Acad. Sci. U. S. A. 94, 7314-7319 (1997). 
50. Donzeau, M., Kaldi, K. \& Adam, A. Tim23 Links the Inner and Outer Mitochondrial Membranes. Cell 101, 401-412 (2000).

51. Fritz, S., Rapaport, D., Klanner, E., Neupert, W. \& Westermann, B. Connection of the mitochondrial outer and inner membranes by Fzo1 is critical for organellar fusion. J. Cell Biol. 152, 683-692 (2001).

52. Hermann, G. J. et al. Mitochondrial fusion in yeast requires the transmembrane GTPase Fzo1p. J. Cell Biol. 143, 359-373 (1998).

53. Hackenbrock, C. R. Ultrastructural bases for metabolically linked mechanical activity in mitochondria. II. Electron transport-linked ultrastructural transformations in mitochondria. J. Cell Biol. 37, 345-369 (1968).

54. Tateo, I. et al. A novel human gene that is preferentially transcribed in heart muscle. Gene 144, 301-306 (1994).

55. Odgren, P. R., Toukatly, G., Bangs, P. L., Gilmore, R. \& Fey, E. G. Molecular characterization of mitofilin ( HMP), a mitochondria-associated protein with predicted coiled coil and intermembrane space targeting domains. Most 2264, 2253-2264 (1996).

56. Gieffers, C., Korioth, F., Heimann, P., Ungermann, C. \& Frey, J. Mitofilin is a transmembrane protein of the inner mitochondrial membrane expressed as two isoforms. Exp. Cell Res. 232, 395-399 (1997).

57. Rabl, R. et al. Formation of cristae and crista junctions in mitochondria depends on antagonism between Fcj1 and Su e/g. J. Cell Biol. 185, 1047-1063 (2009).

58. Harner, M. et al. The mitochondrial contact site complex, a determinant of mitochondrial architecture. EMBO J. 30, 4356-4370 (2011).

59. Xie, J., Marusich, M. F., Souda, P., Whitelegge, J. \& Capaldi, R. A. The mitochondrial inner membrane protein Mitofilin exists as a complex with SAM50, metaxins 1 and 2, coiled-coil-helix coiled-coil-helix domain-containing protein 3 and 6 and DnaJC11. FEBS Lett. 581, 3545-3549 (2007).

60. Alkhaja, A. K. et al. MINOS1 is a conserved component of mitofilin complexes and required for mitochondrial function and cristae organization. Mol. Biol. Cell 23, 247-257 (2012).

61. von der Malsburg, K. et al. Dual Role of Mitofilin in Mitochondrial Membrane Organization and Protein Biogenesis. Dev. Cell 21, 694-707 (2011).

62. Hoppins, S. et al. A mitochondrial-focused genetic interaction map reveals a scaffold-like complex required for inner membrane organization in mitochondria. J. Cell Biol. 195, 323-340 (2011).

63. Pfanner, N. et al. Uniform nomenclature for the mitochondrial contact site and cristae organizing system. J. Cell Biol. 204, 1083-1086 (2014).

64. van der Laan, M., Bohnert, M., Wiedemann, N. \& Pfanner, N. Role of MINOS in mitochondrial membrane architecture and biogenesis. Trends Cell Biol. 22, 185-192 (2012). 
65. Zerbes, R. M. et al. Mitofilin complexes: Conserved organizers of mitochondrial membrane architecture. Biol. Chem. 393, 1247-1261 (2012).

66. Zerbes, R. M. et al. Role of MINOS in mitochondrial membrane architecture: Cristae morphology and outer membrane interactions differentially depend on mitofilin domains. J. Mol. Biol. 422, 183-191 (2012).

67. Rabl, R. et al. Formation of cristae and crista junctions in mitochondria depends on antagonism between Fcj1 and Su e/g. J. Cell Biol. 185, 1047-1063 (2009).

68. Darshi, M. et al. ChChd3, an inner mitochondrial membrane protein, is essential for maintaining Crista integrity and mitochondrial function. J. Biol. Chem. 286, 2918-2932 (2011).

69. Ott, C. et al. Sam50 Functions in Mitochondrial Intermembrane Space Bridging and Biogenesis of Respiratory Complexes. Mol. Cell. Biol. 32, 1173-1188 (2012).

70. Korner, C. et al. The C-terminal domain of Fcj1 is required for formation of crista junctions and interacts with the TOB/SAM complex in mitochondria. Mol. Biol. Cell 23, 2143-2155 (2012).

71. Voeltz, G. K., Prinz, W. A., Shibata, Y., Rist, J. M. \& Rapoport, T. A. A class of membrane proteins shaping the tubular endoplasmic reticulum. Cell 124, 57386 (2006).

72. Barbot, M. et al. Mic10 Oligomerizes to Bend Mitochondrial Inner Membranes at Cristae Junctions. Cell Metab. 21, 756-763 (2015).

73. Bohnert, M. et al. Central Role of Mic10 in the Mitochondrial Contact Site and Cristae Organizing System. Cell Metab. 21, 747-755 (2015).

74. Head, B. P., Zulaika, M., Ryazantsev, S. \& van der Bliek, A. M. A novel mitochondrial outer membrane protein, MOMA-1, that affects cristae morphology in Caenorhabditis elegans. Mol. Biol. Cell 22, 831-841 (2011).

75. Mun, J. Y. et al. Caenorhabditis elegans mitofilin homologs control the morphology of mitochondrial cristae and influence reproduction and physiology. J. Cell. Physiol. 224, 748-756 (2010).

76. Muñoz-Gómez, S. A. et al. Ancient homology of the mitochondrial contact site and cristae organizing system points to an endosymbiotic origin of mitochondrial cristae. Curr. Biol. 25, 1489-1495 (2015).

77. Muñoz-Gómez, S. A., Wideman, J. G., Roger, A. J., Slamovits, C. H. \& Agashe, D. The origin of mitochondrial cristae from alphaproteobacteria. Mol. Biol. Evol. 34, 943-956 (2017).

78. Niederman, R. A. Structure, Function and Formation of Bacterial Intracytoplasmic Membranes. in 193-227 (Springer, Berlin, Heidelberg, 2006). doi:10.1007/7171_025

79. Spieck, E., Ehrich, S., Aamand, J. \& Bock, E. Isolation and immunocytochemical location of the nitrite-oxidizing system in Nitrospira moscoviensis. Arch. Microbiol. 169, 225-230 (1998). 
80. Yamanaka, T. \& Fukumori, Y. The nitrite oxidizing system of Nitrobacter winogradskyi. FEMS Microbiol. Lett. 54, 259-270 (1988).

81. Hanson, R. S. et al. Methanotrophic bacteria. Microbiol. Rev. 60, 439-71 (1996).

82. Brantner, C. A., Remsen, C. C., Owen, H. A., Buchholz, L. A. \& Collins, M. Intracellular localization of the particulate methane monooxygenase and methanol dehydrogenase in Methylomicrobium album BG8. Arch. Microbiol. 178, 59-64 (2002).

83. Zahn, J. A., Bergmann, D. J., Boyd, J. M., Kunz, R. C. \& DiSpirito, A. A. Membrane-associated quinoprotein formaldehyde dehydrogenase from Methylococcus capsulatus Bath. J. Bacteriol. 183, 6832-6840 (2001).

84. Tucker, J. D. et al. Membrane invagination in Rhodobacter sphaeroides is initiated at curved regions of the cytoplasmic membrane, then forms both budded and fully detached spherical vesicles. Mol. Microbiol. 76, 833-847 (2010).

85. Konorty, M., Kahana, N., Linaroudis, A., Minsky, A. \& Medalia, O. Structural analysis of photosynthetic membranes by cryo-electron tomography of intact Rhodopseudomonas viridis cells. J. Struct. Biol. 161, 393-400 (2008).

86. Scheuring, S. et al. The architecture of Rhodobacter sphaeroides chromatophores. Biochim. Biophys. Acta - Bioenerg. 1837, 1263-1270 (2014).

87. Konorty, M. et al. Photosynthetic system in Blastochloris viridis revisited. Biochemistry 48, 4753-4761 (2009).

88. Callister, S. J. et al. Comparison of aerobic and photosynthetic Rhodobacter sphaeroides 2.4.1 proteomes. J. Microbiol. Methods 67, 424-436 (2006).

89. D’Amici, G. M., Rinalducci, S., Murgiano, L., Italiano, F. \& Zolla, L. Oligomeric Characterization of the Photosynthetic Apparatus of Rhodobacter sphaeroides R26.1 by Nondenaturing Electrophoresis Methods. J. Proteome Res. 9, 192-203 (2010).

90. Jackson, P. J., Lewis, H. J., Tucker, J. D., Hunter, C. N. \& Dickman, M. J. Quantitative proteomic analysis of intracytoplasmic membrane development in Rhodobacter sphaeroides. Mol. Microbiol. 84, 1062-1078 (2012).

91. Selao, T. T. et al. Identification of chromatophore membrane protein complexes formed under different nitrogen availability conditions in Rhodospirillum rubrum. J Proteome Res. 10, 2703-2714 (2011).

92. Fejes, A. P., Yi, E. C., Goodlett, D. R. \& Beatty, J. T. Shotgun proteomic analysis of a chromatophore-enriched preparation from the purple phototrophic bacterium Rhodopseudomonas palustris. Photosynth. Res. 78, 195-203 (2003).

93. Gentle, I., Gabriel, K., Beech, P., Waller, R. \& Lithgow, T. The Omp85 family of proteins is essential for outer membrane biogenesis in mitochondria and bacteria. J. Cell Biol. 164, 19-24 (2004).

94. Li, H. et al. The Outer Membrane Usher Forms a Twin-pore Secretion Complex. 
J. Mol. Biol. 344, 1397-1407 (2004).

95. Bayer, M. E. Zones of membrane adhesion in the cryofixed envelope of Escherichia coli. J. Struct. Biol. 107, 268-80 (1991).

96. Gietz, R. D. \& Woods, R. A. Transformation of yeast by lithium acetate/singlestranded carrier DNA/polyethylene glycol method. Methods Enzymol. 350, 8796 (2002).

97. Yaffe, M. P. \& Schatz, G. Two nuclear mutations that block mitochondrial protein import in yeast (mitochondrial biogenesis/temperature-sensitive yeast mutants). Cell Biology 81, (1984).

98. Reid, G. A., Yonetani, T. \& Schatz, G. Import of Proteins into Mitochondria. Import and maturation of the mitochondrial intermembrane space enzymes cytochrome b2 and cytochrome c peroxidase in intact yeast cells. Biol. Chem. 257, 13068-13074 (1982).

99. Mullis, K. et al. Specific enzymatic amplification of DNA in vitro: the polymerase chain reaction. Cold Spring Harb. Symp. Quant. Biol. 51 Pt 1, 263-73 (1986).

100. Aaij, C. \& Borst, P. The gel electrophoresis of DNA. Biochim. Biophys. Acta Nucleic Acids Protein Synth. 269, 192-200 (1972).

101. Laemmli, U. K. Cleavage of structural proteins during the assembly of the head of bacteriophage T4. Nature 227, 680-5 (1970).

102. Towbin, H., Staehelin, T. \& Gordon, J. Electrophoretic transfer of proteins from polyacrylamide gels to nitrocellulose sheets: procedure and some applications. Proc. Natl. Acad. Sci. U. S. A. 76, 4350-4 (1979).

103. Walser, P. J. et al. Constitutive Formation of Caveolae in a Bacterium. Cell 150, 752-763 (2012).

104. Truscott, K. N. et al. A presequence- and voltage-sensitive channel of the mitochondrial preprotein translocase formed by Tim23. Nat. Struct. Biol. 8, 1074-1082 (2001).

105. Angelova, M. I. \& Dimitrov, D. S. Liposome electroformation. Faraday Discuss. Chem. Soc. 81, 303 (1986).

106. Ferguson, S. J. Paracoccus denitrificans Oxidative Phosphorylation: Retentions, Gains, Losses, and Lessons En Route to Mitochondria. IUBMB Life 70, 12141221 (2018).

107. Harrison, N. et al. Characterization of N-Acyl phosphatidylethanolamine-specific phospholipase-D isoforms in the nematode Caenorhabditis elegans. PLoS One 9, 1-21 (2014).

108. Zuber, J., Danial, S. A., Connelly, S. M. \& Naider, F. Identification of Destabilizing and Stabilizing Mutations of Ste2p, a G Protein Coupled Receptor in Saccharomyces cerevisiae. 54, 1787-1806 (2015).

109. Stehle, J. et al. Characterization of the ground state dynamics of 
proteorhodopsin by NMR and optical spectroscopies. J. Biomol. NMR 54, 401413 (2012).

110. Lai, J. Y., Poon, Y. S., Kaiser, J. T. \& Rees, D. C. Open and shut: Crystal structures of the dodecylmaltoside solubilized mechanosensitive channel of small conductance from Escherichia coli and Helicobacter pylori at $4.4 \AA$ and $4.1 \AA$ resolutions. Protein Sci. 22, 502-509 (2013).

111. Calcutta, A. et al. Mapping of unfolding states of integral helical membrane proteins by GPS-NMR and scattering techniques: TFE-induced unfolding of KcsA in DDM surfactant. Biochim. Biophys. Acta - Biomembr. 1818, 2290-2301 (2012).

112. Guigas, G. \& Weiss, M. Effects of protein crowding on membrane systems. Biochim. Biophys. Acta 1858, 2441-2450 (2016).

113. Stachowiak, J. C. et al. Membrane bending by protein-protein crowding. Nat. Cell Biol. 14, 944-9 (2012).

114. Mokranjac, D. et al. Role of Tim50 in the transfer of precursor proteins from the outer to the inner membrane of mitochondria. Mol. Biol. Cell 20, 1400-7 (2009).

115. Schulz, C. et al. Tim50's presequence receptor domain is essential for signal driven transport across the TIM23 complex. J. Cell Biol. 195, 643-56 (2011).

116. Masuda, M. et al. Endophilin BAR domain drives membrane curvature by two newly identified structure-based mechanisms. EMBO J. 25, 2889-97 (2006).

117. Gallop, J. L. et al. Mechanism of endophilin N-BAR domain-mediated membrane curvature. EMBO J. 25, 2898-2910 (2006).

118. Giménez-Andrés, M., Čopič, A. \& Antonny, B. The many faces of amphipathic helices. Biomolecules 8, 1-14 (2018).

119. Hessenberger, M. et al. Regulated membrane remodeling by Mic60 controls formation of mitochondrial crista junctions. Nat. Commun. 8, (2017).

120. Kaksonen, M. \& Roux, A. Mechanisms of clathrin-mediated endocytosis. Nat. Rev. Mol. Cell Biol. 19, 313-326 (2018).

121. Mettlen, M., Chen, P.-H., Srinivasan, S., Danuser, G. \& Schmid, S. L. Regulation of Clathrin-Mediated Endocytosis. Annu. Rev. Biochem. 87, 871-896 (2018).

122. Zerbes, R. M., Höß, P., Pfanner, N., van der Laan, M. \& Bohnert, M. Distinct Roles of Mic12 and Mic27 in the Mitochondrial Contact Site and Cristae Organizing System. J. Mol. Biol. 428, 1485-1492 (2016).

123. Friedman, J. R., Mourier, A., Yamada, J., Michael McCaffery, J. \& Nunnari, J. MICOS coordinates with respiratory complexes and lipids to establish mitochondrial inner membrane architecture. Elife 2015, 1-61 (2015).

124. Sakowska, P. et al. The Oxidation Status of Mic19 Regulates MICOS Assembly. Mol. Cell. Biol. 35, 4222-37 (2015). 
125. Rampelt, H. et al. Mic10, a Core Subunit of the Mitochondrial Contact Site and Cristae Organizing System, Interacts with the Dimeric F1Fo-ATP Synthase. J. Mol. Biol. 429, 1162-1170 (2017). 


\section{ACKNOWLEDGMENTS}

I would like to thank my supervisor Prof. Dr Michael Meinecke for giving me the opportunity to work on this project, for his trust, encouragement and support. Thank you very much for being there with advice and your great understanding.

I also would like to thank members of my thesis committee, Prof. Dr Blanche Schwappach-Pignataro and Dr Roland Dosch, for valuable comments and fruitful discussions.

I want to thank Prof. Dr Stefan Jakobs for the collaborative work on this project, as well as his lab members Dr Daniel C. Jans and Gudrun Heim for providing microscopy pictures of yeast cells and yeast mitochondria.

Also, I would like to say thank you to Dr Wiebke Möbius and her group, especially Boguslawa Sadowski, for their valuable help and advice on the electron microscopy of bacterial cells, as well as the amazing working atmosphere in their lab.

I would like to thank Dr Michael Hoppert for the advice on the microbiology of alphaproteobacteria and Dr Partho Halder for helping with obtaining CD spectra.

I want to thank my colleagues Dr Benjamin Kroppen, Dr Niels Denkert and, especially, Dr Mariam Barbot for her help and advice in the lab.

Also, I thank all members of the group of Prof. Dr Peter Rehling, especially Dr Christian Schulz, Dr David Pacheu Grau, Dr Alexander Schendzielorz and of course Dr Nataliia Naumenko, Dr Isotta Lorenzi, Dr Mariia Levchenko, Dr Sylvie Callegari and Cong Wang for being not just great colleagues but also amazing friends.

And last but not least, I would like to thank the coordinators of my MSc. /PhD graduate programme IMPRS "Molecular biology" Dr Steffen Burkhardt and Kerstin Grüniger. Without your help all of this would be very difficult to accomplish. 